\title{
Field Calibration of Soil-Core Microcosms for Evaluating Fate and Effects of Genetically Engineered Microorganisms in Terrestrial Ecosystems
}
H. Bolton, Jr.
D. J. Workman
J. K. Fredrickson
S. W. Li
S. A. Bentjen
J. M. Thomas

April 1991

Prepared for the

U.S. Environmental Protection Agency under a Related Services Agreement with the U.S. Department of Energy under Contract DE-AC06-76RLO 1830

Pacific Northwest Laboratory

Operated for the U.S. Department of Energy

by Battelle Memorial Institute 


\title{
DISCLAIMER
}

This report was prepared as an account of work sponsored by an agency of the United States Government. Neither the United States Government nor any agency thereaf, nor Battelle Memorial Institute, nor any of their employees, makes any warranty, expressed or implied, or assumes any legal liability or responsibility for the accuracy, completeness, or usefulness of any information, apparatus, product, or process disclosed, or represents that its use would not infringe privately owned rights. Reference herein to any specific commercial product, pracess, or service by trade name, trademark, manufacturer, or otherwise does not necessarily canstitute or imply its endorsement, recommendation, or favoring by the United States Government or any agency thereof, or Batteile Memorial Institute. The views and opinions of authors expressed herein do not necessarily state ar reflect those of the United States Government or any agency thereof.

\author{
PACIFIC NORTHWEST LABORATORY \\ operated by \\ BATTELLE MEMORIAL INSTITUTE \\ for the \\ UNITED STATES DEPARTMENT OF ENERGY \\ under Contract DE-ACO6-76RLO 1830
}

Printed in the United States of America

Available to DOE and DOE contractors from the

Office of Scientific and Technical Information, P.O. Box 62, Oak Ridge, TN 37831;

prices available from (615) 576-8401. FTS 626-8401.

Available to the public from the National Technical Information Service, U.S. Department of Commerce, 5285 Port Royal Rd., Springfield, VA 22161. 
PNL-7667

UC-403

FIELD CALIBRATION OF SOLL-CORE MICROCOSMS

FOR EVALUATING FATE AND EFFECTS OF

GENETICALLY ENGINEERED MICROORGANISMS

IN TERRESTRIAL ECOSYSTEMS

H. Bolton, Jr.

J. K. Fredrickson

S. A. Bentjen

D. J. Workman

S. W. Li

J. M. Thomas

April 1991

Prepared for the

U.S. Environmental Protection Agency under a Related Services Agreement with the U. S. Department of Energy under contract DE-AC06-76RLO 1830

Pacific Northwest Laboratory

Richland, Washington 99352 



\section{ABSTRACT}

Pacific Northwest Laboratory compared intact soil-core microcosms and the field for ecosystem structural and functional properties after the introduction of a model genetically engineered microorganism (GEM). This project used two distinct microbial types as model GEMs, Gram-negative Pseudomonas sp. RC1, which was an aggressive root colonizer, and Gram-positive Streptomyces lividans TK24. The model GEMs were added to surface soil in separate studies, with RC1 studied throughout the growth of winter wheat (Triticum aestivum), while TK24 was studied throughout a ten month period. Also, RC1 was used in studies conducted during two consecutive field seasons (1988 to 1990) to determine how year-to-year field variability influenced the calibration of microcosms with the field.

Populations of $\mathrm{RCl}$ in soil decreased more rapidly at $22^{\circ} \mathrm{C}$, but population size at the three-leaf stage of wheat growth were similar in the field, and in microcosms incubated either at $22^{\circ} \mathrm{C}$ or in a growth temperature with temperature fluctuations that simulated average field values. In comparing populations of $\mathrm{RC} 1$ in microcosms and the field, populations on the rhizoplane of wheat were the same at the three-leaf stage, and colonization with depth at the final boot-stage of wheat growth was also similar. There was some variability between microcosms and the field for ecosystem functional parameters. The study conducted with $\mathrm{RC} 1$ the second year found trends similar to the first year for the survival of $\mathrm{RC} 1$ in soil, colonization of wheat roots at the three-leaf stage of growth, and microbial structural properties. Differences in trends found the first and second year were rhizoplane colonization by $\mathrm{RCl}$ at the boot stage of wheat growth, shoot biomass, and soil dehydrogenase activity. In the TK24 study, the population of TK24 had a slower rate of decline in soil than $\mathrm{RCl}$. The main conclusions of this research were that intact soilcore microcosms can be useful to simulate the field for studies of microbial fate and effects on ecosystem structural and functional properties. In general, microcosms in the growth chamber, which simulated average field variations, were similar to the field for most parameters or differences could be attributed to the great extremes in temperature that occurred in the field compared to the microcosms. Better controls of environmental variables including temperature and moisture will be necessary to more closely simulate the field for future use of microcosms for risk assessment. 



\section{EXECUTIVE SUMMARY}

Microcosms consisting of intact soil-cores are a potential tool for assessing the fate and risks associated with the release of genetically engineered microorganisms (GEMs) to the environment. Before a microcosm design can become a standard tool for biotechnology risk assessment, the microcosms must first be calibrated to ensure they adequately simulate key parameters in the field. The principal objective of this project was to calibrate, by comparing key results obtained from intact soil-core microcosms with the field, for microbial fate, and ecosystem structural and functional properties and the resultant effect of introduced microorganisms on these properties. This project used two distinct microbial types as model GEMs, Gram-negative Pseudomonas sp. $\mathrm{RC} 1$ ( $\mathrm{RC} 1$ ), which is an aggressive root colonizer, and Gram-positive Streptomyces lividans TK24 (TK24). The model GEMs were added to surface soil in separate studies, with RC1 studied throughout the growth of winter wheat (Triticum aeslivum), while TK24 was studied throughout a ten month period. Also, RC1 was used in studies conducted during two consecutive field seasons (1988 to 1990) to determine how year-to-year field variability influenced the calibration of microcosms with the field.

In the first year of this project (October 1988 to September 1989), four systems were compared: intact soil-core microcosms located in the laboratory at ambient temperature $\left(22^{\circ} \mathrm{C}\right)$ and in a growth chamber with temperature fluctuations that simulated average conditions in the field, field lysimeters, and field plots. These four systems were inoculated with the rifampicin-resistant rhizobacterium $\mathrm{RCl}$ and planted to winter wheat. The fate of $\mathrm{RCl}$ in soil and on the wheat rhizoplane was determined as a function of time in the various systems. Populations of RC1 in soil decreased more rapidly at ambient temperature, but population size at the three-leaf stage of wheat growth was similar in all four systems. Population densities of $\mathrm{RCl}$ on the thizoplane of wheat were the same at the three-leaf stage in all four systems. Similar trends were observed in the extent of root colonization by $\mathrm{RCl}$ as a function of depth at the boot stage of wheat growth, except at the middle depth where there was a range of three orders of magnitude among the various treatments. In general, results from microcosms incubated at ambient temperature in the laboratory or in the growth chamber were similar to those obtained from the field with respect to the survival and colonization of the rhizoplane by the introduced Pseudomonas sp. However, the results from the colonization of roots from the middle depth suggest caution in using microcosms for simulating the survival and dispersal of introduced microorganisms in the field.

A study of the effect of the introduced $\mathrm{RC} 1$ on ecosystem smuctural and functional properties 
as well as a comparison between the four systems was also conducted the first year (October 1989 to September 1990). The effects of introducing RC1 on structural properties, including wheat rhizoplane populations of total and fluorescent pseudomonads, total heterotrophic bacteria, and the diversity of total heterotrophic bacteria were determined. Of the different structural measurements, the fluorescent pseudomonads were present on the rhizoplane in significantly lower population densities in RC1-inoculated soil in both microcosms and the field. Conditions for microbial growth and activity in soil appeared to be most favorable in the growth chamber microcosm, as evidenced by higher heterotroph populations and species diversity on the rhizoplane at the threeleaf stage of wheat growth. Ecosystem functional parameters as determined by soil dehydrogenase activity, plant biomass production, and ${ }^{15} \mathrm{~N}$ fertilizer uptake by wheat were different at the four locations. Soil dehydrogenase activity, stimulated by the addition of alfalfa, was exaggerated in microcosms compared to the field. In general, the growth chamber microcosms, which simulated average daily high and low field temperatures, were better predictors of field behavior than the microcosms incubated continuously at $22^{\circ} \mathrm{C}$. However, while some parameters and/or trends were identical in the growth chamber microcosms and the field (e.g., shoot biomass), others were quite different (e.g., soil dehydrogenase activity, species diversity on the rhizoplane). It is likely that favorable diumal temperatures and moisture conditions, which were maintained in the growth chamber, favored higher general microbial populations and activity. The growth chamber used in this study was not able to simulate winter conditions because of a lower temperature limit of $5^{\circ} \mathrm{C}$. These results emphasize the need to control, monitor, and/or simulate key environmental variables, such as moisture and temperature, to better calibrate microcosms with the field.

The second year (October 1989 to September 1990), experiments with soil-core microcosms located in a growth chamber with temperature fluctuations that simulated average daily high and low temperatures in the field and field lysimeters were repeated with $\mathrm{RC} 1$ to obtain an additional year of microcosm-field data for assessing year-to-year variation. The decline in the population of $\mathrm{RCl}$ in surface soil was similar in the microcosms and the field and was also similar to the first study. There was no difference in the colonization of wheat roots by $\mathrm{RCl}$ at the three-leaf stage, similar to first year results. The population of $\mathrm{RCl}$ on the rhizoplane at the boot stage of wheat was different than the first year with significantly higher populations associated with the microcosms than the field and the distribution of $\mathrm{RC} 1$ on the rhizoplane as a function of depth in the microcosms was also different from the field. Microbial structural properties of the rhizoplane were very similar in the microcosms and field, similar to the previous year's results. Shoot biomass and dehydrogenase activity of soils were no different in the microcosm and the field at the three-leaf stage of wheat growth, but were lower and higher, respectively, in microcosms versus the field at the boot stage. These results were different than the previous year where the growth 
chamber and the field had a similar final biomass.

The second year (October 1989 to September 1990), experiments with soil-core microcosms located in a growth chamber with diumal temperature fluctuations were compared to field lysimeters for the fate of the introduced Gram-positive bacterium TK24, and its effects on ecosystem structural and functional properties. Soil populations of TK24 declined less than 2 log units over the ten-month study. There were no differences between the microcosms and the field for the soil population of TK24 until after 45 weeks when the population was $1 \log$ unit higher in the microcosms. At the initial sampling in the fall, soil dehydrogenase activity was larger in the microcosms than the field and inoculation with TK24 depressed activity. Dehydrogenase activities were higher in microcosms than in the field during the winter and summer, but there were no differences at the spring sampling. Soil B-glucosidase activity was higher in microcosms than the field during the winter and summer, but were the same during the fall and spring. Aerobic heterotroph and actinomycete populations were higher in microcosms than in field soils during winter and summer, while the field had larger populations in spring. The rate of ${ }^{14} \mathrm{C}$-cellulose mineralization was similar until early May when there was a flush of ${ }^{14} \mathrm{CO}_{2}$ in the field. The ${ }^{14} \mathrm{C}$ labelled soil microbial biomass was significanuly larger in the microcosm than the field, while inoculation with TK24 had no effect. In summary, results obtained for most parameters using microcosms in a growth chamber were similar to those obtained in the field, or differences could be attributed to the greater extremes in temperature that occurred in the field compared to the microcosms.

The results from all first- and second-year studies suggest that microcosms can accurately simulate the field with respect to the fate and effects on ecosystem structural and functional properties of both Gram-negative and Gram-positive introduced microorganisms. However, better controls of environmental variables including temperature and moisture will be necessary to more closely simulate the field for future use of microcosms for risk assessment. 
- 


\section{ACKNOWLEDGMENTS}

For studies conducted the first year (Sections 2 and 3 of this report), we thank L. E. Rogers for help in planting the field lysimeters and plots and Glendon Gee and Michael Kanyid for the micro-meterological data. For studies conducted the second year (Sections 4 and 5 of this report), we thank Glendon Gee and Janelle Downs for the micro-meterological data and Don Crawford and Bruce Bleakly for providing Streptomyces lividans strain TK24 and technical assistance. Steve Bentjen was the first author on Section 5.0. Jeff Smith of the U. S. Department of Agriculture Agricultural Research Service was a major contributor to Sections 3 and 4 of this report. This work was supported by the U. S. Environmental Protection Agency under a Related Service Agreement with the U.S. Deparment of Energy under contract DE-AC06-76RLO 1830 with Pacific Northwest Laboratory. Pacific Northwest Laboratory is operated for the U. S. Deparment of Energy by Battelle Memorial Institute. The information in this document has been funded wholly or in par by the U. S. Environmental Protection Agency under Interagency Agreement (DW89933345-01-0) to Pacific Northwest Laboratory. It has been subject to the Agency's peer and administrative review, and it has been approved for publication as an EPA document. 


\section{PAPERS AND PRESENTATIONS RESULTING FROM THIS PROJECT}

Bentjen, S. A., H. Bolton, Jr., J. K. Fredrickson, and D. J. Workman. 1990. Field calibration of intact soil-core microcosms inoculated with Streptomyces lividans TK24. American Society for Microbiology Abstracts pp. 315.

Bolton, Jr., H. and J. K. Fredrickson. 1988. Field calibration of soil-core microcosms for evaluating fate and effects of genetically engineered microorganisms in terrestrial ecosystems. U.S., E.P.A, Biotechnology Risk Assessment Research Review, Baltimore, MD., Oct. 11-14, 1988.

Bolton, Jr., H., J. K. Fredrickson, S. A. Bentjen, D. J. Workman, S. W. Li, and J. M. Thomas. 1991. Field calibration of soil-core microcosms : Fate of a genetically altered rhizobacterium. Microb. Ecol, in press.

Bolton, Jr., H., J. K. Fredrickson, J. M. Thomas, S. W. Li, D. J. Workman, S. A. Bentjen, and J. L. Smith. 1991. Field calibration of soil-core microcosms: Ecosystem structural and functional comparisons. Microb. Ecol, in press.

Bolton, Jr., H., J. K. Fredrickson, D. J. Workman, S. A. Bentjen, and S. W. Li. 1990. Field calibration of microcosms to assess the fate and ecological effects of a genetically altered rhizobacterium. American Society for Microbiology Abstracts pp. 314.

Fredrickson, J. K. 1989. Terrestrial microcosms and field evaluations of the fate and effects of genetically altered mizosphere bacteria. Symposia on GEMs in the Environment at the American Society for Microbiology Annual Meeting, New Orleans, La., May 15, 1989

Fredrickson, J. K., S. A. Bentjen, H. Bolton, Jr., S. W. Li, and P. Van Voris. 1989. Fate of Tn5 mutants of root growth-inhibiting Pseudomonas sp. in intact soil-core microcosms. Can. J. Microbiol 35:867-873.

Fredrickson, J. K., H. Bolton, Jr., S. A. Bentjen, K. M. McFadden, S. W. Li, and P. Van Voris. 1990. Evaluation of intact soil-core microcosms for determining potential impacts on nutrient cycling by genetically engineered microorganisms. Environ, Toxicol, Chem 9:551-558.

Fredrickson, J. K., H. Bolton, Jr., S. A. Bentjen, D. J. Workman, and S. W. Li. 1990. Fate and ecosystem effects of a root-colonizing Pseudomonas sp. and Streptomyces lividans TK24 in soil-core microcosms and field trials. European Environmental Research Organization - Molecular Microbial Ecology Workshop, May 1, 1990.

Fredrickson, J. K., H. Bolton, Jr., D. J. Workman, and S. A. Bentjen. 1989. Field calibration of microcosms for evaluating the fate and effects of genetically engineered hizobacteria. American Society of Agronomy, Agronomy Abstracts pp. 215.

Fredrickson, J. K., P. Van Voris, S. A. Bentjen, and H. Bolton, Jr. 1990. Terrestrial microcosms for evaluating the environmental fate and risks associated with the release of chemicals or genetically engineered microorganisms to the environment. Haz. Assess. Chem. 7:157-202.

Fredrickson, J. K. H. Bolton, Jr., and G. Stotsky. 1991. Methods for evaluating the effects of GEMs on nutrient cycling processes. Methods for Microbial Ecology, McGraw-Hill Pub. Co., New York, in press. 
Fredrickson, J. K. and C. Hagedom. 1991. Methods for evaluating the effects of GEMs and MCPAs on ecological processes. Methods for Microbial Ecology, McGraw-Hill Pub. Co., New York, in press. 


\section{CONTENTS}

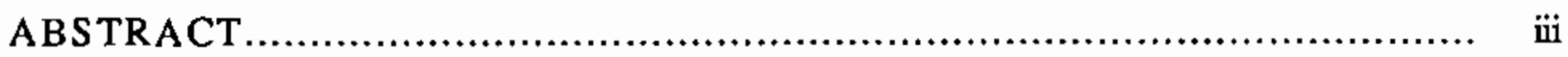

EXECUTIVE SUMMARY ...........................................................

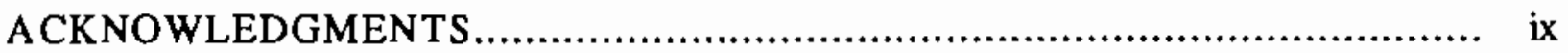

PAPERS AND PRESENTATIONS RESULTING FROM THIS PROJECT ................

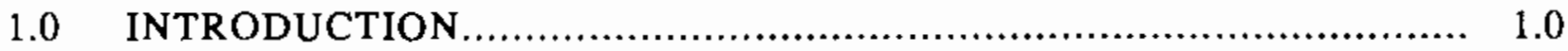

2.0 FIELD CALIBRATION OF SOIL-CORE MICROCOSMS: FATE OF A
GENETICALLY ALTERED RHIZOBACTERIUM................................... 2.0

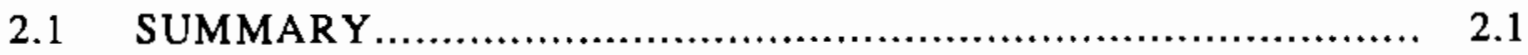

$2.2 \quad$ INTRODUCTION. .................................................. 2.1

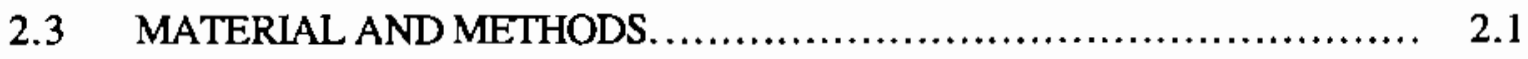

2.3.1 Bacterial Strain and Media............................................... 2.1

2.3.2 Field Site, Microcosms, Inoculation and Locations.................. 2.1

2.3.3 Nondestructive Sampling............................................ 2.5

2.3.4 Destructive Sampling. .......................................... 2.5

2.3.5 Experimental Design.......................................... 2.5

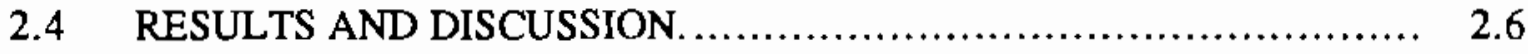

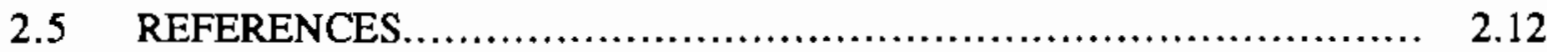

3.0 FIELD CALIBRATION OF SOIL-CORE MICROCOSMS: ECOSYSTEM
STRUCTURAL AND FUNCTIONAL COMPARISONS........................... 3.0

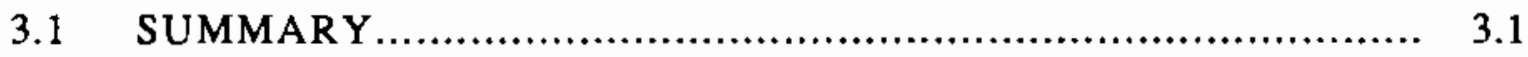

$3.2 \quad$ INTRODUCTION. .................................................... 3.1

$3.3 \quad$ MATERIALS AND METHODS. ...................................... 3.3

3.3.1 Bacterial Strain, Field Site, Microcosms, Inoculation and Locations. .................................................... 3.3

3.3.2 Sampling. ......................................................... 3.3

3.3.3 Ecosystem Structural Measurements.............................. $\quad 3.4$

3.3.4 Ecosystem Functional Measurements............................. 3.4 
3.3.5 Experimental Design............................................ 3.5

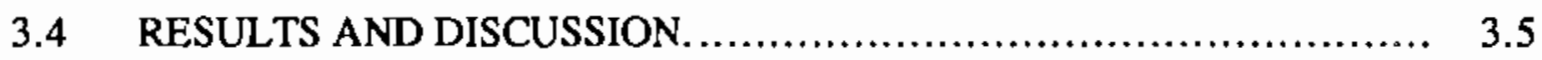

3.4.1 Ecosystem Structural Comparisons at the Three-Leaf

Stage of Wheat Growth..................................................... 3.5

3.4.2 Ecosystem Structural Comparisons at the Boot

Stage of Wheat Growth.................................................. 3.11

3.4.3 Ecosystem Functional Comparisons............................. 3.14

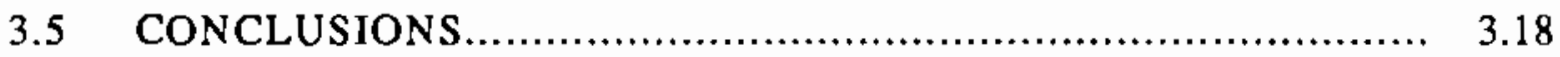

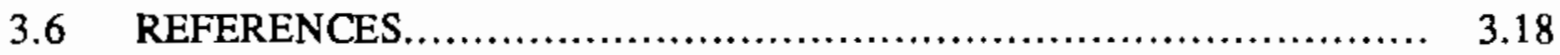

4.0 FATE AND ECOLOGICAL EFFECTS OF AN INTRODUCED

RHIZOBACTERIUM IN MICROCOSMS AND THE FIELD ........................... 4.0

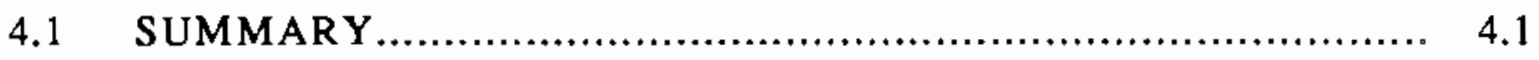

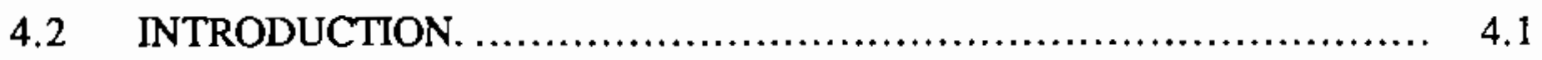

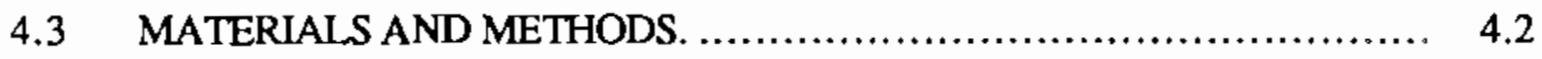

4.3.1 Bacterial Strain, Field Site, Microcosms and

Lysimeters and Inoculation............................................. 4.2

4.3.2 Sampling and Fate of RCt...................................... 4.4

4.3.3 Ecosystem Structural Measurements............................. 4.5

4.3.4 Ecosystem Functional Measurements............................. 4.5

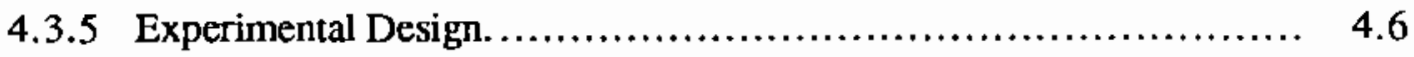

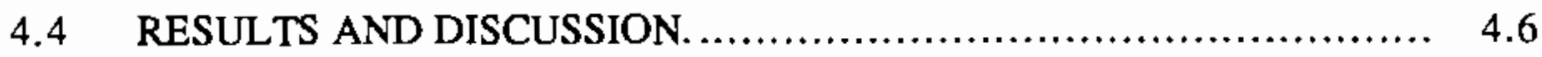

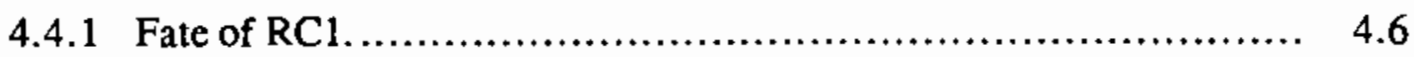

4.4.2 Ecosystem Structural Comparisons............................... 4.12

4.4.3 Ecosystem Functional Comparisons.............................. 4.13

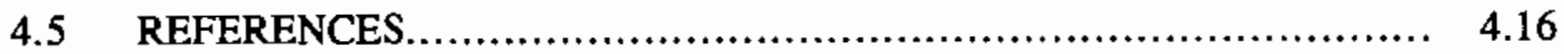

5.0 FIELD CALIBRATION OF SOIL-CORE MICROCOSMS INOCULATED

WITH STREPTOMYCES LIVIDANS TK24 .................................. 5.0

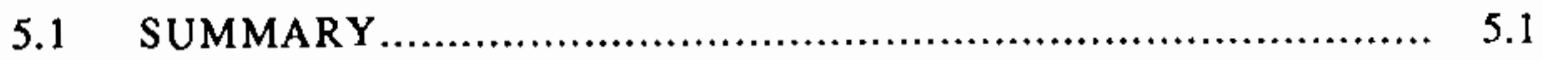

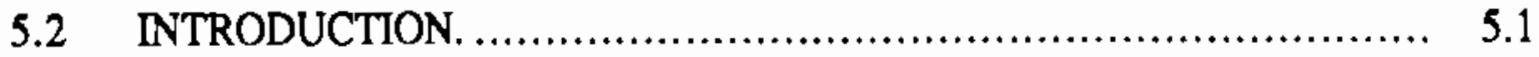


5.3 MATERIALS AND METHODS. ..................................... 5.3

5.3.1 Bacterial Strain and Media................................................ 5.3

5.3.2 Field Site, Microcosms, and Inoculation.......................... 5.3

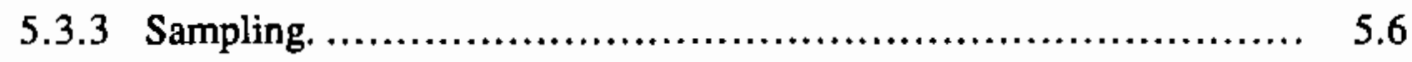

5.3 .4 Experimental Design............................................. 5.6

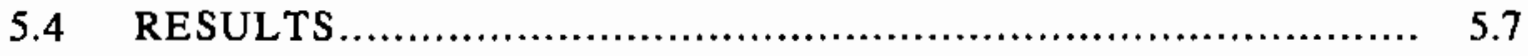

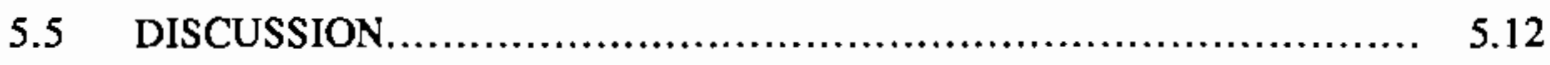

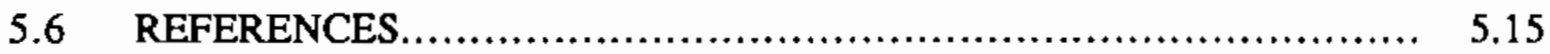




\section{EIGURES}

2.1 Average Daily Air Temperatures at the Three Study Sites Over the Duration

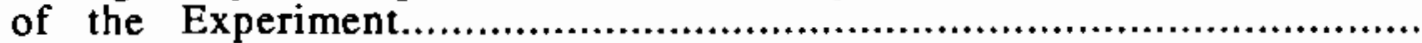

2.2 Surface (0 to $15 \mathrm{~cm}$ depth) Soil Populations of the Introduced Pseudomonas sp. $\mathrm{RCl}$ rif ${ }^{100}$ in the Various Microcosm and Field Treatments.

2.3 Wheat Rhizoplane Populations of the Introduced Pseudomonas sp. RC1 rif ${ }^{100}$ as a Function of Depth in the Various Microcosm and Field Treatments at the Final Boot Stage Sampling.

3.1 Wheat Rhizoplane Populations (Log Colony Forming Units (CFU) g-1 Dry Root) of Total Pseudomonads as a Function of Depth in the Various Microcosm and Field Treatments at the Final Boot Stage Sampling

3.2 Wheat Rhizoplane Populations (Log Colony Forming Units (CFU) g ${ }^{-1}$ Dry Root) of Total Heterotrophic Bacteria as a Function of Depth in the Various Microcosm and Field Treatments at the Final Boot Stage Sampling

3.3 Soil Dehydrogenase Activity in the Various Microcosm and Field Treatments at the Three-Leaf Stage of Wheat Growth

4.1 Average Daily Air Temperatures in the Growth Chamber and the Field Over the Duration of the Experiment

4.2 Populations of the Introduced Pseudomonas sp. RC1 in Surface Soil (0 to $15 \mathrm{~cm}$ Depth) from the Microcosms and Field.

4.3 Populations of the Introduced Pseudomonas sp. RC1 on the Rhizoplane of Wheat as a Function of Depth in Microcosms and the Field at the Final Boot Stage Sampling.

5.1 Average Daily Air Temperature in the Growth Chamber and Field during the Study Period

5.2 Streptomyces lividans TK24 Population in Microcosm and Field Soils as a Function of Time

5.3 Microbial Community Structure and Function in Soils Sampled in the Fall, Winter, Spring, and Summer from Microcosms and the Field

5.4 Cumulative ${ }^{14} \mathrm{CO}_{2}$ Evolved from Sealed Minitubes Containing Soil Amended with ${ }^{14} \mathrm{C}$-Labelled Cellulose as a Function of Time. 


$$
\text { . }
$$




\section{TABLES}

2.1 Mean Surface Soil (0 to $15 \mathrm{~cm}$ depth) Populations of Pseudomonas sp. $\mathrm{RCl}$ rif ${ }^{100}$ at the Seedling (Three-Leaf) Stage of Wheat Growth in the Various Microcosm and Field Treatments with and without an Alfalfa

Amendment

2.2 Coefficients of Variation for Mean Rhizoplane Populations of Pseudomonas sp. RC1 rif 100 at Three Depths at the Final Boot Stage Sampling of Wheat in the Various Microcosm and Field Treatments.

3.1 Ecosystem Structural Measurements on the Wheat Rhizoplane at the ThreeLeaf Stage of Growth.

3.2 Species Diversity Indices on the Wheat Rhizoplane at the Three-Leaf Stage of Growth

3.3 Ecosystem Structural Measurements on the Wheat Rhizoplane at the Boot Stage of Growth

3.4 Ecosystem Functional Measurements (Soil and Plant) at the Three-Leaf and Boot Stage of Wheat Growth

4.1 Microbial Populations on the Rhizoplane of Wheat at the Three-Leaf Stage of Growth

4.2 Microbial Populations on the Rhizoplane of Wheat at the Boot Stage of Growth

4.3 Ecosystem Functional Measurements (Soil and Plant) at the Three-Leaf and Boot Stage of Wheat Growth

4.4 Inorganic $\mathrm{N}\left(\mathrm{NH}_{4}-\mathrm{N}, \mathrm{NO}_{3}-\mathrm{N}\right.$, and their Sum) Content of the Surface Soil (0 to $15 \mathrm{~cm}$ Depth)

4.5 Inorganic $\mathrm{N}\left(\mathrm{NH}_{4}-\mathrm{N}, \mathrm{NO}_{3}-\mathrm{N}\right.$, and their Sum) Content of Soils as a Function of Depth at the Boot Stage Sampling.

$5.1{ }^{14}$ C-Labelled Soil Microbial Biomass of the Surface Soil (0 to $15 \mathrm{~cm}$ Depth). 



\subsection{INTRODUCTION}

Intact soil-core microcosms are a potential tool for assessing the fate and risks associated with the release of genetically engineered microorganisms (GEMs) to the environment. Microcosms are an atrractive option for determining the fate and environmental risks associated with the release of GEMs, because tests and microorganisms can be contained within the laboratory. Also, intact soilcore microcosms retain many structural and functional elements of the ecosystem, which are present in the field, possibly making them useful field models. Before a microcosm design can become a standard tool for biotechnology risk assessment, the microcosm must first be calibrated to ensure they adequately simulate key parameters in the field.

Pacific Northwest Laboratory conducted this research for the U. S. Environmental Protection Agency - Corvallis Environmental Research Laboratory through Interagency Agreement IAG DW89933345-01-0.

The scope of the project was to compare intact soil-core microcosms and the field for ecosystem structural and functional properties after the introduction of a GEM. This project used two distinct microbial types as model GEMs, Gram-negative Pseudomonas sp. RC1, which was an aggressive root colonizer, and Gram-positive Streptomyces lividans TK24. The model GEMs were added to surface soil in separate studies, with RC1 studied throughout the growth of winter wheat (Triticum aestivum), while TK24 was studied throughout a ten month period. Also, RCl was used in studies conducted during two consecutive field seasons (1988 to 1990) to determine how year-to-year field variability influenced the calibration of microcosms with the field.

The rest of this report is organized into four sections. Sections two and three describe studies conducted concurrently the first year (October 1988 to September 1989), which investigated four systems: microcosms located in the laboratory at ambient temperature $\left(22^{\circ} \mathrm{C}\right)$ and in a growth chamber with temperature fluctuations that simulated average conditions in the field, field lysimeters, and field plots. Section two describes the survival and fate of the introduced rhizobacterium, Pseudomonas sp. RCl rif ${ }^{100}$ (RC1), in the four systems. Section three describes the effect of the introduced $\mathrm{RC} 1$ on ecosystem structural and functional properties and compares these parameters in the four systems. Section four describes studies conducted the second year (October 1989 to September 1990), which compared microcosms located in a growth chamber with temperature fluctuations that simulated average daily high and low temperatures in the field, and field lysimeters for the fate of $\mathrm{RCl}$ and effects on ecosystem structural and functional 
properties. This second year study (October 1989 to September 1990) also compared results obtained in this study with those obtained the previous year (October 1988 to September 1989) to determine the effects of year-to-year field variability on the field-calibracion of microcosms. Section five describes studies conducted the second year (October 1989 to September 1990), which compared microcosms located in a growth chamber with temperature fluctuations that simulated average daily high and low temperatures in the field, and field lysimeter for the fate of the Gram-positive bacterium Streptomyces lividans TK24 and effects on ecosystem structural and functional properties. TK24 provided a comparison of the survival, ecosystem effects, and microcosm-field comparisons for Gram-positive (TK24) and Gram-negative (RC1) bacteria.

Each of the following sections of this report have been written so that they contain enough information to be considered separate pieces of work and can be read alone. For this reason, there is some repetition in Introduction of each section.

1.2 


\subsection{FIELD CALIBRATION OF SOIL-CORE MICROCOSMS: FATE OF A GENETICALLY ALTERED RHIZOBACTERIUM}

\subsection{SUMMARY}

Microcosms containing intact soil cores are a potential tool for assessing the risks of releasing genetically engineered microorganisms (GEMs) to the environment. Before microcosms become a standard assessment tool, however, they must first be calibrated to ensure that they adequately simulate key parameters in the field. Four systems were compared: intact soil-core microcosms located in the laboratory at ambient temperature and in a growth chamber with temperature fluctuations that simulated average conditions in the field, field lysimeters, and field plots. These four systems were inoculated with rifampicin-resistant Pseudomonas sp. and planted to winter wheat. Populations of the Pseudomonas sp. in soil decreased more rapidly at ambient temperature, but population size at the three-leaf stage of wheat growth was the same in all four systems. Populations of the Pseudomonas sp. on the rhizoplane of wheat were the same at the three-leaf stage in all four systems, and colonization with depth at the final boot stage-sampling was also similar. In general, microcosms incubated at ambient temperature in the laboratory or in the growth chamber were similar to the field with respect to the survival and colonization of the rhizoplane by the introduced Pseudomonas sp.

\subsection{INTRODUCTION}

Terrestrial microcosms incubated in the laboratory are potential tools for evaluating the fate and effects issues associated with the release of genetically engineered microorganisms (GEMs) into the environment (Cairns and Pratt 1986, Omenn 1986, Strauss et al. 1986, Trevors 1988). Microcosms have been used to assess the fate of chemicals (Gile et al. 1982, Van Voris et al. 1985) and the interactions of pollutants and microorganisms (Pritchard and Bourquin 1984). Microcosms are atractive for determining the environmental risks associated with the release of GEMs, because tests and microorganisms can be contained within the laboratory. Microcosms have been shown to be cost-effective for evaluating the fate, transport, and toxicity of chemicals (Van Voris et al. 1983). Recently, microcosms consisting of intact soil cores have been used to evaluate the fate and ecological effects of transposon mutants of Azospirillum lipofenum with com (Zea mays) and wheat (Triticum aestivum) (Bentjen et al. 1989) and a deleterious wheat rootinhibiting Pseudomonas sp. with wheat (Fredrickson et al. 1989). However, to have credibility as 
field models, microcosms need to be calibrated with observations from the field (Dean-Ross 1986, Fredrickson et al. 1990b, Gillett and Witt 1979, Pritchard and Bourquin 1984).

A rhizobacterium of the Pseudomonas sp., which was capable of inhibiting the root growth of winter wheat (Fredrickson and Elliott 1985), as well as the growth of other microorganisms in vitro (Bolton et al. 1989), was selected for this study of field calibration. This organism is an aggressive colonizer of roots, which can reach high populations on both the rhizoplane (Fredrickson and Elliott 1985) and various plant residues (Fredrickson et al. 1987, Stroo et al. 1988). The objective of this research was to determine the comparability of results obtained in microcosms with those obtained in the field by assessing the fate of root-colonizing Pseudomonas sp. in soil and in the wheat rhizoplane in field plots, field lysimeters, and intact soil-core microcosms. Section 3.0 describes the comparability of microcosms and the field for ecosystem structural and functional analyses.

\subsection{MATERIALS AND METHODS}

\subsubsection{Bacterial Strain and Media}

The isolation and characterization of Pseudomonas sp. suain RC1 was described by Bolton and Elliott (1989). A spontaneous mutant of this root-growth inhibiting rhizobacterium, which was resistant to $100 \mathrm{\mu g}$ rifampicin $\mathrm{ml}^{-1}$, was isolated for this study. This strain, Pseudomonas sp. $\mathrm{RC} 1$ rif 100 , will be referred to as $\mathrm{RC} 1$. The medium of Sands and Rovira (1970), amended with $50 \mu$ g rifampicin (Sigma ${ }^{\circledR}$ Chemical Company, St. Louis, Missouri) $\mathrm{ml}^{+1}$ (Sands rif ${ }^{\circ}$ ), was used to enumerate $\mathrm{RC} 1$.

\subsubsection{Field Site, Microcosms, Inoculation, and Locations}

The field site was located on the Arid Lands Ecology Reserve contained within the U.S. Department of Energy's Hanford Site in southeastem Washington State. The study site receives $19.5 \mathrm{~cm}$ of annual precipitation and has a mean annual temperature of $10^{\circ} \mathrm{C}$ (Rickard and Vaughan 1988). The soil is classified as coarse-silty, mixed, mesic, Xerollic Camborthid. The native vegetation is predominantly Agropyron spicatum, Poa secunda, and a cryptogamic soil lichen crust. This same soil type is used for irrigated agriculture or dryland winter wheat production in 
other areas of southeastern Washington.

Intact soil cores for use as microcosms $(17.5 \mathrm{~cm}$ diameter, $60 \mathrm{~cm}$ length) were obtained from the field site using a steel coring device containing Driscopipe ${ }^{\circledR}$ (polyethylene pipe, Phillips Petroleum Co., Dallas, Texas), as described by Van Voris (1988). The intact soil cores, held inside the polyethylene pipe after removal from the driving tube, were returned to the laboratory. The surface soil (top $15 \mathrm{~cm}$ ) was removed from all cores and combined, mixed, and sieved to pass a 2-mm screen. The sieved surface soil was divided into four equal portions for the soil treatments. The four soil treatments included inoculation with $\mathrm{RC}$, with and without a $1 \%(\mathrm{w} / \mathrm{w})$ alfalfa amendment (dried at $60^{\circ} \mathrm{C}$ and chopped), and uninoculated with and without an alfalfa amendment. Inoculum was prepared by growing $\mathrm{RCl}$ on Sands rif ${ }^{50}$ agar and harvesting by flooding agar plates with sterile deionized water and dislodging the cells with a sterile bent glass rod. The alfalfa-amended soil received $1.7 \times 10^{8}$ colony forming units (CFU) of $\mathrm{RCl}^{\mathrm{g}} \mathrm{g}^{-1}$ dry soil, while the unamended soil received $5.5 \times 10^{7} \mathrm{CFU} \mathrm{g}^{-1}$ dry soil. A solution of ${ }^{15} \mathrm{~N}$-labeled ammonium sulfate was added to all treatments for a final enrichment of 15 atom $\% 15 \mathrm{~N}$ and a N addition equivalent to $100 \mathrm{~kg} \mathrm{~N} \mathrm{ha}^{-1}$. All treatments were brought to a final soil moisture content of $16 \%$ with tap water.

There were three sites (the laboratory, a growth chamber, and the field) with four location treatments (ambient microcosms incubated in a laboratory, microcosms incubated in a growth chamber, field plots, and field lysimeters). The ambient microcosms were incubated at $22^{\circ} \mathrm{C}$ (ambient laboratory temperature) and maintained as described by Bentjen et al. (1989). Photoperiod was set at 12 -h with an initial light intensity at the soil surface of $400 \mu$ Einsteins $\mathrm{m}^{-2}$ (4100K Ultralume ${ }^{T M}$ lamps, Phillips Lighting Co., Bloomfield, New Jersey). Growth chamber microcosms were incubated under a cycling temperature regime that approximated the average daily minimum temperature during the night and the average daily high temperature during the photoperiod at the Hanford Site (Stone et al. 1983). A photoperiod of 10-h was used to simulate fall and winter and a photoperiod of 12 -h was used for spring and summer. A micrometeorological weather station, which measured air temperature and precipitation, was located near the field site. Average daily air temperature profiles for the field, growth chamber, and laboratory are shown in Fig. 2.1.

The field site included both soil-core lysimeters and microplots, to evaluate the influence of a restricted rooting zone on the survival and fate of $\mathrm{RCl}$. The field lysimeters consisted of intact soil-cores within polyethylene pipe, which were placed back into the soil at the field site. The bottoms of the microcosms and field lysimeters were wrapped with polyester monofilament cloth 


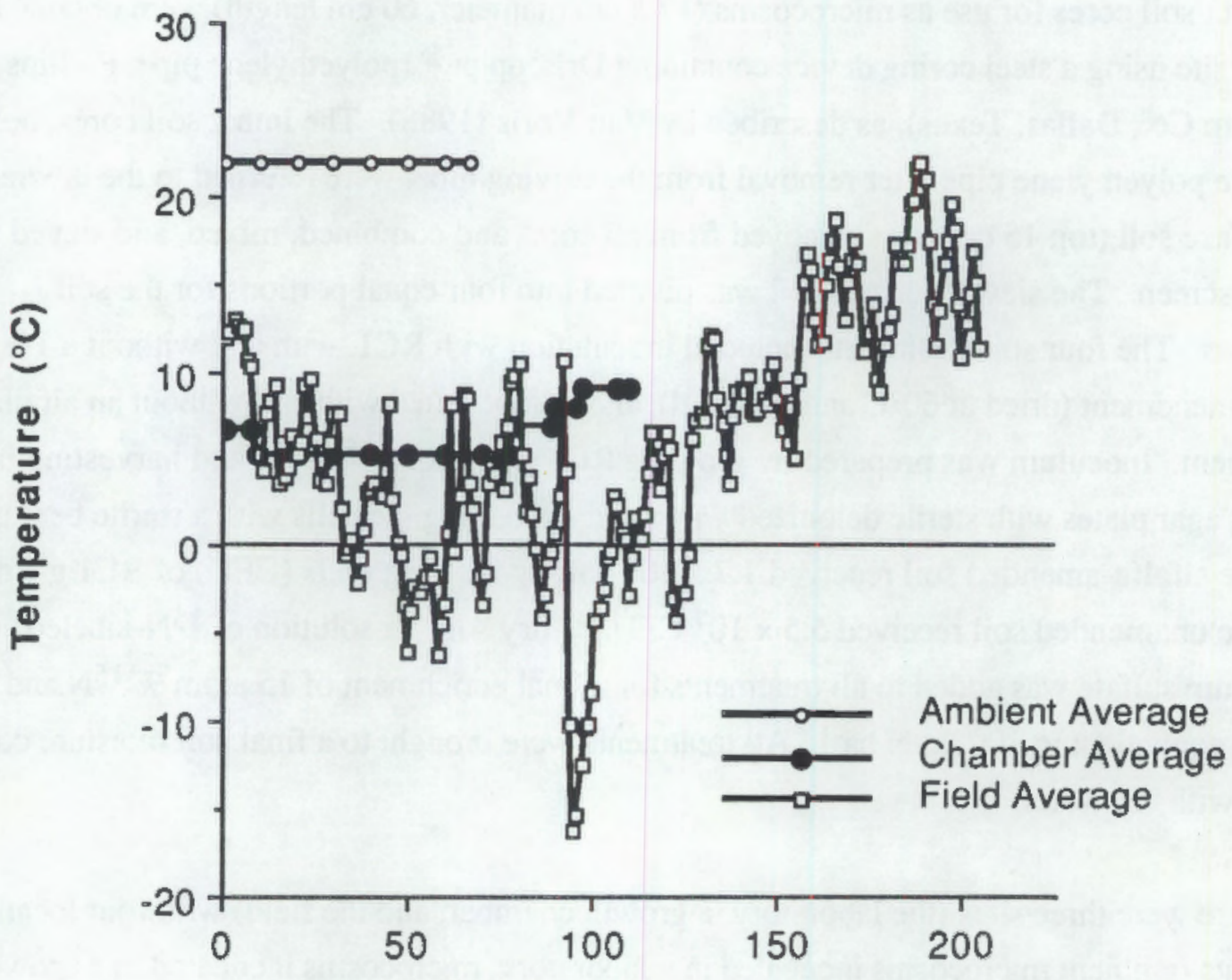

Time (days)

FIGURE 2.1. Average Daily Temperatures at the Three Study Sites Over the Duration of the Experiment.

(160 mesh) to prevent root movement outside the core. The field plots consisted of $17.5-\mathrm{cm}-$ diameter and 15-cm-deep open-ended rings of polyethylene pipe placed into the ground at the field site, the soil removed, treated as described earlier, and replaced. All soil cores and plots were replicated four times and seeded with five 'Daws' winter wheat seeds that were later thinned to two wheat seedlings. Soil inoculation and placement at the four locations occurred on October 29, 1988. Microcosms, field plots, and field lysimeters were routinely watered with tap water as the soil dried. 


\subsubsection{Nondestructive Sampling}

$\mathrm{RC} 1$ populations in the surface soil ( 0 to $15 \mathrm{~cm}$ depth) were measured as a function of time at the four locations. Approximately $25 \mathrm{~g}$ of soil was removed from the surface, taking care not to disturb the wheat plants. Soil samples were serially diluted, plated onto Sands rif ${ }^{50} \mathrm{agar}$, and colonies counted after incubating at $22^{\circ} \mathrm{C}$ for 24 to $48 \mathrm{~h}$. Soil populations of $\mathrm{RC} 1$ are reported on a per g dry weight $\left(105^{\circ} \mathrm{C}, 24 \mathrm{~h}\right)$ of soil basis.

At the three-leaf stage, one wheat seedling was removed with intact roots from each of the laboratory and growth chamber microcosms and the field on 18,45 , and 144 days after planting, respectively. The soil adhering to the roots was removed by washing the root in a sterile dilution blank. The washed roots were then macerated using a sterilized mortar and pestle, and the resulting macerate was serially diluted and plated onto $S a n d$ rif 50 to enumerate rhizoplane populations of $\mathrm{RC} 1$. Rhizoplane populations of $\mathrm{RCl}$ are reported on a per gram dry weight $\left(55^{\circ} \mathrm{C}\right.$, $48 \mathrm{~h})$ of root basis.

\subsubsection{Destructive Sampling}

Microcosms, field lysimeters, and plots were sacrificed at the boot stage of wheat growth, which was reached at 67,110 , and 205 days after planting for the ambient microcosms, growth chamber microcosms, and field plots and lysimeters, respectively. Field lysimeters were removed from the field intact. The 15 -cm-deep ring delineating the field plots was removed and replaced with a 15 -cm-diameter, $60-\mathrm{cm}$-long, PVC pipe, the same size as the soil-core microcosms. The PVC pipe was driven straight into the ground and excavated to obtain intact soil cores with the same dimensions as the microcosms. Wheat shoots were then cut at the soil surface. Two cuts were made along the length of the polyethylene pipe using a saber saw and the intact soil-core was divided into three sections (top: 0 to $15 \mathrm{~cm}$, middle: 15 to $35 \mathrm{~cm}$, and bottom: 35 to $55 \mathrm{~cm}$ ). The outer $1 \mathrm{~cm}$ of soil and root, at the pipe-soil interface, was pared to avoid samples that may have received $\mathrm{RC} 1$ from surface water that migrated at the soil-pipe interface. Roots from the three sections (top, middle, and bottom) were processed as described earlier.

\subsubsection{Experimental Design}

The experimental design was a $2 \times 2 \times 4$ completely randomized factorial design with two 
inoculation treatments (with $\mathrm{RCl}$ and without), two alfalfa treatments (amended and unamended), and four locations (ambient microcosms, chamber microcosms, field lysimeters, and field plots).

Log transformed data were used for the statistical analysis of microbial plate counts. Results from four replicates were statistically analyzed using a fixed-effects model (StatView ${ }^{\text {TM }}$ II Program, Abacus Concepts, Inc., Berkeley, California). Duncan's multiple range test was used to test differences among means ( $\mathrm{p} \leq 0.05$ ), but only when F-tests (ANOVA) for main effects or interactions were statistically significant, to ensure a conservative estimate of treatment mean differences (Steel and Torrie 1980).

\subsection{RESULTS AND DISCUSSION}

The population of $\mathrm{RCl}$ in surface ( 0 to $15 \mathrm{~cm}$ depth) soil declined more rapidly in the order: ambient microcosm > chamber microcosm > field plot $=$ field lysimeter (Fig. 2.2). The end point of each curve is the soil population at the final destructive sampling (the boot stage of wheat growth). The addition of alfalfa to the surface soil initially increased the population of RC1 in soil compared to the unamended soil (Fig. 2.2). When populations of $\mathrm{RCl}$ in soil were compared at the various locations at the three-leaf stage of wheat growth, the populations in soil amended with alfalfa were significantly higher than those in soil not amended, independent of location (Table 2.1). The ambient microcosms with alfalfa had the highest population of $\mathrm{RCl}$ in soil at the threeleaf stage, while the unamended field plots and lysimeters had the lowest (Table 2.1). At the final destructive sampling, there was no significant effect on the population of $\mathrm{RCl}$ in soil as a result of the alfalfa amendment, although populations in the soil of the chamber microcosms ( $4.3 \log \mathrm{CFU}$ $\mathrm{g}^{-1}$ dry soil) were significantly higher than at the other locations $\left(2.9,3.0\right.$, and $3.1 \log \mathrm{CFU} \mathrm{g}{ }^{-1}$ dry soil in the ambient microcosms, field plots, and field lysimeters, respectively).

The variations in temperature at the four locations could have contributed to the variation found in microbial survival between microcosms and the field, because variation in temperature is a major factor that influences microbial survival and growth in soil (Beringer and Bale 1988). The ambient laboratory microcosms were maintained at $22^{\circ} \mathrm{C}$, whereas the growth chamber was programmed to simulate the 30 -year average fall and then spring field temperatures, with average high and low temperatures used for the light and dark periods, respectively. Winter could not be simulated in the growth chamber because temperatures below $5^{\circ} \mathrm{C}$ could not be attained. The surface air temperature of the field plots and lysimeters was below freezing during several periods, with a low of $-18^{\circ} \mathrm{C}$ (Fig. 2.1). RC1 is a psychrophile, which grows well in culture at $4^{\circ} \mathrm{C}$ (Bolton 


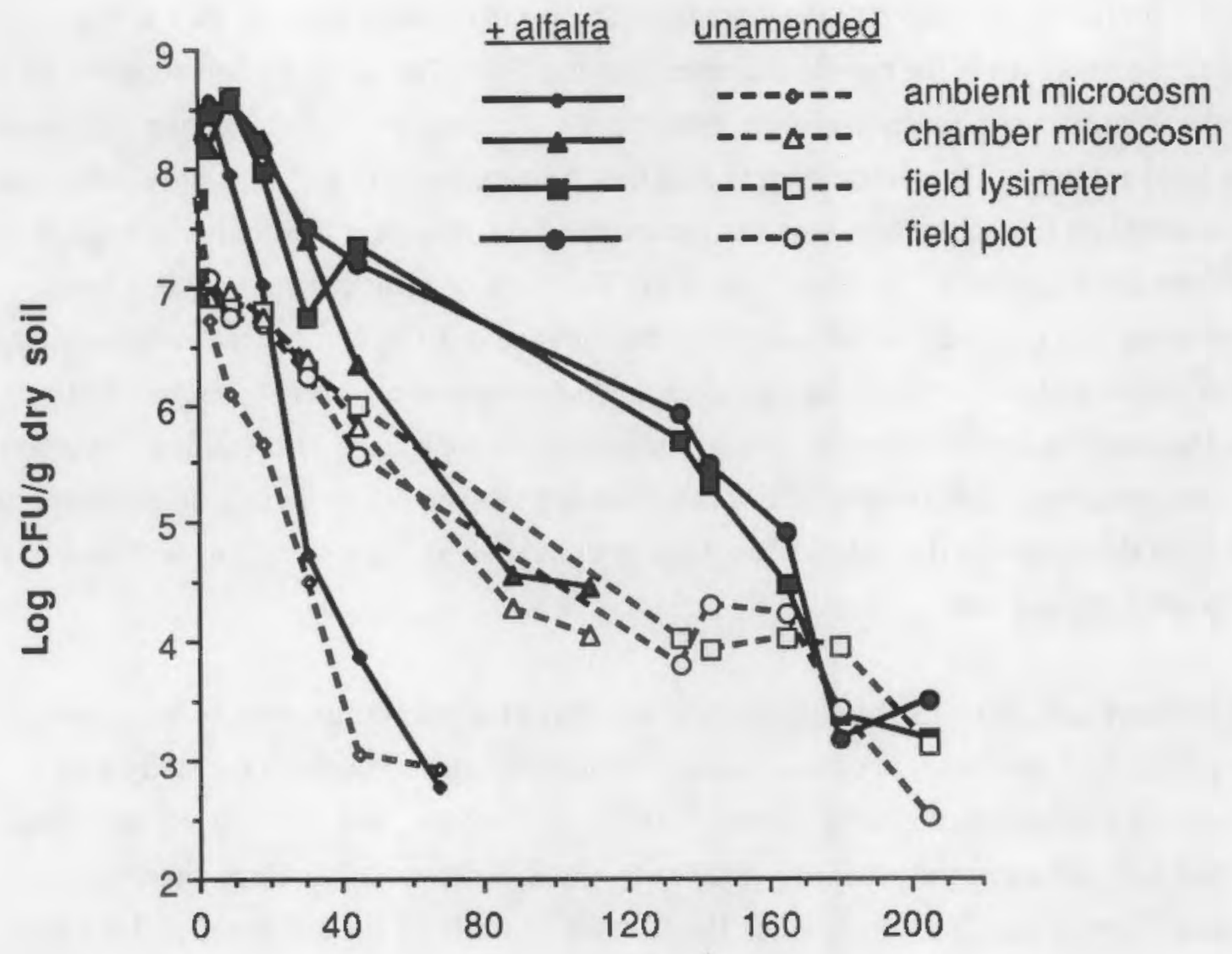

Time (days)

FIGURE 2.2. Surface Soil ( 0 to $15 \mathrm{~cm}$ Depth) Populations of The Introduced Pseudomonas sp. $\mathrm{RC} 1$ rif 100 in the Various Microcosm and Field Treatments

TABLE 2.1. Mean Surface Soil (0 to $15 \mathrm{~cm}$ Depth) Populations of Pseudomonas sp. RC1 rif 100 at the Seedling (Three-Leaf) Stage of Wheat Growth in the Various Microcosm and Field Treatments with and without an Alfalfa Amendment

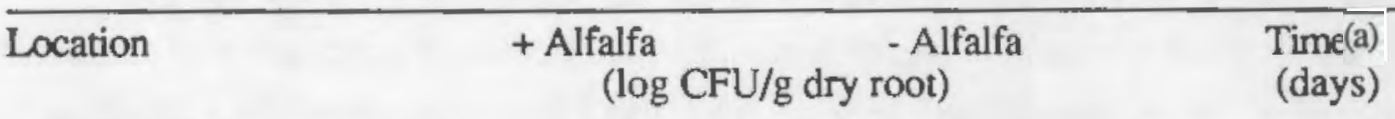

\begin{tabular}{lllr}
\hline Ambient microcosm & $7.0 \mathrm{e}^{(\mathrm{b})}$ & $5.7 \mathrm{bc}$ & 18 \\
Chamber microcosm & $6.3 \mathrm{~d}$ & $5.8 \mathrm{c}$ & 45 \\
Field plot & $5.5 \mathrm{bc}$ & $4.3 \mathrm{a}$ & 144 \\
Field lysimeter & $5.3 \mathrm{~b}$ & $4.0 \mathrm{a}$ & 144
\end{tabular}

(a) Time from planting to reach the three-leaf stage of wheat growth.

(b) Means followed by the same letter are not significantly different $(p \leq 0.05, n=4)$ 
and Elliott 1989) and was able to survive throughout the winter in the field and maintain relatively high populations in soil $\left(10^{6} \mathrm{CFU} \mathrm{g}^{-1} \mathrm{dry}\right.$ soil). The relatively constant and higher incubation temperatures probably contributed to the more rapid decline in the population of $\mathrm{RC} 1$ in the ambient microcosms than in the growth chamber or in the field. The varying populations of RC1 in soil at the three sites as a function of time, demonstrate the importance of calibrating microcosms for use as field analogues. It is interesting to note that the population of $\mathrm{RC} 1$ in soil was the same at the final sampling for the ambient microcosms and the field, despite a threefold difference in the length of time from the start of the study (Fig. 2.2). The stage of plant growth may be a better calibration point than elapsed time for comparing the survival of $\mathrm{RC} 1$, because the environmental factors that influence wheat growth (i.e., temperature and moisture) are also key factors that influence rhizobacterial growth and survival in soil and the rhizoplane. Therefore, it is important to measure the populations of introduced rhizoplane colonizers in soil at key periods linked to specific stages of plant development (i.e., plant phenology or units such as degree-days) as well as a function of total elapsed time.

Soil moisture can also influence the survival and growth of microorganisms in soil (Beringer and Bale 1988). The total amount of water added to the three sites throughout the study was similar, with the ambient microcosms, growth chamber microcosms, and the field site receiving $8.7,9.2$, and $8.9 \mathrm{~L}$ of water, respectively. However, water additions at the three sites were distributed differently as a function of time. Precipitation at the field site amounted to $3.4 \mathrm{~L}$ and occurred at variable intervals and intensity mainly during the winter, while a total of $5.5 \mathrm{~L}$ of tap water was added incrementally throughout the spring when the surface soil $(10 \mathrm{~cm})$ became dry. Water was also added to the ambient and growth chamber microcosms when the surface soil became dry. The length and extent of soil wet/dry cycles at the three sites could have been different and affected the survival of RC1. More research is needed to understand how soil wet/dry cycles influence microbial survival and fate and how soil wet/dry cycles influence the use of microcosms as field surrogates.

The rate of decline in the population of $\mathrm{RCl}$ in soil in this study was in agreement with previous studies, which investigated the fate of bacterial populations after inoculation of surface soil (Fredrickson et al. 1989, Nesmith and Jenkins 1983, van Elsas et al. 1986). In a previous study with $\mathrm{RC} 1$ transposon Tn 5 mutants, the soil population declined by $3.5 \mathrm{log}$ units after 54 days in soil-core microcosms incubated at 21 to $23^{\circ} \mathrm{C}$ (Fredrickson et al. 1989). In this study, rifampicin-resistant mutants of RC1 declined by 4.3 and $4.7 \mathrm{log}$ units in ambient laboratory microcosms with and without an alfalfa amendment, respectively, after 45 days (Fig. 2.2). The more rapid decline of $\mathrm{RC} 1$ in this study may have been the result of differences in soil type, genetic 
marker, or both. The study with Tn 5 mutants of $\mathrm{RC} 1$ was conducted in Palouse soil (Fredrickson et al. 1989), whereas Ritzville soil was used in this study. Palouse soil has a higher organic carbon content $(2.0 \%)$ than Ritzville soil $(1.1 \%)$, which may favor the survival of RCl. In addition, $\mathrm{RCl}$ was initially isolated from Palouse soil (Bolton and Elliott 1989). The mechanism of antibiotic resistance in these two strains is different. The rifampicin-resistant mutants of RCl were spontaneous mutants, which typically have an altered ribosome structure preventing binding of the antibiotic. The Tn 5 mutants are resistant to kanamycin via direct enzymatic detoxification. Rifampicin-resistant mutants of Pseudomonas sp. can be affected in their growth, competition, and survival in soil when compared to the parent strain (Compeau et al. 1988). This suggests that the rifampicin-resistant mutants used in this study may not have been as competitive as the parent or transposon mutants. However, Tn 5 mutants of Rhizobium leguminosarum can also be ecologically and biochemically impaired when compared to the parent strain (Brockman et al. 1991). The results from this and other studies (Brockman et al. 1991, Compeau et al. 1988) indicate that genetic alterations of bacteria must be considered when evaluating the environmental competency of microorganisms.

There was no difference in the colonization of wheat roots by $\mathrm{RCl}$ at the three-leaf stage of wheat growth as a result of location or alfalfa amendment. Colonization ranged from 8.3 to 9.1 $\log \mathrm{CFU} \mathrm{g}^{-1} \mathrm{dry}$ root, with an average across all treatments of $8.7 \log \mathrm{CFU} \mathrm{g}^{-1}$ dry root. RC1 was able to colonize the rhizoplane to the same extent at the three sites regardless of the inoculum size of RC1 in soil at the three-leaf stage (Table 2.1) or differences in the time of incubation. The colonization of the rhizoplane by $\mathrm{RC} 1$ may have been more dependent on plant factors than on the survival of RC1 in surface soil.

At the final sampling (boot stage of wheat growth), the population of $\mathrm{RCl}$ on the rhizoplane decreased with increasing depth (Fig. 2.3). This decrease in the population of an introduced microorganism on the rhizoplane as a function of depth confirms previous observations with $\mathrm{RC} 1$ (Fredrickson et al. 1989) and with Pseudomonas sp. biocontrol agents in the laboratory (Howie et al. 1987), and the field (Weller 1984). The amendment with alfalfa did not influence the population of $\mathrm{RC} 1$ on the rhizoplane, which was similar to the three-leaf stage sampling. There was no difference in the colonization of wheat roots in the top segments of the soil-cores by $\mathrm{RCl}$ at the boot stage of wheat growth as a result of location (Fig. 2.3). Colonization ranged from 6.5 to $6.9 \log _{\mathrm{CFU} \mathrm{g}} \mathrm{g}^{-1} \mathrm{dry}$ root, with an average across all treatments of $6.6 \mathrm{log}_{\mathrm{CFU} \mathrm{g}} \mathrm{g}^{-1} \mathrm{dry}$ root. The mean population of $\mathrm{RCl}$ on the rhizoplane in the top segment of the core ( 0 to $15 \mathrm{~cm}$ depth) therefore decreased approximately two $\log$ units from the seedling $\left(8.7 \log _{\text {CFU g }}{ }^{-1}\right.$ dry root) to the boot stage sampling (6.6 log $\mathrm{CFU} \mathrm{g}^{-1} \mathrm{dry}$ root). Fredrickson et al. (1989) found a similar 


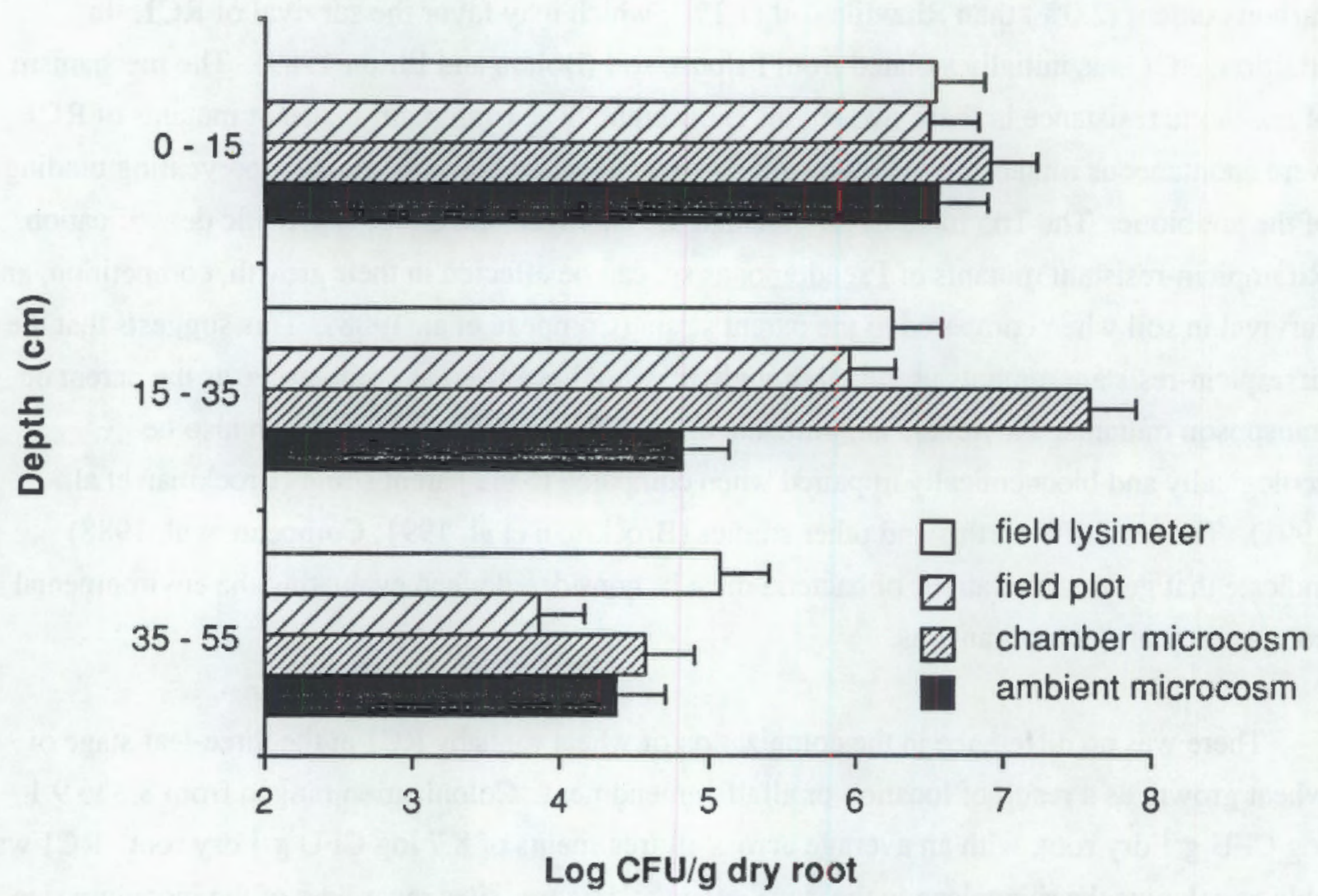

FIGURE 2.3. Wheat Rhizoplane Populations of the Introduced Pseudomonas sp. RC1 rif 100 as a Function of Depth in the Various Microcosm and Field Treatments at the Final Boot Stage Sampling. Error bars represent the difference between treatment means $(\mathrm{p} \leq 0.05, \mathrm{n}=8)$.

decrease in population of $\mathrm{RCl}$ on the rhizoplane with increasing plant growth. Bacterial populations in the wheat rhizosphere have been shown to decrease as the plant matures and decline sharply as it enters the flowering stage (Sivasithamparam et al. 1979).

There was generally close agreement between the various locations for populations of $\mathrm{RCl}$ on the rhizoplane at the bottom segments of the soil core. However, the field plots had a population of $\mathrm{RCl}$ on the rhizoplane in the bottom segment of the soil core that was one log unit less than the field lysimeters. This may have been caused by differences in the distribution of roots between the two treatments and/or water infiltration through the soil profile. The polyethylene pipe $(17.5 \mathrm{~cm}$ 
diameter, $60 \mathrm{~cm}$ length) enclosing the ambient and growth chamber microcosms and field lysimeters restricted lateral and, to a lesser degree, vertical wheat root growth and possibly enhanced water movement through a confined volume of soil. Visual observations of the distribution of roots in dissected cores indicated that the density of roots below the top $15 \mathrm{~cm}$ in the microcosm and lysimeter soil cores was greater than in the field plots soil cores. The polyethylene pipe may result in an enhanced density of roots in a volume of soil when compared to unrestricted growth in the field. These observations indicate that when soil-core microcosms are used to assess microbial survival and fate on the rhizoplane, the length of time for which results from microcosms simulate the field will be dictated in part by the plant species, the volume of soil within the core, and the rate of plant growth. Studies that evaluated nutrient leaching from soil cores, as a means to assess the impacts of microorganisms on ecological processes, also supported this conclusion (Fredrickson et al. 1990a).

The greatest variation in the rhizoplane populations between the locations was in the middle segment of the soil cores (Fig. 2.3), where the chamber and ambient microcosms differed by almost three orders of magnitude. The population of $\mathrm{RCl}$ on the rhizoplane in the ambient and chamber microcosms was lower and higher than in the field (Fig. 2.3), respectively. It is unclear why there was such a large discrepancy in the populations of $\mathrm{RCl}$ on the rhizoplane in the middle segment. These results suggest a measure of caution in blindly accepting laboratory and growth chamber based data for simulating field survival of an introduced organism. Also, the larger difference in the rhizoplane populations in the middle layer at the four locations demonstrates the importance of quantifying bacterial populations at different soil depths and not relying on a single composite sample for evaluating bacterial survival and fate.

The coefficients of variation (CV) for colonization of the rhizoplane by $\mathrm{RCl}$ at the final boot stage at each of the four locations ( $n=8$, because averages used both alfalfa levels, as the alfalfa amendment was not significant at the boot stage) were calculated for all three depths to compare variations among microcosm and field replicates. One criticism of microcosms is that they can be inherently variable. In this study, the $\mathrm{CVs}$ for the population of $\mathrm{RCl}$ on the rhizoplane were very similar in the top soil layer for the four locations (Table 2.2). This may be the result of the removal of the surface soil from the microcosms, field lysimeters and field plots, which was then composited, sieved, and mixed. The low CV for the field plots in the bottom soil layer was caused by the low population of $\mathrm{RCl}$ present and because several samples had populations below the detection limit of $3.7 \log \mathrm{CFU} \mathrm{g-1}$ dry root; the detection limit was used to calculate the means. The $\mathrm{CV}$ for the chamber microcosm was similar to the field lysimeter demonstrating that microcosms may exhibit the approximate statistical variability observed in the field. 
TABLE 2.2. Coefficients of Variation for Mean Rhizoplane Populations of Pseudomonas sp. $\mathrm{RC} 1$ rif 100 at Three Depths at the Final Boot Stage Sampling of Wheat in the Various Microcosm and Field Treatments.

Location

\section{Depth $(\mathrm{cm})$}

15 to 35
35 to 55

0 to 15

(coefficient of variation, $\%, n=8$ )

$\begin{array}{llrr}\text { Ambient microcosm } & 7.5 & 23.1 & 11.9 \\ \text { Chamber microcosm } & 6.9 & 6.7 & 22.1 \\ \text { Field plot } & 8.6 & 12.4 & 3.6 \\ \text { Field lysimeter } & 6.2 & 7.4 & 25.4\end{array}$

In summary, these results demonstrate that intact soil-core microcosms can model field survival and the colonization of the wheat rhizoplane by a rhizobacterium. Results from the final sampling of the population of $\mathrm{RCl}$ on the rhizoplane at the middle depth suggest a measure of caution in using laboratory and growth chamber based data for simulating field survival of an introduced organism. The stage of plant growth was determined to be a better reference point for predicting the fate of this bacterium in the field from microcosm results than the length of time from inoculation. These results demonstrate that limitations exist in using soil-core microcosms as field models for assessing the risks associated with the field release of GEMs and that more research is needed to investigate these limitations.

\subsection{REFERENCES}

Bentjen S. A., J. K. Fredrickson, S. W. Li, and P. Van Voris. 1989. "Intact Soil-Core Microcosms for Evaluating the Fate and Ecological Impacts From the Release of Genetically Engineered Microorganisms." Appl. Environ. Microbiol. 55:198-202.

Beringer, J. E., and M. J. Bale. 1988. "The Survival and Persistence of Genetically-Engineered Micro-Organisms." In The Release of Genetically-Engineered Micro-Organisms, eds. M. Sussman, C. H. Collins, F. A. Skinner, and D. E. Stewart-Tull, pp. 29-46. Academic Press, London.

Bolton, Jr, H., and L. F. Elliott. 1989. "Toxin Production by a Rhizobacterial Pseudomonas sp. That Inhibits Wheat Root Growth." Plant Soil 114:269-278.

Bolton, Jr, H., L. F. Elliott, S. Gurusiddaiah, and J. K. Fredrickson. 1989. "Characterization of a Toxin Produced by a Rhizobacterial Pseudomonas sp. That Inhibits Wheat Growth." Plant Soil 114:279-287. 
Brockman, F. J., L. B. Forse, D. F. Bezdicek, and J. K. Fredrickson. 1991. "Impairment of Transposon-Induced Mutants of Rhizobium leguminosarum." Soil, Biol. Biochem. 23:302-309.

Cairns J., and J. R. Pratt. 1986. "Ecological Consequence Assessment: Effects of Bioengineered Organisms." In Biotechnology Risk Assessment. Issues and Methods for Environmental Introductions, eds. J. Fiksel, and V. T. Covello, pp. 88-108. Pergamon Press, New York.

Compeau, G., B. J. Al-Achi, E. Platsouka, and S. B. Levy. 1988. "Survival of RifampinResistant Mutants of Pseudomonas fluorescens and Pseudomonas putida in Soil Systems." Appl. Environ. Microbiol, 54:2432-2438.

Dean-Ross, D. 1986. "Release of genetically engineered microorganisms: hazard assessment." ASMNews 11:572-575.

Fredrickson, J. K., and L. F. Elliott. 1985a. "Colonization of Winter Wheat Roots by Inhibitory Rhizobacteria." Soil Sci. Soc. Am. J. 49:1172-1177.

Fredrickson, J. K., and L. F. Elliott. 1985b. "Effect on Winter Wheat Seedling Growth by Toxin Producing Rhizobacteria. Plant Soil 83:399-409.

Fredrickson, J. K., L. F. Elliott, and J. C. Engibous. 1987. "Crop Residues as Substrate for Host-Specific Inhibitory Pseudomonads." Soil. Biol. Biochem, 19:127-134.

Fredrickson, J. K., S. A. Bentjen, H. Bolton, Jr., S. W. Li, and P. Van Voris. 1989. "Fate of $\operatorname{Tn} 5$ Mutants of Root Growth-Inhibiting Pseudomonas sp. in Intact Soil-Core Microcosms." Can. J. Microbiol. 35:867-873.

Fredrickson, J. K., H. Bolton, Jr., S. A. Bentjen, K. M. McFadden, S. W. Li, and P. Van Voris. 1990a. "Nutrient Efflux From Intact Soil-Core Microcosms for Evaluating the Impacts of Genetically Engineered Microorganisms on Ecological Processes." Environ. Tox. Chem 9:551-558.

Fredrickson, J. K., P. Van Voris, S. A. Bentjen, and H. Bolton, Jr. 1990b. "Terrestrial Microcosms for Evaluating the Environmental Fate and Risks Associated with the Release of Chemicals or Genetically Engineered Microorganisms to the Environment." Hazard Assess. Chem.-Curr. Develop 7:157-202.

Gile, J. D., J. C. Collins, and J. W. Gillett. 1982. "Fate and Impacts of Wood Preservatives in a Terrestrial Microcosm." J. Agric. Food Chem, 30:295-301.

Gillett, J. W., and J. M. Witt. 1979. "Terrestrial Microcosms." In Proceedings of the Workshop at Otter Rock and Portland. OR June and December. 1977, NSF/RA-790034, p. 34. National Science Foundation, Washington, D.C.

Howie, W. J., R. J. Cook, and D. M. Weller. 1987. "Effects of Soil Matric Potential and Cell Motility on Wheat Root Colonization by Fluorescent Pseudomonads Suppressive to Take-All." Phytopathology 77:286-292.

Nesmith, W. C., and S. F. Jenkins, Jr. 1983. "Survival of Pseudomonas solanacearum in Selected North Carolina Soils." Phytopathology 73:1300-1304.

Omenn, G. S. 1986. "Controlled Testing and Monitoning Methods for Microorganisms." In Biotechnology Risk Assessment, Issues and Methods for Environmental Introductions, eds. J. Fiksel, and V. T. Covello, pp 144-163. Pergamon Press, New York. 
Pritchard, P.H., and A. W. Bourquin. 1984. "The Use of Microcosms for Evaluation of Interactions Between Pollutants and Microorganisms." Adv, Microb. Ecol, 7:133-217.

Rickard, W. H., and B. E. Vaughan. 1988. "Plant Community Characteristics and Responses." In Shrub-Steppe: Balance and Change in a Semi-Arid Terestrial Ecosystem, eds. W. H. Rickard, L. E. Rogers, B. E. Vaughan, and S. F. Liebetrau. Elsevier, New York.

Sands, D. C., and A. D. Rovira. 1970. "Isolation of Fluorescent Pseudomonads with a Selective Medium." Appl. Microbiol, 20:513-514.

Sivasithamparam K., C. A. Parker, and C. S. Edwards. 1979. "Rhizosphere Microorganisms of Seminal and Nodal Roots of Wheat Grown in Pots." Soil. Biol. Biochem. 11:155-160.

Steel, R. G. D., and J. H. Torrie. 1980. Principles and Procedures of Statistics: a Biometrical Approach. 2nd ed., McGraw-Hill Book Company, New York.

Stone, W. A., J. M. Thorp, O. P. Gifford, and D. J. Hoitink. 1983. Climatological Summary for the Hanford Area. PNL-4622, UC-11, National Technical Information Service, Springfield, Virginia.

Strauss, H. S., D. Hattis, G. Page, K. Harrison, S. Vogel, and C. Caldert. 1986. "GeneticallyEngineered Microorganisms: II. Survival, Multiplication, and Genetic Transfer." RAC. Tech. Bull. 9:16-28.

Stroo, H. F., L. F. Elliott, and R. I. Papendick. 1988. "Growth, Survival and Toxin Production of Root-Inhibitory Pseudomonads on Crop Residues." Soil. Biol. Biochem. 20:201-207.

Trevors, J. T. 1988. "Use of Microcosms to Study Genetic Interactions Between Microorganisms." Microbiol. Sci. 5:132-136.

van Elsas, J. D., A. F. Dijkstra, J. M. Govaert, J.A. van Veen. 1986. "Survival of Pseudomonas fluorescens and Bacillus subrilis Introduced into Two Soils of Different Texture in Field Microplots." FEMS Microbiol. Ecol, 38:151-160.

Van Voris, P. 1988. "Standard Guide for Conducting a Terrestrial Soil-Core Microcosm Test." Standard E 1197. In Annual Book of ASTM Standards, Vol. 11.04, pp. 743-755. American Society for Testing and Materials, Philadelphia.

Van Voris, P., D. A. Tolle, M. F. Arthur. 1983. Experimental Terrestrial Soil-Core Microcosm Test Protocol. A Method for Measuring Potential Ecological Effects. Fate, and Transport of Chemicals in Terrestrial Ecosystems. EPA/600/3-85/047, PNL-5450, Corvallis Environmental Research Laboratory, Corvallis, Oregon.

Van Voris, P., D. A. Tolle, M. F. Arthur, J. Chesson. 1985. "Terrestrial Microcosms: Application, Validation, and Cost-Benefit Analysis." In Multispecies Toxicity Testing, ed. J. Caims, pp 117-142. Pergamon Press, New York.

Weller, D. M. 1984. "Distribution of a Take-All Suppressive Strain of Pseudomonas fluorescens on Seminal Wheat Roots." Appl. Environ. Microbiol 48:897-899. 


\subsection{FIELD CALIBRATION OF SOIL-CORE MICROCOSMS: ECOSYSTEM STRUCTURAL AND FUNCTIONAL COMPARISONS}

\subsection{SUMMARY}

Microcosms containing intact soil cores are a potential biotechnology risk assessment tool for assessing the ecological effects of genetically engineered microorganisms before they are released to the field. However, microcosms must first be calibrated to ensure that they adequately simulate key field parameters. Soil-core microcosms were compared with the field in terms of ecological response to the introduction of a large inoculum of a rifampicin-resistant rhizobacterium, Pseudomonas sp. $\mathrm{RCl}$. RCl was inoculated into intact soil-core microcosms incubated in the laboratory at ambient temperature $\left(22^{\circ} \mathrm{C}\right)$ and in a growth chamber with temperature fluctuations that mimicked average field values and into field lysimeters and plots. The effect of the introduced bacterium on ecosystem structure, including wheat rhizoplane populations of total and fluorescent pseudomonads, total heterotrophic bacteria, and the diversity of total heterotrophic bacteria, was determined. Fluorescent pseudomonads were present on the rhizoplane in significantly lower numbers in soil inoculated with $\mathrm{RCl}$, in both microcosms and the field. Conditions for microbial growth appeared to be most favorable in the growth chamber microcosm, as evidenced by higher populations of heterotrophs and a greater species diversity on the rhizoplane at the three-leaf stage of wheat growth. Ecosystem functional parameters, as determined by soil dehydrogenase activity, plant biomass production, and $15 \mathrm{~N}$-fertilizer uptake by wheat were different in the four systems. The stimulation of soil dehydrogenase activity by the addition of alfalfa was greater in the microcosms than in the field. In general, growth chamber microcosms, which simulated average field temperatures, were better predictors of field behavior than microcosms incubated continuously at $22^{\circ} \mathrm{C}$.

\subsection{INTRODUCTION}

The effects of genetically engineered microorganisms (GEMs) on the structure and function of ecosystems must be known before GEMs are released into the environment (Tiedje et al. 1989). Microcosms are one option for obtaining preliminary information on the fate and effects of GEMs, because tests and microorganisms can be contiined within the laboratory (Cairns and Pratt 1986, Omenn 1986, Strauss et al. 1986). Recently, microcosms containing intact cores of soil have been used to evaluate the fate and ecological effects of transposon mutants of Azospirillum lipoferum 
(Bentjen et al. 1989) and a deleterious wheat (Triticum aestivum)-root inhibiting Pseudomonas sp. (Fredrickson et al. 1989). However, before microcosms can be used as a standard biotechnology risk assessment tool, they must first be calibrated with field observations, in order to be effective field models (Dean-Ross 1986, Fredrickson et al. 1990b, Gillett and Witt 1979, Pritchard and Bourquin 1984).

The evaluation of ecological processes has been suggested as an indicator of the impacts to the ecosystem resulting from the introduction of GEMs (Cairns and Pratt 1986). Intact soil-core microcosms retain many structural and functional elements of the ecosystem, which were present in the field. The best measure of whether or not soil-core microcosms mimic the field and are useful for biotechnology risk assessment is if similar ecological structure and function are found (O'Neill et al. 1988). Changes in nutrient cycling processes are often used to determine the disturbance of ecosystems (Dean-Ross 1986) and for field calibrating microcosms for microbial function (Pritchard and Bourquin 1984). Previous studies have investigated intact soil-core microcosms for structural effects on ecosystems including the displacement of Rhizobium leguminosarum and nitrifiers from the rhizosphere of wheat and maize (Zea mays) by inoculated with $\mathrm{A}$. lipoferum (Bentjen et al. 1989) and of aerobic heterotrophic bacteria on the wheat rhizoplane by a Pseudomonas sp. deleterious to the growth of wheat (Fredrickson et al. 1989). Ecosystem functional effects have also been investigated in laboratory microcosms, including the effect of fly ash on the primary producrivity of plants and the uptake of elements (Tolle et al. 1983, 1985), the effects of A. lipoferum on the $\mathrm{N}$ content of wheat and maize leaves (Bentjen et al. 1989), and the export of soil nutrients from microcosms resulting from leaching and uptake by plants (Fredrickson et al. 1990a).

The objective of this research was to determine the comparability of results obtained from microcosms with those obtained in the field for ecosystem structural and functional properties. The approach was to determine the effect of a rhizobacterial Pseudomonas sp. on the structure and function of the ecosystem when introduced to soil, which was planted with winter wheat, in field plots, field lysimeters, and intact soil-core microcosms in the growth chamber and the laboratory. The fate of this introduced rhizobacterial Pseudomonas sp. in microcosms and the field is described in Section 2.0. 


\subsection{MATERIALS AND METHODS}

\subsubsection{Bacterial Strain. Field Site, Microcosms, Inoculation, and Locations}

A description of the bacterial strain, field site, soil-core microcosm collection, inoculation, and treatment locations is presented in Section 2.0 . Briefly, intact soil-core microcosms $(17.5 \mathrm{~cm}$ diameter, $60 \mathrm{~cm}$ length), field lysimeters $(17.5 \mathrm{~cm}$ diameter, $60 \mathrm{~cm}$ length), and field plots ( 17.5 $\mathrm{cm}$ diameter, $15 \mathrm{~cm}$ deep open-ended rings) contained four surface soil ( 0 to $15 \mathrm{~cm}$ depth) treatments, including: 1) inoculation with Pseudomonas sp. RC1 (hereafter referred to as RC1), which was resistant to $100 \mu \mathrm{g}$ rifampicin $\mathrm{ml}^{-1}$ (Section 2.0 ), and a soil amendment of $1 \%(\mathrm{w} / \mathrm{w}$ ) alfalfa (dried at $60^{\circ} \mathrm{C}$ and chopped); 2) inoculated with $\mathrm{RC} 1$ and unamended; 3) uninoculated and amended with alfalfa; and 4) uninoculated and unamended. Soil inoculation and placement at the four locations, including: 1) microcosms incubated at ambient laboratory temperature $\left(22^{\circ} \mathrm{C}\right)$ (ambient microcosms); 2) microcosms incubated in a growth chamber (chamber microcosms) with temperature fluctuations that simulated field averages; 3) field lysimeters; and 4) field plots, occurred on October 29,1988 . The soil amended with alfalfa received $1.7 \times 10^{8}$ colony forming units (CFU) of $\mathrm{RC}^{-1} \mathrm{~g}^{-1} \mathrm{dry}$ soil (oven-dried at $105^{\circ} \mathrm{C}$ for $24 \mathrm{~h}$ ), while the unamended soil received $5.5 \times 10^{7} \mathrm{CFU} \mathrm{g}{ }^{-1} \mathrm{dry}$ soil. A solution of ${ }^{15} \mathrm{~N}$-labeled $\left(\mathrm{NH}_{4}\right)_{2} \mathrm{SO}_{4}$ was added to all treatments for a final enrichment of 15 atom $\% 15 \mathrm{~N}$ and a $\mathrm{N}$ addition equivalent to $100 \mathrm{~kg} \mathrm{~N} \mathrm{ha}^{-1}$. All treatments were brought to a final soil moisture content of $16 \%$ with tap water. All microcosms, field lysimeters, and field plots were seeded with five 'Daws' winter wheat seeds, which were later thinned to two wheat seedlings, and routinely watered with tap water as the soil dried.

\subsubsection{Sampling}

A description of the sampling protocol is presented in Section 2.0. Briefly, there were two samplings of winter wheat, one at the three-leaf stage and a final destructive sampling at the boot stage of growth. At the three-leaf stage, one wheat seedling with intact roots was removed from the ambient microcosms, chamber microcosms, and field lysimeters and plots at 18,45, and 144 days after planting, respectively. The final sampling was conducted at 67,110 , and 205 days after planting, respectively. At the final sampling, the intact soil-cores from each treatment were divided into three sections as a function of depth (top: 0 to $15 \mathrm{~cm}$; middle: 15 to $35 \mathrm{~cm}$; and bottom: 35 to $55 \mathrm{~cm}$ ). 


\subsubsection{Ecosystem Structural Measurements}

The soil adhering to wheat roots from seedlings at the three-leaf stage and from wheat roots at three soil depths from the boot stage was rinsed off in sterile water. Microbial populations on the rhizoplane were determined by macerating the washed roots in a sterile mortar and pestle, serially diluting, and plating the appropriate dilutions onto media, including Sands medium (Sands and Rovira 1970) for total and fluorescent pseudomonads, Sands medium amended with $50 \mu \mathrm{g}$ rifampicin (Sigma ${ }^{\circledR}$ Chemical Company, St. Louis, Missouri) $\mathrm{ml}^{-1}$ (Sands-rif ${ }^{50}$ ) for RC1, tryptic soy agar (TSA) (Martin 1975) for total aerobic heterorrophs, and most probable number (MPN) tubes for denitrifiers (Tiedje 1982) and ammonium-oxidizing bacteria (Schmidt and Belser 1982). Microbial populations are reported on a per gram dry weight $\left(55^{\circ} \mathrm{C}, 48 \mathrm{~h}\right)$ of root basis. The fluorescent pseudomonad population was detennined by examining individual colonies on dilution plates of Sands medium for fluorescence under UV light. The pseudomonad population, which was fluorescent, was expressed as a percent of the total pseudomonad population counted on Sands medium.

Several indices of species diversity (Atlas and Bariha 1987) were calculated for the heterotrophic bacteria present on the rhizoplane. Each distinct colony type and all members representing that colony type were enumerated on TSA plates from the appropriate dilutions. Distinct colony types were treated as separate species. Species diversity was calculated as species richness, the Shannon-Weaver Index (Shannon and Weaver 1963), evenness, and equitability as described in Atlas (1984).

\subsubsection{Ecosystem Functional Measurements}

The biomass of wheat shoots was detenmined at the three-leaf and boot stage of growth. Wheat shoots were cut at the soil surface, dried at $55^{\circ} \mathrm{C}$ for $48 \mathrm{~h}$, and weighed. Plant material was ground to pass a 100 -mesh screen, and the total $\mathrm{N}$ and atom $\% 15 \mathrm{~N}$ contents of wheat shoots at the boot stage were determined by combustion-mass spectrometry (Dumas combustion/reduction Mass Spectrometer Continuous Flow Technique, ISOTEC Inc.). The percent recovery of $\mathrm{N}$ fertilizer by wheat shoots was calculated using the methods of Hauck and Bremner (1976):

$$
\begin{aligned}
& \% \text { recovery }=100 \times(\mathrm{g} \text { shoot } \mathrm{N}) \times \text { (atom } \%^{15} \mathrm{~N} \text { excess in shoot) } \\
& \text { ( } g \text { fertilizer } \mathrm{N} \text { added) } \mathrm{x} \text { (atom \% } 15 \mathrm{~N} \text { excess in fertilizer) }
\end{aligned}
$$


Dehydrogenase activity in the surface (0 to $15 \mathrm{~cm}$ depth) soil was deternined at the three-leaf stage of wheat growth using a modification of the method of Tabatabai (1982). Soils were incubated for $24 \mathrm{~h}$. The absorbance from a control soil (no triphenyltetrazolium chloride added to the soil) was subtracted from the absorbance from a treated soil (triphenyltetrazolium chloride added to the soil) to arrive at the soil dehydrogenase activity. Data are reported on a per $\mathrm{g}$ dry weight $\left(105^{\circ} \mathrm{C}, 24 \mathrm{~h}\right)$ of soil basis.

\subsubsection{Experimental Design}

The experimental design was a $2 \times 2 \times 4$ completely randomized factorial design with two inoculation treatments (with RC1 and without), two alfalfa treatments (amended and unamended), and four locations (ambient microcosm, chamber microcosm, field lysimeters, and field plots). Log transformed data were used for the statistical analysis of microbial plate counts, unless otherwise mentioned in the text. All soil results are reported on an oven $\left(105^{\circ} \mathrm{C}, 24 \mathrm{~h}\right) \mathrm{dry}$ weight basis. Results from four replicates were statistically analyzed using a fixed-effects model (StatView ${ }^{\text {TM }}$ II Program, Abacus Concepts, Inc., Berkeley, Califomia). Duncan's multiple range test was used to test for differences among means ( $p \leq 0.05$ ), but only when F-tests (ANOVA) for the main effects or interactions were statistically significant, to ensure a conservative estimate of treatment mean differences (Steel and Torrie 1980).

\subsection{RESULTS AND DISCUSSION}

\subsubsection{Ecosystem Structural Comparisons at the Three-Leaf Stage of Wheat Growth}

The population of pseudomonads (defined as the numbers of colonies on Sands medium) on the rhizoplane of wheat was significantly higher in treatments inoculated with $\mathrm{RCl}$ and those amended with alfalfa (Table 3.1). There was no significant effect of location and there were no significant interactions among the treatments. When the populations of $\mathrm{RCl}$ on the rhizoplane (see Section 2.0) were expressed as a percent of total pseudomonads on the rhizoplane (using nonrransformed data), there was no difference resulting from location or alfalfa amendment (Table 3.1). Greater than $80 \%$ of the total pseudomonads on the wheat rhizoplane was the introduced rhizobacterium, $\mathrm{RCl}$. The percentage of total pseudomonads on the rhizoplane that fluoresced on Sands medium was significantly higher in microcosms in the growth chamber than in the three 
TABLE 3.1. Ecosystem Structural Measurements on the Wheat Rhizoplane at the Three-Leaf Stage of Growth. The means of the main effects of location, alfalfa amendment, and inoculation with Pseudomonas sp. RCl are presented.

\begin{tabular}{|c|c|c|c|c|c|}
\hline & & & Pseudomonas sp. RC1 & & \\
\hline Treatment & Pseudomonads & Bacteria & 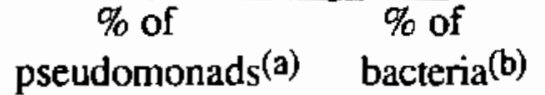 & $\begin{array}{cc}\text { \% Fluorescent } & \mathrm{NH}_{4} \text {-Oxidizing } \\
\text { pseudomonads } & \text { bacteria }\end{array}$ & Denitrifiers \\
\hline
\end{tabular}

$$
(\log \text { CFU/g dry root) }
$$

$(\log$ CFU/g dry root)

Location

$\begin{array}{llllllll}\text { Ambient microcosms } & 8.3 \mathrm{a}(\mathrm{d}) & 9.0 \mathrm{a} & 86 \mathrm{a} & 48 \mathrm{a} & 10 \mathrm{~b} & 3.1 \mathrm{~b} & 6.6 \mathrm{a} \\ \text { Chamber microcosms } & 8.8 \mathrm{a} & 9.4 \mathrm{a} & 82 \mathrm{a} & 36 \mathrm{a} & 18 \mathrm{a} & 2.5 \mathrm{c} & 7.2 \mathrm{a} \\ \text { Field plots } & 8.4 \mathrm{a} & 9.2 \mathrm{a} & 85 \mathrm{a} & 20 \mathrm{a} & 10 \mathrm{~b} & 3.6 \mathrm{a} & 6.4 \mathrm{a} \\ \text { Field lysimeters } & 8.7 \mathrm{a} & 9.1 \mathrm{a} & 83 \mathrm{a} & 58 \mathrm{a} & 8 \mathrm{~b} & 3.2 \mathrm{~b} & 6.6 \mathrm{a}\end{array}$

$\omega$ alfalfa Amendment

$\begin{array}{llllllll}\text { With } & 8.8 \mathrm{a} & 9.5 \mathrm{a} & 76 \mathrm{a} & 27 \mathrm{a} & 15 \mathrm{a} & 3.6 \mathrm{a} & 7.0 \mathrm{a} \\ \text { Without } & 8.3 \mathrm{~b} & 8.9 \mathrm{~b} & 91 \mathrm{a} & 53 \mathrm{~b} & 9 \mathrm{~b} & 2.7 \mathrm{~b} & 6.6 \mathrm{a}\end{array}$

Inoculation with Pseudomonas sp. RCl

$\begin{array}{lllrrrrr}\text { With } & 8.8 \mathrm{a} & 9.3 \mathrm{a} & 84 \mathrm{a} & 41 \mathrm{a} & 1 \mathrm{~b} & 3.2 \mathrm{a} & 7.1 \mathrm{a} \\ \text { Without } & 8.3 \mathrm{~b} & 9.1 \mathrm{a} & 0 \mathrm{~b} & 0 \mathrm{~b} & 24 \mathrm{a} & 3.0 \mathrm{a} & 6.2 \mathrm{~b}\end{array}$

(a) Sands-rif 50 counts from Section 2.0 divided by Sands counts using non-tranformed data

(b) Sands-rif ${ }^{50}$ counts from Section 2.0 divided by TSA counts using non-transformed data

(c) Percent of colonies on Sands plates that were fluorescent

(d) Main effect means in the same column that are followed by the same letter are not significantly different ( $p \leq 0.05$, $n=16,32$, and 32 for location, alfalfa amendment, and inoculation with Pseudomonas sp. RC1, respectively) 
other locations (Table 3.1). The percentage was lower in treatments that received $\mathrm{RCl}$ and was higher when alfalfa was added. This decrease resulting from the inoculation with $\mathrm{RCl}$ is not surprising, because $\mathrm{RCl}$, which was the dominant pseudomonad population on the thizoplane at this sampling, is non-fluorescent (Bolton and Elliott 1989). Therefore, RCl out-competed a significant proportion of native soil pseudomonads for colonization of the root surface and also altered the bacterial composition of the rhizoplane by decreasing the percentage of fluorescent pseudomonads. Previous work has demonstrated the ability of these deleterious rhizobacteria to compete favorably in the rhizosphere and on the rhizoplane (see Section 2.0. Fredrickson et al. 1989, Fredrickson and Elliott 1985). The high population of the introduced RCl (approximately $10^{8} \mathrm{CFU} \mathrm{g}^{-1}$ dry soil) likely contributed to the exclusion of fluorescent pseudomonads on the rhizoplane. This exclusion phenomena has also been observed for phylloplane colonization by epiphytic bacteria (Lindow 1987).

It has been suggested (Tiedje et al. 1989) that because there is a considerable redundancy of function in microbial communities, the displacement of a microbial species in the ecosystem as a result of direct competition with an introduced species would probably not be deleterious. However, the exclusion of a broad group of bacteria, which encompasses a number of species, such as the fluorescent pseudomonads, from the rhizoplane of wheat could be detrimental to plant growth, even though it did not appear to be so in this study. A number of fluorescent pseudomonads can function as biological control agents of root pathogens in the rhizosphere (Murdock et al. 1984, Scher and Baker 1982, Weller 1983).

When RC1 populations (see Section 2.0) were calculated as a percent of total aerobic heterotrophs on the rhizoplane (using non-transformed data), there was no significant effect of location. However, the addition of alfalfa significantly decreased the percentage of $\mathrm{RCl}$ (Table 3.1). The addition of alfalfa probably stimulated the population of total bacteria in soil, allowing them to compete more favorably on the rhizoplane with $\mathrm{RCl}$ (Table 3.1). RCl competed favorably with aerobic heterotrophic bacteria on the rhizoplane in the unamended soil, where $\mathrm{RCl}$ comprised over one-half of the total aerobic heterotrophs on the rhizoplane (Table 3.1). Although $\mathrm{RC} 1$ was stimulated in the soil by the addition of alfalfa, RC1 did not achieve higher populations on the rhizoplane in soil amended with alfalfa than in the unamended soil (see Section 2.0). Therefore, the decreased percentage of total bacteria on the rhizoplane that were $\mathrm{RC} 1$ in soil amended with alfalfa was the result of an increase in total heterotrophs on the rhizoplane, while the population of $\mathrm{RC} 1$ remained approximately the same.

The population of ammonium-oxidizing bacteria associated with the rhizoplane at the three-leaf 
stage was significantly different at the four locations (Table 3.1). The alfalfa amendment significantly increased the population of ammonium-oxidizers, whereas inoculation with $\mathrm{RCl}$ had no effect. The relative niches of $\mathrm{RCl}$ and ammonium-oxidizing bacteria on the rhizoplane are different and, therefore, effects caused by $\mathrm{RCl}$ inoculation would not be expected. The increase in ammonium-oxidizing bacteria when alfalfa was added may have been caused by an increase in soil ammonium from the mineralization of alfalfa $\mathrm{N}$. However, soil $\mathrm{NH}_{4}{ }^{+}$and $\mathrm{NO}_{3}^{-}$levels were not measured in this experiment. The ammonium-oxidizing population on the rhizoplane in the field plot and lysimeter treatments were significantly different, although the differences are probably not ecologically significant, as the means differed by only one-half log unit.

Populations of denitrifiers on the rhizoplane were not significantly affected by location or alfalfa amendment (Table 3.1). However, inoculation with RC1 significantly increased the denitrifier population presumably because $\mathrm{RCl}$ was a major population on the rhizoplane, which can denitrify (presumptive evidence from the procedure of Tiedje, 1982).

Species richness and the Shannon-Weaver index of species diversity for heterotrophic bacteria on the rhizoplane were significantly higher in the chamber microcosms than in the three other locations (Table 3.2). Species richness represents the number of species normalized to the number of total individuals (Atlas 1984) and, therefore, is a measure of the variability of the microbial population. The Shannon-Weaver index is a measure of the diversity of species, which is comprised of both species richness and relative species abundance (Atlas and Barha 1987) and is used as an indicator of the abundance and distribution of individuals within the various species. The higher species richness and Shannon-Weaver indices in the chamber microcosms compared to the three other locations may have been the result of more favorable temperature and moisture conditions present in the growth chamber (see Section 2.0). This may also be indicated by the increase in soil dehydrogenase activity, a measure of general microbial activity, in the chamber microcosms compared to the three other locations at this same time period, i.e., the three-leaf stage of wheat growth (Table 3.3). The growth chamber could not simulate completely average field temperatures, because it has a lower temperature limit of $5^{\circ} \mathrm{C}$. Also, although the total amount of water added to the soil for the four locations was similar, the amendments as a function of time were different (see Section 2.0). The two environmental factors of temperature and moisture could have resulted in more favorable conditions in the soil and rhizoplane of the growth chamber.

Inoculation with RC1 had no effect on species richness or the Shannon-Weaver index determined for the heterotroph population on the rhizoplane (Table 3.2). Although the alfalfa amendment had no effect on species richness, the Shannon-Weaver index increased with the alfalfa 
TABLE 3.2. Species Diversity Indices on the Wheat Rhizoplane at the Three-Leaf Stage of Growth. The means of the main effects of location, alfalfa amendment, and inoculation with Pseudomonas sp. $\mathrm{RCl}$ are presented.

\begin{tabular}{lcccc}
\hline Treatment & Richness & Shannon-Weaver & Evenness & Equitability \\
\hline Location & & & & \\
& & $2.0 \mathrm{~b}$ & $2.3 \mathrm{a}$ & $0.7 \mathrm{a}$ \\
Ambient microcosms & $4.0 \mathrm{~b}(\mathrm{a})$ & $2.7 \mathrm{a}$ & $2.5 \mathrm{a}$ & $0.8 \mathrm{a}$ \\
Chamber microcosms & $6.6 \mathrm{a}$ & $2.3 \mathrm{~b}$ & $2.7 \mathrm{a}$ & $0.8 \mathrm{a}$ \\
$\quad$ Field plots & $4.0 \mathrm{~b}$ & $2.1 \mathrm{~b}$ & & \\
$\quad$ Field lysimeters & $3.8 \mathrm{~b}$ & & & \\
Alfalfa Amendment & & $2.5 \mathrm{a}$ & $2.7 \mathrm{a}$ & $0.8 \mathrm{a}$ \\
With & $4.6 \mathrm{a}$ & $2.2 \mathrm{~b}$ & $2.3 \mathrm{~b}$ & $0.7 \mathrm{~b}$ \\
Without & $4.6 \mathrm{a}$ & & & \\
Inoculation with Pseudomonas sp. RC1 & & & \\
With & $4.6 \mathrm{a}$ & $2.2 \mathrm{a}$ & $2.3 \mathrm{~b}$ & $0.7 \mathrm{~b}$ \\
Without & $4.6 \mathrm{a}$ & $2.4 \mathrm{a}$ & $2.6 \mathrm{a}$ & $0.8 \mathrm{a}$
\end{tabular}

(a) Main effect means in the same column that are followed by the same letter are not significantly different $(\mathrm{p} \leq 0.05, \mathrm{n}=\overline{16}$, 32, and 32 for location, alfalfa amendment, and inoculation with Pseudomonas sp. RC1, respectively) 
TABLE 3.3. Ecosystem Structural Measurements on the Wheat Rhizoplane at the Boot Stage of Growth. The means of the main effects of location, alfalfa amendment, depth, and inoculation with Pseudomonas Sp. RC1 are presented.

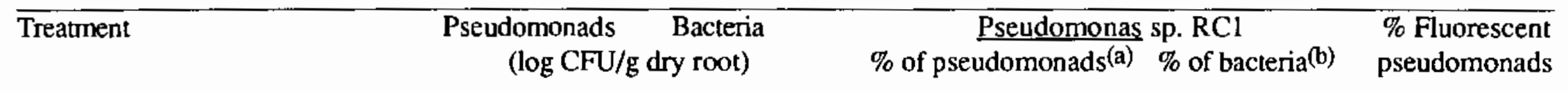

\section{Location}

Ambient microcosms

Chamber microcosms

Field plots

Field lysimeters

Alfalfa Amendment

\section{With}

Without

Depth

$\begin{array}{ll}6.4 \mathrm{c}(\mathrm{c}) & 8.0 \mathrm{a} \\ 7.1 \mathrm{a} & 8.3 \mathrm{~b} \\ 6.4 \mathrm{c} & 8.4 \mathrm{~b} \\ 6.8 \mathrm{~b} & 8.8 \mathrm{c}\end{array}$

\section{0a}

$8.4 \mathrm{~b}$

$8.8 \mathrm{c}$

$8.4 a$

$8.3 b$

$6.8 \mathrm{~b}$

$7.3 \mathrm{a}$

$6.8 \mathrm{~b}$

6.0c

$8.6 \mathrm{a}$
$8.4 \mathrm{~b}$
$8.0 \mathrm{c}$ $\%$ of pseudomonads ${ }^{(a)} \%$ of bacteria(b)

pseudomonads

Middle (15 to $35 \mathrm{~cm})$

Inoculation with Pseudomonas sp. RC1

With

Without
$6.5 b$

$6.8 \mathrm{a}$
$8.3 a$

$8.4 a$
$36 \mathrm{a}$

$51 \mathrm{a}$

$31 \mathrm{a}$

$49 a$

$32 b$

$51 \mathrm{a}$

$2,3 \mathrm{a}$

$3.4 \mathrm{a}$

$2.2 \mathrm{a}$

$6.1 \mathrm{~b}$

$0.3 \mathrm{a}$

$\begin{array}{ll}58 \mathrm{a} & 6.1 \mathrm{~b} \\ 14 \mathrm{~b} & 0.3 \mathrm{a}\end{array}$

$15 \mathrm{a}$

$18 \mathrm{a}$

$16 \mathrm{a}$

$6.8 \mathrm{~b} \quad 16 \mathrm{a}$

$1.5 \mathrm{a} \quad 15 \mathrm{a}$

$0.5 a \quad 20 a$

(a) Sands-rif 50 counts from Section 2.0 divided by Sands counts

(b) Sands-rif 50 counts from Section 2.0 divided by TSA counts

(c) Main effect means in the same column that are followed by the same letter are not significantly different ( $p \leq 0.05, n=48,96$, 64, and 96 for location, alfalfa amendment, depth, and inoculation with Pseudomonas sp. RCl, respectively) 
amendment (Table 3.2). This increase in the Shannon-Weaver index as the result of the alfalfa amendment may have been related to a stimulation of the growth of the general soil microbial population causing a more even distribution of individuals among the various species. This is supported by the evenness and equitability indices, which were also higher in the soil amended with alfalfa (Table 3.2). Evenness and equitability decrease when dominant populations are present and indicate whether individuals are evenly distributed among the various species (Atlas 1984). The evenness and equitability indices were no different at the four locations (Table 3.2). However, inoculation with RC1 significantly decreased evenness and equitability, because $\mathrm{RCl}$ was dominant on the rhizoplane, and the distribution of individuals among the various species was skewed.

\subsubsection{Ecosystem Structural Comparisons at the Boot Stage of Wheat Growth}

Populations of total pseudomonads on the rhizoplane at the boot stage of wheat growth were significantly different as a function of location, alfalfa amendment, depth, and inoculation (Table 3.4). There was a greater than one log-unit decrease in the population of pseudomonads with increasing depth. The location by depth interaction was significant with the population of pseudomonads on the rhizoplane declining, in general, with an increase in depth, although the magnitude of the decline varied with location (Fig. 3.1). The alfalfa by depth interaction was also significant because the alfalfa amendment increased the population of pseudomonads on the rhizoplane only in the amended surface layer.

Location had no effect on the rhizoplane population of $\mathrm{RCl}$ calculated as a percent of the total pseudomonads (Table 3.4). The percent of total pseudomonads consisting of RC1 decreased when alfalfa was added and at the 35-to 55 -cm depth. The alfalfa by depth interaction was again significant. The decrease in the proportion of $\mathrm{RCl}$ present as a function of depth was the result of a greater decline in the population of $\mathrm{RC} 1$ on the rhizoplane with increasing depth (see Section 2.0) than of the total pseudomonad population (Table 3.4). This would be expected, as RCl was inoculated only in the surface soil. Weller (1984) found a similar reduction in the percentage of fluorescent pseudomonads, consisting of a seed-inoculated Pseudomonas fluorescens as a function of distance from the seed along the wheat root. These results demonstrate the importance of quantifying broad microbial groups, such as total pseudomonads or heterotrophs, in addition to the introduced organism. This information is necessary to understand what proportion of the carrying capacity of the rhizoplane/rhizosphere is composed of the introduced organism. 
TABLE 3.4. Ecosystem Functional Measurements (Soil and Plant) at the Three-Leaf and Boot Stage of Wheat Growth. The means of the main effects of location, alfaifa amendment, and inoculation with Pseudomonas sp. RCl are presented.

\begin{tabular}{|c|c|c|c|c|c|c|}
\hline \multirow[t]{2}{*}{ Treatment } & \multirow{2}{*}{$\begin{array}{l}\text { Soil dehydrogenase activity(a) } \\
\text { Three-leaf stage }\end{array}$} & \multicolumn{2}{|c|}{ Shoot biomass (g) } & \multicolumn{2}{|c|}{ Boot stage shoot $\mathbf{N}$} & \multirow{2}{*}{$\begin{array}{c}\text { Fertilizer used }(\mathrm{b}) \\
(\%)\end{array}$} \\
\hline & & Three-leaf stage & Boot stage & $\%$ total $\mathrm{N}$ & atom $\% 15 \mathrm{~N}$ & \\
\hline \multicolumn{7}{|l|}{ Location } \\
\hline $\begin{array}{l}\text { Ambient microcosms } \\
\text { Chamber microcosms } \\
\text { Field plots } \\
\text { Field lysimeters }\end{array}$ & $\begin{array}{l}10.0 \mathrm{ab}(\mathrm{c}) \\
11.7 \mathrm{a} \\
6.9 \mathrm{c} \\
8.2 \mathrm{bc}\end{array}$ & $\begin{array}{l}0.02 \mathrm{~b} \\
0.07 \mathrm{a} \\
0.06 \mathrm{a} \\
0.05 \mathrm{ab}\end{array}$ & $\begin{array}{l}5.7 \mathrm{c} \\
15.3 \mathrm{a} \\
11.7 \mathrm{~b} \\
13.7 \mathrm{ab}\end{array}$ & $\begin{array}{l}3.9 \mathrm{a} \\
1.7 \mathrm{~b} \\
1.2 \mathrm{c} \\
1.7 \mathrm{~b}\end{array}$ & $\begin{array}{l}5.36 \mathrm{ab} \\
5.25 \mathrm{bc} \\
4.99 \mathrm{c} \\
5.57 \mathrm{a}\end{array}$ & $\begin{array}{l}26 a \\
28 a \\
14 b \\
27 a\end{array}$ \\
\hline \multicolumn{7}{|l|}{ Alfalfa Amendment } \\
\hline $\begin{array}{l}\text { With } \\
\text { Without }\end{array}$ & $\begin{array}{r}14.0 \mathrm{a} \\
4.4 \mathrm{~b}\end{array}$ & $\begin{array}{l}0.04 b \\
0.06 a\end{array}$ & $\begin{array}{r}14.0 \mathrm{a} \\
9.8 \mathrm{~b}\end{array}$ & $\begin{array}{l}3.2 \mathrm{a} \\
1.4 \mathrm{~b}\end{array}$ & $\begin{array}{l}1.87 \mathrm{~b} \\
7.96 \mathrm{a}\end{array}$ & $\begin{array}{l}17 b \\
29 a\end{array}$ \\
\hline \multicolumn{7}{|c|}{ Inoculation with Pseudomonas sp. RCl } \\
\hline $\begin{array}{l}\text { With } \\
\text { Without }\end{array}$ & $\begin{array}{l}9.2 \mathrm{a} \\
9.2 \mathrm{a}\end{array}$ & $\begin{array}{l}0.06 \mathrm{a} \\
0.04 \mathrm{a}\end{array}$ & $\begin{array}{l}12.2 \mathrm{a} \\
10.9 \mathrm{a}\end{array}$ & $\begin{array}{l}2.2 \mathrm{a} \\
2.1 \mathrm{a}\end{array}$ & $\begin{array}{l}4.85 \mathrm{a} \\
5.85 \mathrm{a}\end{array}$ & $\begin{array}{l}23 \mathrm{a} \\
25 \mathrm{a}\end{array}$ \\
\hline
\end{tabular}

(a) $\mu \mathrm{g}$ triphenylformazan produced $\mathrm{g}^{-1}$ dry soil $24 \mathrm{~h}^{-1}$

(b) Percent recovery of fertilizer $N$ by wheat shoots $=100 \times$ (g shoot $N$ ) $\times$ (atom $\% 15 \mathrm{~N}$ excess in shoot)

( $\mathrm{g}$ fertilizer $\mathrm{N}$ added) $\mathrm{x}$ (atom $\% 15 \mathrm{~N}$ excess in fertilizer)

(c) Main effect means in the same column that are followed by the same letter are not significantly different $(p \leq 0.05, n=16,32$, and 32 for location, alfalfa amendment, and inoculation with Pseudomonas sp. RC1, respectively) 


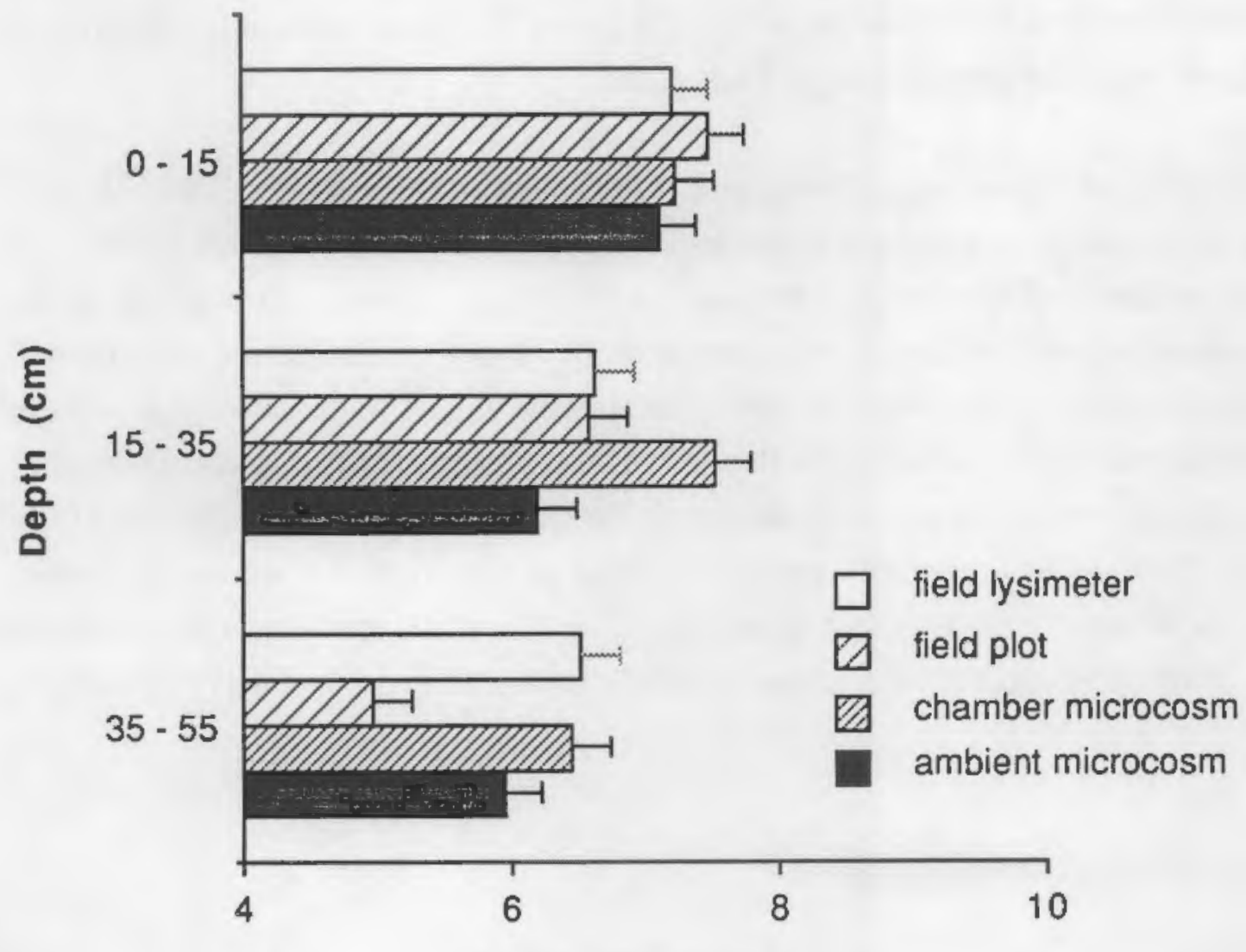

Log CFU/g dry root

FIGURE 3.1. Wheat Rhizoplane Populations (Log Colony Forming Units (CFU) $\mathrm{g}^{-1}$ Dry Root) of Total Pseudomonads as a Function of Depth in the Various Microcosm and Field Treatments at the Final Boot Stage Sampling. Error bars represent the difference between treatment means by Duncan's Multiple Range Test $(\mathrm{p} \leq 0.05, \mathrm{n}=8)$.

The percent of total pseudomonads present as $\mathrm{RC} 1$ decreased as a function of time as evidenced by results from the three-leaf and boot stage samplings (Table 3.1 and 3.4). The population of $\mathrm{RC} 1$ on the rhizoplane (see Section 2.0) declined more rapidly than the population of total pseudomonads as a function of time (Table 3.1 and 3.4). A fluorescent pseudomonad, suppressive to the take-all (Gaumannomyces graminis) pathogen of wheat, aggressively competed with native pseudomonads and bacteria on the wheat rhizoplane when it was inoculated onto seeds (Weller 1983). Weller (1983) also found the proportion of fluorescent pseudomonads, total pseudomonads, and total bacteria present as the introduced pseudomonad decreased as a function 
of wheat growth, similar to the results of this study. There was no difference in the percent of pseudomonads on the rhizoplane, which were fluorescent, as the result of location, alfalfa amendment, or depth (Table 3.4). Inoculation with $\mathrm{RC} 1$ again resulted in a significant reduction in the number of fluorescent pseudomonads on the rhizoplane (Table 3.4), although this difference was less than it was at the three-leaf stage (Table 3.1).

Bacterial populations of total heterotrophs on the rhizoplane were one to two orders of magnitude higher than the populations of total pseudomonads (Table 3.4). Location, alfalfa amendment, and depth all significantly influenced heterotrophic populations. Total heterotrophic bacteria on the rhizoplane decreased as a function of depth, although the magnitude of the decline varied at the different locations (Fig. 3.2). When the numbers of $\mathrm{RCl}$ were calculated as a percent of the total heterotrophic population on the rhizoplane, the chamber microcosm had the highest percentage of the four locations and the middle depth had the highest percentage of the three depths (Table 3.4). These percentages at the boot stage of wheat growth (Table 3.4) were nearly tenfold less than those observed at the three-leaf stage (Table 3.1). The alfalfa amendment did not alter the proportion of total heterotrophic bacteria that were $\mathrm{RC} 1$, in contrast to the three-leaf stage sampling (Table 3.1).

\subsubsection{Ecosystem Functional Comparisons}

The activity of soil dehydrogenase at the three-leaf stage of wheat growth varied among the four locations and was significantly higher in soil that received alfalfa, while inoculation with $\mathrm{RC} 1$ had no effect (Table 3.3). The soil dehydrogenase activity was assayed at all four locations during the same phenological stage of wheat growth. The addition of alfalfa increased soil dehydrogenase activity to three times that of the unamended soil (Table 3.4), which coincided with increases in populations of total pseudomonads and total bacteria on the rhizoplane (Table 3.1). The location by inoculation by alfalfa amendment interaction was significant, with the treatments in ambient and chamber microcosms exhibiting larger differences among treatments that received $\mathrm{RC} 1$ or alfalfa than in the field plots or lysimeters (Fig. 3.3). The inoculated and uninoculated treatments without alfalfa did not have significantly different soil dehydrogenase activities at the four locations. The principal difference between the four locations was associated with the alfalfa amendment. The ambient and chamber microcosms amended with alfalfa had significantly higher dehydrogenase activity than the field treatments.

The biomass of wheat shoots was used in this study as an integrated measure of plant growth 


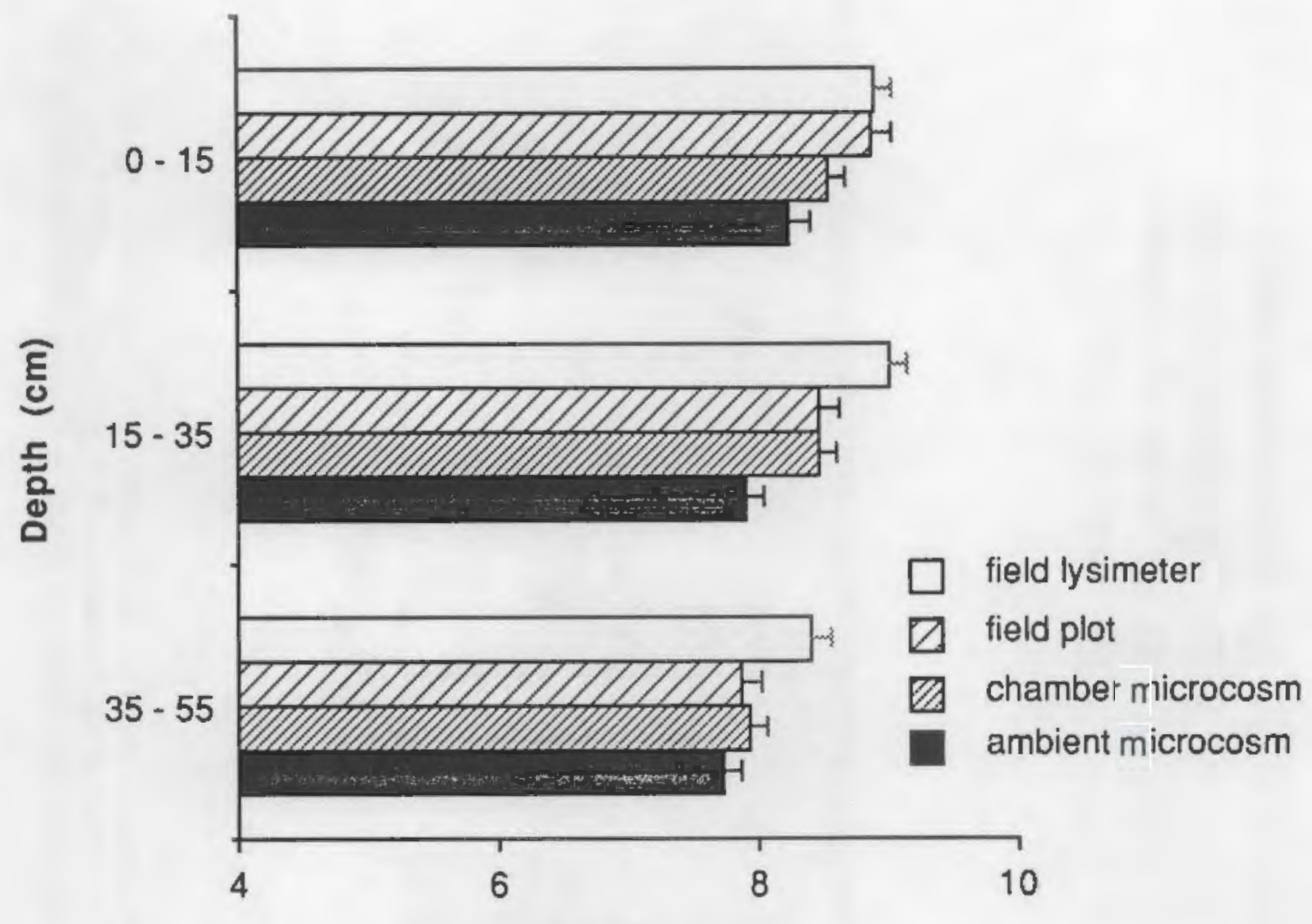

Log CFU/g dry root

FIGURE 3.2. Wheat Rhizoplane Populations (Log Colony Forming Units (CFU) $\mathrm{g}^{-1}$ Dry Root) of Total Heterotrophic Bacteria as a Function of Depth in the Various Microcosm and Field Treatments at the Final Boot Stage Sampling. Error bars represent the difference between treatment means by Duncan's Multiple Range Test $(\mathrm{p} \leq 0.05$, $\mathrm{n}=8$ ).

and function in the various treatments. Wheat shoot biomass at both the three-leaf and boot stage samplings was significantly different at the various locations (Table 3.3). Inoculation with RC1 had little influence on shoot biomass at either stage of plant growth. These results are similar to those obtained in earlier microcosm studies in the laboratory, which showed that $\mathrm{Tn} 5 \mathrm{Tox}{ }^{+}$and Tox mutants of $\mathrm{RCl}$ had no effect on the biomass of wheat shoots at boot stage (Fredrickson et al. 1989). The alfalfa amendment significantly decreased wheat biomass at the three-leaf stage (Table 3.3). In contrast, the alfalfa amendment significantly increased the biomass of wheat shoots at boot stage (Table 3.3). This reversal may have been caused by the additional plant nutrients, 


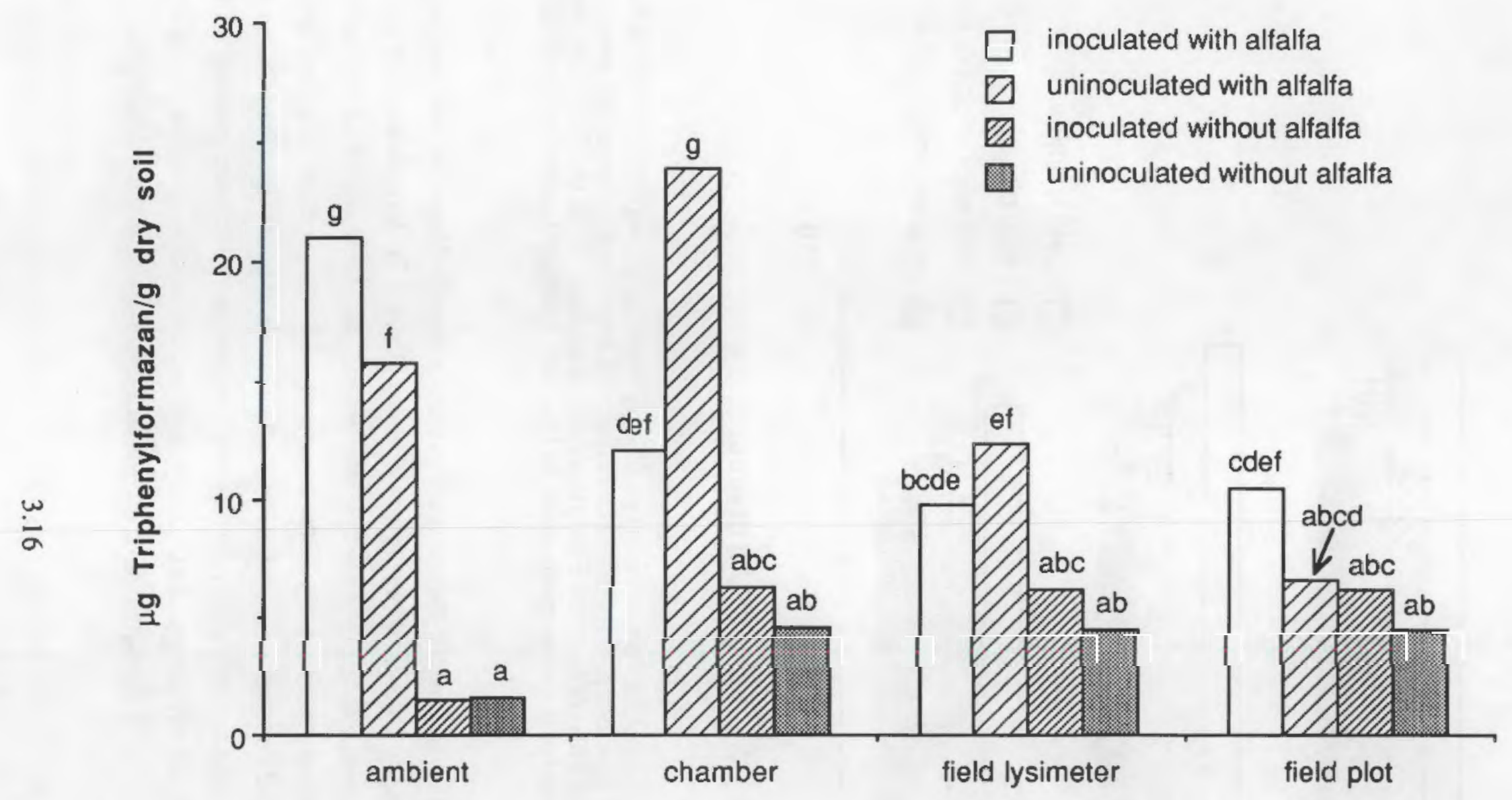

\section{Location}

FIGURE 3.3. Soil Dehydrogenase Activity in the Various Microcosm and Field Treatments at the Three-Leaf Stage of Wheat Growth. The four soil treatments included inoculated or uninoculated with Pseudomonas sp. RC1 and with or without alfalfa. Bars labeled with different letters are significantly different by Duncan's Multiple Range Test $(\mathrm{p} \leq 0.05, \mathrm{n}=4)$. 
mainly $\mathrm{N}$, supplied during the decomposition of the alfalfa. Increased plant $\mathrm{N}$ in wheat shoots at the boot stage and a lower proportion of fertilizer utilized by wheat in the soil amended with alfalfa supports this conclusion (Table 3.3). The low biomass of wheat shoots in the ambient microcosms at the three-leaf and boot stage samplings indicated that incubation of soil-core microcosms at ambient laboratory temperatures did not simulate the growth of winter wheat in the field. The growth chamber, with diumal temperature fluctuations, was considerably better at simulating the the growth of winter wheat in the field, at both the three-leaf and boot stage, as evidenced by shoot biomass values that were similar to those in the field treatments (Table 3.3). Although laboratory incubated microcosms may not always duplicate results from the field, they may still be useful for predicting results, or at least trends, in the field (Fredrickson et al. 1990b, Pritchard 1982). For example, Tolle et al. $(1983,1985)$ constructed dose-response curves relating fly ash concentrations to plant productivity. This allowed the utilization of microcosm results to predict the effect of fly ash on alfalfa (Medicago sativa), timothy (Phleum praetense), and oat (Avena sativa) productivity and elemental uptake in the field.

The $\mathrm{N}$ and atom $\%{ }^{15} \mathrm{~N}$ contents of the wheat shoots at the boot stage of growth were significantly influenced by location (Table 3.3 ). Wheat grown in field plots had a significantly lower recovery of fertilizer $\mathrm{N}$ than the three other locations (Table 3.3). The field plots were 15$\mathrm{cm}$-deep open-ended rings, which enclosed only the surface treated soil. The wheat roots and ${ }^{15} \mathrm{~N}$-labeled fertilizer in the field plots, unlike the field lysimeters and microcosms, were not constrained by the polyethylene pipe to a depth of $60 \mathrm{~cm}$. Wheat roots in the plots were able to grow laterally below the pipe and explore a greater volume of soil. The root distributions in the field plots and the field lysimeters were visually different, with a greater root density in the field lysimeters than in a similar volume of soil from the field plots (see Section 2.0). Also, the polyethylene pipe prevented lateral movement of the ${ }^{15} \mathrm{~N}$-labeled fertilizer to a depth of $60 \mathrm{~cm}$. Differences between the movement or dispersion of chemicals in field plots and in microcosms have been noted before. For example, Jackson and Levin (1979) found that although microcosms predicted transport of arsenic in the field, the microcosms were more sensitive to arsenic-induced stress than field plots, probably the result of the confinement of the arsenic in the microcosm and the greater dispersion in the unconfined field plots.

The addition of alfalfa to the soil increased the $\mathrm{N}$ content, but decreased the atom $\% 15 \mathrm{~N}$ enrichment, of the wheat shoots. Mineralization of organic $\mathrm{N}$ in the alfalfa would have supplied unlabeled $\mathrm{N}$ for plant uptake, thereby decreasing the ${ }^{15} \mathrm{~N}$ content of the shoot. Also, the addition of organic material to the soil can result in a "priming effect," where native soil organic matter is mineralized at a faster rate than in the unamended soil (Stevenson 1986), which would have also 
increased the unlabeled $\mathrm{N}$ available for uptake by the plant. This effect was also apparent in the lower utilization of fertilizer when the soil was amended with alfalfa. Inoculation with RC1 did not influence shoot $\mathrm{N}$ or atom $\%{ }^{15} \mathrm{~N}$ content. The percent recovery of fertilizer $\mathrm{N}$ by wheat shoots in the field lysimeters and microcosms (Table 3.3) was within the range reported for wheat grown in field lysimeters (Fredrickson et al. 1982).

\subsection{CONCLUSIONS}

In this study, soil-core microcosms were used to predict the effects of an introduced rhizobacterium on the structure and function of a soil ecosystem. However, there were variations and differences between the location treatments corresponding to differences between the microcosms and the field. In general, soil-core microcosms in a growth chamber favored the survival and the colonization of the rhizoplane by both introduced and indigenous microbial populations. It is likely that favorable diumal temperatures and moisture conditions, which were maintained in the growth chamber microcosms in comparison to the two field treatments or ambient laboratory microcosms (see Section 2.0), favored general microbial growth and activity. Low plant biomass was produced in the ambient microcosms compared to the field and growth chamber, indicating that ambient laboratory conditions did not simulate the field as well as the growth chamber. These results emphasize the need to control, monitor, and/or simulate key environmental variables, such as moisture and temperature, to better calibrate the behavior of microcosms with the field. Confinement of the soil cores by polyethylene pipe was not a major factor influencing the behavior of soil-core microcosms in comparison to the field. This was evidenced by the relatively few statistically significant differences between the field lysimeters and plots for ecosystem structural and functional measurements.

\subsection{REFERENCES}

Atlas, R. M. 1984. "Diversity of Microbial Communities." Adv, Microb. Ecol 7:1-47.

Atlas, R. M., and R. Bartha. 1987. Microbial Ecology 2nd. ed. Benjamin/Cummings Publishing Company, California.

Bentjen, S. A., J. K. Fredrickson, S. W. Li, and P. Van Voris. 1989. "Intact Soil-Core Microcosms for Evaluating the Fate and Ecological Impacts from the Release of Genetically Engineered Microorganisms." Appl. Environ. Microbiol. 55:198-202. 
Bolton, Jr., H., and L. F. Elliott. 1989. "Toxin Production by a Rhizobacterial Pseudomonas sp. That Inhibits Wheat Root Growth." Plant Soil 114:269-278.

Bolton, Jr., H., L. E. Elliott, R. F. Turco, and A. C. Kennedy. 1990. "Rhizoplane Colonization of Pea Seedlings by Rhizobium leguminosarum and a Deleterious Root Colonizing Pseudomonas sp. and Effects on Plant Growth." Plant Soil 123:121-124.

Cairns J., and J. R. Pratt. 1986. "Ecological Consequence Assessment: Effects of Bioengineered Organisms." In Biotechnology Risk Assessment. Issues and Methods for Environmental Introductions, eds. J. Fiskel, and V. T. Covello, pp 88-108. Pergamon Press, New York.

Dean-Ross, D. 1986. "Release of Genetically Engineered Microorganisms: Hazard Assessment." ASM News 11:572-575.

Fredrickson, J. K., S. A. Bentjen, H. Bolton, Jr., S. W. Li, and P. Van Voris. 1989. "Fate of Tn5 Mutants of Root Growth-Inhibiting Pseudomonas sp. in Intact Soil-Core Microcosms." Can. J. Microbiol. 35:867-873.

Fredrickson, J. K., H. Bolton, Jr., S. A. Bentjen, K. M. McFadden, S. W. Li, and P. Van Voris. 1990a. "Evaluation of Intact Soil-Core Microcosms for Determining Potential Impacts on Nutrient Cycling Dynamics by Genetically Engineered Microorganisms." Environ. Toxicol. Chem. 9:551-558.

Fredrickson, J. K., and L. F. Elliott. 1985. "Colonization of Winter Wheat Roots by Inhibitory Rhizobacteria. Soil Sci. Soc. Am. J. 49:1172-1177.

Fredrickson, J. K., F. E. Koehler, H. H. Cheng. 1982. "Availability of ${ }^{15} \mathrm{~N}$-labeled Nitrogen in Fertilizer and in Wheat Straw to Wheat in Tilled and No-Tilled Soil. Soil Sci. Soc. Am. J. 46:1218-1222.

Fredrickson, J. K., P. Van Voris, S. A. Bentjen, H. Bolton, Jr. 1990b. "Terrestrial Microcosms for Evaluating the Environmental Fate and Risks Associated with the Release of Chemicals or Genetically Engineered Microorganisms to the Environment." In Hazard Assessment of Chemicals - Current Developments, Vol. 7, ed. J. Saxena, pp.157-202. Hernisphere Publishing Company, New York.

Gillett, J. W., and J. M. Witt. 1979. "Terrestrial Microcosms." In Proceedings of the Workshop at Otter Rock and Portland, OR June and December, 1977, NSF/RA-790034, p. 34. National Science Foundation, Washington, D.C.

Hauck, R. D., and J. M. Bremner. 1976. "Use of Tracers for Soil and Fertilizer Nitrogen Research." Adv. Agron. 28:219-266.

Jackson, D. R., and M. Levin. 1979. "Transpor of Arsenic in Grassland Microcosms and Field Plots." Water Air Soil Pollut. 11:3-12.

Lindow, S. E. 1987. "Competitive Exclusion of Epiphytic Bacteria by Ice - Pseudomonas syringae Mutants.” Appl. Environ. Microbiol. 53:2520-2527.

Martin, J. K. 1975. "Comparison of Agar Medium for Counts of Viable Soil Bacteria." Soil Biol. Biochem. 7:401-402. 
Murdock, C. W., R. J. Campana, J. Hoch. 1984. "The Biological Control of Ceratocystis ulmi with Pseudomonas fluorescens." Phytopathology 74: 805.

Omenn, G. S. 1986. "Controlled Testing and Monitoring Methods for Microorganisms." In Biotechnology Risk Assessment. Issues and Methods for Environmental Introductions, eds. J. Fiskel, and V. T. Covello, pp. 144-163. Pergamon Press, New York.

O'Neill, E., M. Hood, C. Cripe, P. Pritchard. 1988. "Field Calibration of Aquatic Microcosms." In Abstracts of the Annual Meeting of the American Society for Microbiology, p. 297. American Society for Microbiology, Washington, D.C.

Pritchard, P. H. 1982. "Model Ecosystems." In Environmental Risk Analysis for Chemicals, ed. R. A. Conway, pp. 257-353. Van Nostrand Reinhold Company, NY.

Pritchard, P. H., and A. W. Bourquin. 1984. "The Use of Microcosms for Evaluation of Interactions Between Pollutants and Microorganisms." Adv. Microb. Ecol, 7:133-217.

Sands, D. C., and A. D. Rovira. 1970. "Isolation of Fluorescent Pseudomonads with a Selective Medium.” Appl. Microbiol. 20:513-514.

Scher, F. M., and R. Baker. 1982. "Effect of Pseudomonas putida and a Synthetic Iron Chelator on Induction of Soil Suppressive to Fusarium Wilt Pathogens." Phytopathology 72:1567-1573.

Schmidt, E. L., and L. W. Belser. 1982. "Nitrifying Bacteria." In Chemical and Microbiological Properties. Part 2 of Methods of Soil Analysis. 2nd ed., eds. A. L. Page, R. H. Miller, D. R. Keeney, pp. 1027-1042. American Society of Agronomy, Madison, Wisconsin.

Shannon, C. E., and W. Weaver. 1963. The Mathematical Theory of Communication, University of Illinois Press, Urbana, Illinois.

Steel, R. G. D., and J. H. Torrie. 1980. Principles and Procedures of Statistics: a Biometrical Approach. 2nd ed., McGraw-Hill Book Company, New York.

Stevenson, F. J. 1986. Cycles of Soil: Carbon, Nitrogen, Phosphorus, Sulfur, Micronutrients. John Wiley \& Sons, New York.

Strauss, H. S., D. Hattis, G. Page, K. Harrison, S. Vogel, and C. Caldert. 1986. "GeneticallyEngineered Microorganisms: II. Survival, Multiplication, and Genetic Transfer." RAC Tech. Bull, 9:16-28.

Tabatabai, M. A. 1982. "Soil Enzymes." In Chemical and Microbiological Properties. Part 2 of Methods of Soil Analysis. 2nd ed., eds. A. L. Page, R. H. Miller, D. R. Keeney, pp. 903-947. American Society of Agronomy, Madison, Wisconsin.

Tiedje, J. M. 1982. "Denitrification." In Chemical and Microbiological properties. Part 2 of Methods of soil analysis. 2nd ed., eds. A. L. Page, R. H. Miller, D. R. Keeney, pp. 1011-1026. American Society of Agronomy, Madison, Wisconsin.

Tiedje, J. M., R. R. Colwell, Y. L. Grossman, R. E. Hodson, R. E. Lenski, R. N. Mack, and P. J. Regal. 1989. "The Planned Introduction of Genetically Engineered Organisms: Ecological Considerations and Recommendations." Ecology 70:298-315. 
Tolle, D. A., M. F. Arthur, J. Chesson, and P. Van Voris (1985). "Comparison of Pots Versus Microcosms for Predicting Agroecosystem Effects Due to Waste Management." Environ. Toxicol. Chem. 4:501-509.

Tolle, D. A., M. F. Arthur, and P. Van Voris. 1983. "Microcosm/field Comparison of Trace Element Uptake in Crops Grown in Fly-Ash Amended Soil. Sci. Tot. Environ. 4:501-509.

Weller, D. M. 1983. "Colonization of Wheat Roots by a Fluorescent Pseudomonad Suppressive to Take-All." Phytopathology 73:1548-1553.

Weller, D.M. 1984. "Distribution of a Take-All Suppressive Strain of Pseudomonas fluorescens on Seminal Roots of Winter Wheat." Appl. Environ. Microbiol 48:897-899. 



\subsection{FATE AND ECOLOGICAL EFFECTS OF AN INTRODUCED RHIZOBACTERIUM IN MICROCOSMS AND THE FIELD}

\subsection{SUMMARY}

Microcosms are being increasingly used for assessing the fate and risks of releasing generically engineered microorganisms (GEMs) to the environment. However, before microcosm results can be used to predict microbial fate and effects in the environment, they should be compared with the field to ensure they provide comparable results. Intact soil-core microcosms were established in a growth chamber with temperature fluctuations that simulated 30-year average conditions in the field. Lysimeters were established in the field and the results from both the microcosms and lysimeters were compared for the fate of an introduced rifampicin-resistant rhizobacterium, Pseudomonas sp. RCl, and effects on ecosystem structural and functional properties. Soil populations of $\mathrm{RCl}$ declined at a similar initial rate in microcosms and the field, but were significantly higher in soil from the microcosm by the three-leaf stage of wheat growth. The soil population of $\mathrm{RCl}$ was the same at the boot stage of wheat growth. The extent of colonization of wheat seedling roots by $\mathrm{RC} 1$ at the three-leaf stage was similar, but by the boot stage sampling rhizoplane populations were significantly higher in microcosms than the field. The size and diversity of rhizoplane microbial populations were very similar in the microcosms and field or could be attributed to variations in the population of $\mathrm{RCl}$. Wheat shoot biomass and soil dehydrogenase acrivity were similar in the microcosms and the lysimeters at the three-leaf stage of wheat growth, but were lower and higher, respectively, in microcosms compared to the field at the boot stage. In general, microcosms incubated in a growth chamber were able to simulate the microbial fate and effects of an introduced rhizobacterial strain in the field.

\subsection{INTRODUCTION}

Microcosms are an attractive option for obtaining preliminary data on the fate and ecological effects issues associated with the release of genetically engineered microorganisms (GEMs) into the environment, because tests and microorganisms can be contained within the laboratory (Cairns and Pratt 1986, Omenn 1986, Strauss et al. 1986, Trevors 1988). Microcosms have been used to assess the fate (Gile et al. 1982, Van Voris et al. 1983, Van Voris et al. 1985), transport (Van Voris et al. 1983), and toxicity of chemicals and pollutants (Pritchard and Bourquin 1984, Van Voris et al. 1983). Recently, intact soil-core microcosms incubated in the laboratory were used to 
evaluate the fate and ecological effects of transposon mutants of Azospirillum lipoferum (Bentjen et al. 1989) and a wheat (Triticum aestivum)-root colonizing Pseudomonas sp. (Fredrickson et al. 1989, 1990a). However, before microcosms can be used as a standard tool for biotechnology risk assessment, they must be compared with the field to ensure that they are effective field models (Dean-Ross 1986, Fredrickson et al. 1990b, Gillett and Witt 1979, Pritchard and Bourquin 1984).

The evaluation of ecosystem structural and functional parameters has been suggested as an indicator of the impacts to the environment resulting from the introduction of GEMs (Cairns and Pratt 1986). Soil-core microcosms retain many aspects of the structural and functional components of the terrestrial ecosystem, which are present in the field. Changes in nutrient cycling processes are often used to determine the disturbance of ecosystems (Dean-Ross 1986) and for field calibrating microcosms for microbial function (Pritchard and Bourquin 1984). Previous laboratory studies have investigated using intact soil-core microcosms for evaluating microbial effects on structural (Bentjen et al. 1989, Fredrickson et al. 1989) and functional (Bentjen et al. 1989, Fredrickson et al. 1990a, Tolle et al. 1983, 1985) properties of terrestrial communities.

Pseudomonas sp. RC1, previously determined to be an aggressive root colonizer (Fredrickson et al. 1989) and capable of inhibiting winter wheat root growth (Bolton and Elliott 1989) as well as the growth of other microorganisms in vitro (Bolton et al. 1989), was selected for this study. The objective of this study was to compare results obtained in this study with studies conducted the previous year (see Sections 2.0 and 3.0), to determine the influence of year-to-year variability in the field on both the fate and ecological effects of an introduced microorganism and on the comparability of microcosm results with the field.

\subsection{MATERIALS AND METHODS}

\subsubsection{Bacterial Strain. Field Site. Microcosms and Lysimeters, and Inoculation}

The bacterial strain used in this study, was a spontaneous rifampicin resistant mutant of Pseudomonas sp. strain RC1, hereafter referred to as $\mathrm{RCl}$ (see Section 2.0), which was resistant to $100 \mu \mathrm{g}$ rifampicin $\mathrm{ml}^{-1}$.

The field site was located on the Arid Lands Ecology Reserve contained within the U.S.

Department of Energy's Hanford Site in southeastern Washington State. The study site receives an 
average of $19.5 \mathrm{~cm}$ of annual precipitation and has a mean annual temperature of $10^{\circ} \mathrm{C}$ (Rickard and Vaughan 1988). The soil is classified as coarse-silty, mixed, mesic, Xerollic Camborthid. This soil type is used for irrigated agriculture or dryland winter wheat production elsewhere in southeast Washington, but was in native grass at the field site.

Intact soil cores for use as microcosms and field lysimeters $(17.5 \mathrm{~cm}$ diameter, $60 \mathrm{~cm}$ length) were obtained from the field site using a steel coring device containing Driscopipe ${ }^{\circledR}$ (polyethylene pipe, Phillips Petroleum Co., Dallas, Texas), as described by Van Voris (1988). The surface soil (top $15 \mathrm{~cm}$ ) was removed from all cores and combined, mixed, and sieved to pass a 2-mm screen. The two surface soil treatments included inoculation with $\mathrm{RCl}$ and uninoculated. Inoculum was prepared by growing RCl on Sands agar (Sands and Rovira 1970) supplemented with $50 \mu \mathrm{g}$ rifampicin (Sigma ${ }^{\circledR}$ Chemical Company, St. Louis, Missouri) $\mathrm{ml}^{-1}$ (Sands rif ${ }^{50}$ ) and harvesting by flooding agar plates with sterile deionized water and dislodging the cells with a sterile bent glass rod. The soil inoculated with $\mathrm{RCl}$ received $2.3 \times 10^{7}$ colony forming units (CFU) of $\mathrm{RCl} \mathrm{g}^{-1} \mathrm{dry}$ soil (oven dried at $105^{\circ} \mathrm{C}$ for $24 \mathrm{~h}$ ). A solution of ammonium sulfate was added to all treatments at $100 \mathrm{~kg} \mathrm{~N} \mathrm{ha}^{-1}$. All treatments were brought to a final soil moisture content of $16 \%$ with tap water.

The microcosms were incubated in a growth chamber under a cycling temperature regime that approximated the average daily minimum temperature during the dark cycle and the average daily high temperature during the photoperiod at the Hanford Site (Stone et al. 1983). A photoperiod of 10-h was used to simulate fall and winter and a photoperiod of 12-h was used for spring and summer. A micro-meteorological weather station, which measured air temperature and precipitation, was located near the field site. Air temperature profiles for the field and the growth chamber during the course of the experiment are shown in Fig. 4.1.

The field lysimeters consisted of intact soil cores within polyethylene pipe, which were taken in a manner similar to that used for the microcosms and placed back into the soil at the field site. The bottoms of the microcosms and field lysimeters were covered with polyester monofilament cloth (160 mesh) to prevent root movement outside the core. All soil cores were replicated six times and seeded with five 'Daws' winter wheat seeds that were later thinned to two wheat seedlings. The study was started on October 25, 1989. Microcosms and field lysimeters were routinely watered with tap water to maintain soil moisture at approximately $-0.03 \mathrm{MPa}$ (water content of $16 \%$ ). 


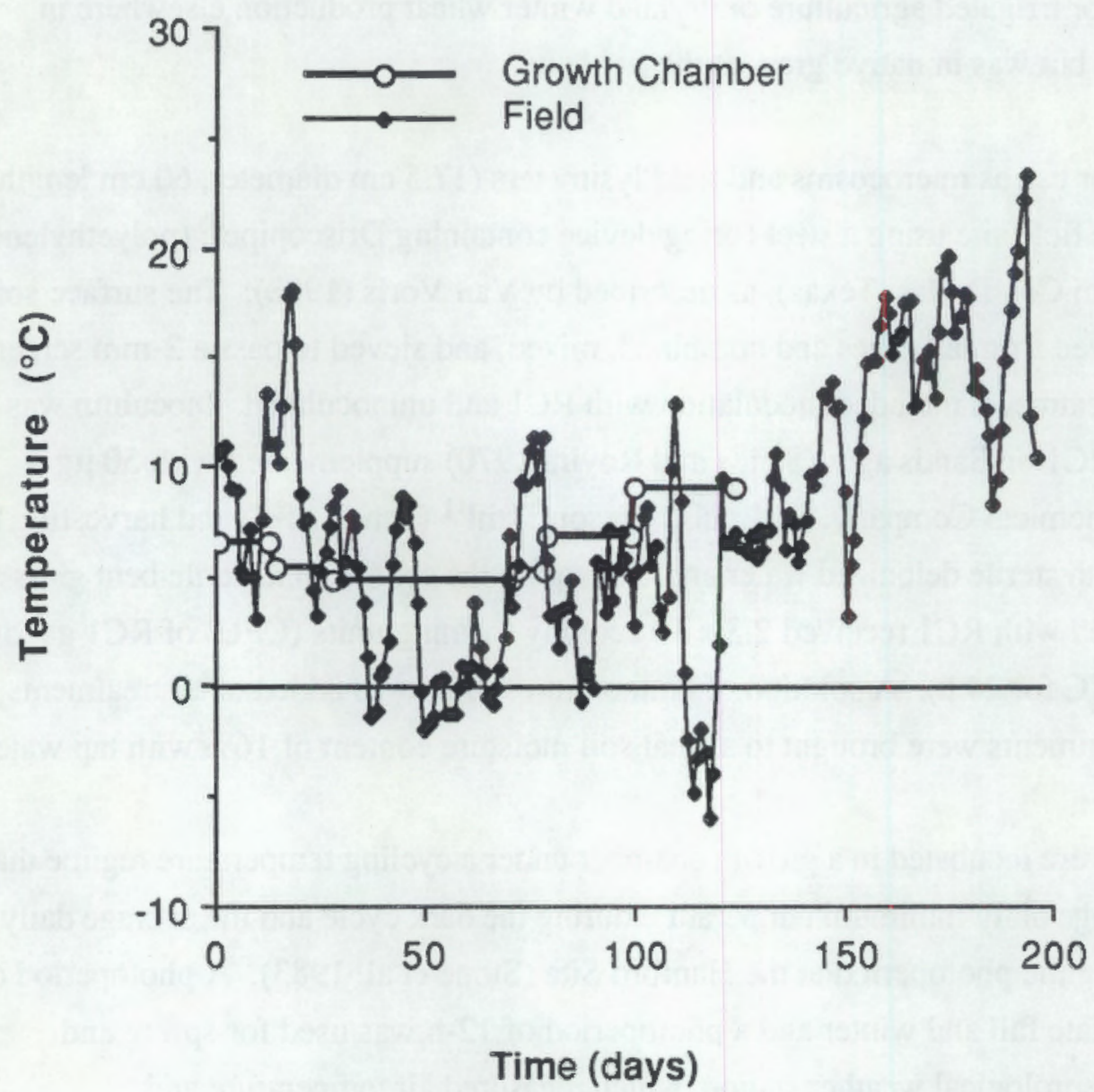

FIGURE 4.1. Average Daily Air Temperatures at the Three Study Sites Over the Duration of the Experiment.

\subsubsection{Sampling and Fate of $\mathrm{RC} 1$}

The surface soil ( 0 to $15 \mathrm{~cm}$ depth) was sampled as a function of time by removing approximately $25 \mathrm{~g}$ of soil, taking care not to disturb the wheat plants. The soil was serially diluted, plated onto Sands rif ${ }^{50}$ agar, and the colonies counted after incubating at $22^{\circ} \mathrm{C}$ for 24 to 48 h. Soil populations of RC1 are reported on a per gram dry weight $\left(105^{\circ} \mathrm{C}, 24 \mathrm{~h}\right)$ of soil basis.

At the three-leaf stage of wheat growth, one seedling was carefully removed with intact roots from each of the microcosms and field lysimeters at 35 , and 119 days after planting, respectively. 
The soil adhering to the roots was removed by gently washing the root with sterile deionized water. The washed roots were then macerated using a sterilized mortar and pestle, and the resulting macerate was serially diluted and plated onto Sands rif ${ }^{50}$ agar to enumerate the rhizoplane populations of $\mathrm{RC} 1$. Rhizoplane populations are reported on a per gram dry weight $\left(55^{\circ} \mathrm{C}, 48 \mathrm{~h}\right)$ of root basis.

Microcosms and field lysimeters were sacrificed at the boot stage of wheat growth, at 124 and 194 days after planting, respectively. Field lysimeters were excavated from the field intact and wheat shoots were cut at the soil surface for both microcosms and lysimeters. Two cuts were made along the length of the polyethylene pipe using a saber saw and one half of the pipe was removed to expose the intact core. The intact soil core was subsequently divided into three sections (top: 0 to $15 \mathrm{~cm}$, middle: 15 to $35 \mathrm{~cm}$, and bottom: 35 to $55 \mathrm{~cm}$ ). The outer $1 \mathrm{~cm}$ of soil and root, at the pipe-soil interface, was pared to avoid samples that may have received $\mathrm{RC} 1$ from water that migrated at the soil-pipe interface. Roots from the three sections (top, middle, and bottom) were processed as described earlier for determining $\mathrm{RCl}$ populations.

\subsubsection{Ecosystem Structural Measurements}

Rhizoplane bacterial populations were enumerated at the three-leaf and boot stage of wheat growth by plating root macerate dilutions onto Sands medium for total and fluorescent pseudomonads and tryptic soy agar (TSA) (Martin 1975) for total aerobic heterotrophs. Colonies arising on Sands medium, which is semi-selective for bacteria in the genus Pseudomonas, were enumerated and populations designated as total pseudomonads. The fluorescent pseudomonad population was determined by examining individual colonies on dilution plates of Sands medium for fluorescence under UV light and was expressed as a percent of the total pseudomonad population counted on Sands medium. The population of $\mathrm{RC} 1$ on the rhizoplane was expressed as a percent of the total pseudomonad and total aerobic heterotroph populations by dividing Sands-rif 50 counts into Sands and TSA counts, respectively, using non-transformed data.

\subsubsection{Ecosystem Functional Measurements}

The biomass of wheat shoots was determined at the three-leaf and boot stage of growth. Wheat shoots, which were cut at the soil surface, were dried at $55^{\circ} \mathrm{C}$ for $48 \mathrm{~h}$ and weighed. 
The inorganic- $\mathrm{N}$ content $\left(\mathrm{NH}_{4}-\mathrm{N}\right.$ and $\mathrm{NO}_{3}-\mathrm{N}$ ) of the soil was determined (Keeney and Nelson 1982) in the surface soil at the three-leaf stage and at all three depths at the boot stage of wheat growth. The inorganic $\mathrm{N}$ content of the $\mathrm{KCl}$ extracts was determined with a continuousflow $\mathrm{N}$ analyzer. The total weight of soil at all three depths in the microcosms and field lysimeters was determined at the boot stage of wheat growth.

Dehydrogenase activity in the surface ( 0 to $15 \mathrm{~cm}$ depth) soil was determined at the three-leaf and boot stage of wheat growth using a modification of the method of Tabatabai (1982). The absorbance from a control soil extract (no triphenyltetrazolium chloride added to the soil) was subtracted from the absorbance from a treated soil extract (triphenyltetrazolium chloride added to the soil), which were both incubated for $24 \mathrm{~h}$, to arrive at the soil dehydrogenase activity.

All soil data are reported on a dry weight $\left(105^{\circ} \mathrm{C}, 24 \mathrm{~h}\right)$ of soil basis.

\subsubsection{Experimental Design}

The experimental design was a $2 \times 2$ completely randomized factorial design with two inoculation treatments (with RCl and without) and two locations (microcosms incubated in a growth chamber and field lysimeters). Log transformed data were used for the statistical analysis of microbial populations. Results from six replicates were statistically analyzed using a fixedeffects model (StatView ${ }^{\mathrm{TM}}$ II Program, Abacus Concepts, Inc., Berkeley, California). Fisher's least significant difference at $p \leq 0.05$ was used for all treatment mean comparisons, but only when F-tests (ANOVA) for main effects or interactions were statistically significant (Steel and Torrie 1980).

\subsection{RESULTS AND DISCUSSION}

\subsubsection{Fate of $\mathrm{RCl}$}

The rate of decline in the population of $\mathrm{RCl}$ in the surface soil was similar in the microcosms and the field (Fig. 4.2). Microcosm plants reached the boot stage at 124 days while in the field this stage was not reached until 194 days, mainly because of the more favorable temperatures in the growth chamber. The population of $\mathrm{RCl}$ in the surface soil was significantly higher in the

microcosms than the field at the three-leaf stage of wheat growth $\left(5.9 \log \mathrm{CFU} \mathrm{g} \mathrm{g}^{-1} \mathrm{dry}\right.$ soil $>4.5$ 


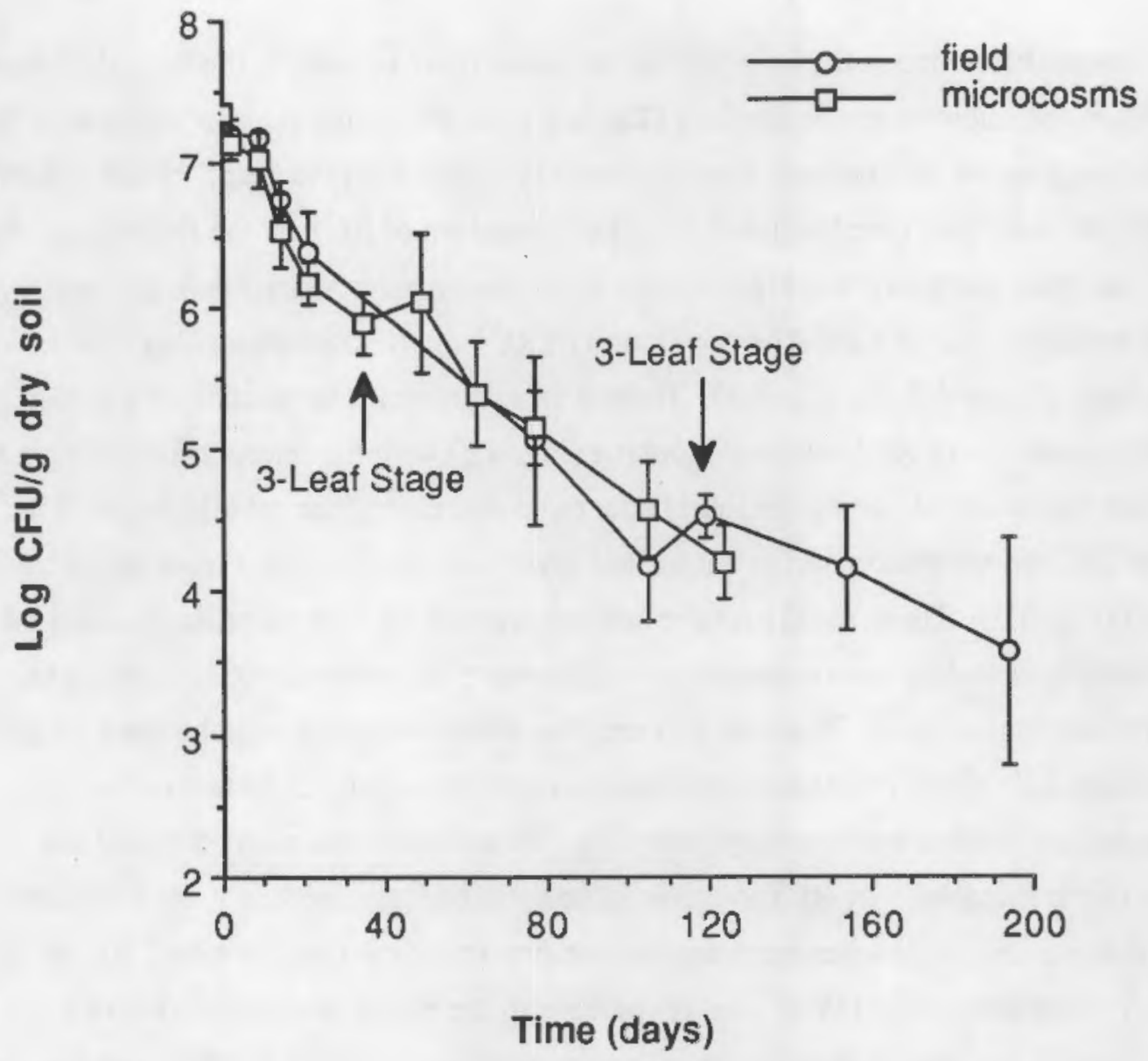

FIGURE 4.2. Populations of the Introduced Pseudomonas sp. RC1 in Surface Soil $(0$ to $15 \mathrm{~cm}$ depth) from the Microcosms and the Field. The sampling time for the three-leaf stage is shown in the figure, while the curves end at the boot stage sampling. Error bars represent standard deviations at each sampling time.

$\log$ CFU g ${ }^{-1}$ dry soil), while the population decreased to similar values at the boot stage (4.2 log CFU g $\mathrm{g}^{-1} \mathrm{dry}$ soil and $3.6 \log \mathrm{CFU} \mathrm{g^{-1 }} \mathrm{dry}$ soil for microcosms and field, respectively). The rate of decline in the population of $\mathrm{RCl}$ in microcosm and field soil found in this study was consistent with results obtained the previous year (see Section 2.0), except there was a significantly higher boot stage population of $\mathrm{RCl}$ in the microcosms incubated in a growth chamber ( $4.3 \log \mathrm{CFU} \mathrm{g}$ g $^{-1}$ dry soil) when compared to the field ( $3.1 \log \mathrm{CFU} \mathrm{g}{ }^{-1} \mathrm{dry}$ soil). These values are the same and/or extremely close to values obtained in this study, suggesting that small differences in the inoculum level of $\mathrm{RC1}\left(2.3 \times 10^{7} \mathrm{CFU}^{-1}\right.$ dry soil in this study and $5.5 \times 10^{7} \mathrm{CFU} \mathrm{g}^{-1}$ dry soil the previous 
year) and year-to-year climatic variability in the field did not greatly influence the decline of $\mathrm{RC} 1$ in soil.

There was no difference in the colonization of wheat roots by $\mathrm{RCl}$ at the three-leaf stage of wheat growth in the microcosms or the field (Table 4.1), even though the soil population of RC1 at the three-leaf stage in the microcosms was significantly higher than the field. These results are similar to the previous year (see Section 2.0). The population of RC1 on the rhizoplane of wheat at the final boot stage sampling was significantly higher in the microcosms than the field when all depths were averaged (Table 4.2). The population of $\mathrm{RCl}$ on the rhizoplane also decreased as a function of depth (Table 4.2 and Fig. 4.3). There was a significant interaction of location and depth for the population of $\mathrm{RCl}$ on the rhizoplane (Fig. 4.3) with the microcosm having a rapid decrease at the bottom depth, while the field had a rapid decrease at the middle depth. The population of $\mathrm{RCl}$ on the rhizoplane in the surface layer was significantly higher in the microcosm than the field (Fig. 4.3). These results for the surface layer at the boot stage are in contrast with the three-leaf stage sampling where there was no difference between microcosm and field rhizoplane populations of $\mathrm{RC} 1$. These results are also different from those obtained the previous year (see Section 2.0) where rhizoplane populations in the surface layer were similar in microcosms and the field at the boot stage sampling. The microcosms overestimated the colonization of the rhizoplane by $\mathrm{RC} 1$ in the field and also had a different pattern of colonization as a function of depth (Fig. 4.3) when compared to the previous year (see Section 2.0). In the previous study (see Section 2.0) there was an increase in the rhizoplane population of $\mathrm{RCl}$ in the middle soil layer of the growth chamber microcosms when compared to the field lysimeters.

This study and the previous one (see Section 2.0) demonstrate the importance of quantifying rhizoplane bacterial populations as a function of depth. In this way, movement of the introduced bacterium through the soil by roots and/or by percolating water can be quantified. The variation between the field and the growth chamber in this study and between this study and the previous year (See Section 2.0) could have been caused by temperature and moisture variations.

Temperature variation between the field and the growth chamber was significant (Fig. 4.1). The addition of water in the field and microcosms also varied as a function of time. The length and extent of soil wet/dry cycles as well as infiltration of water into the soil-cores was different in microcosms and the field and from year-to-year and could have accounted for differences in rhizoplane populations of RCl. Percolating water increased the transport of Rhizobium sp. and Pseudomonas sp. in laboratory soil columns (Madsen and Alexander 1982), while irrigation increased bacterial transport and colonization of the rhizosphere of potato (Solanum tuberosum) in the field (Bahme and Schroth 1987) and pea (Pisum sativum) in the laboratory (Chao et al. 1986). 
TABLE 4.1. Microbial Populations on the Rhizoplane of Wheat at the Three-Leaf Stage of Growth. The Means of the Main Effects of Location and Inoculation with Pseudomonas sp. RC1 are Presented.

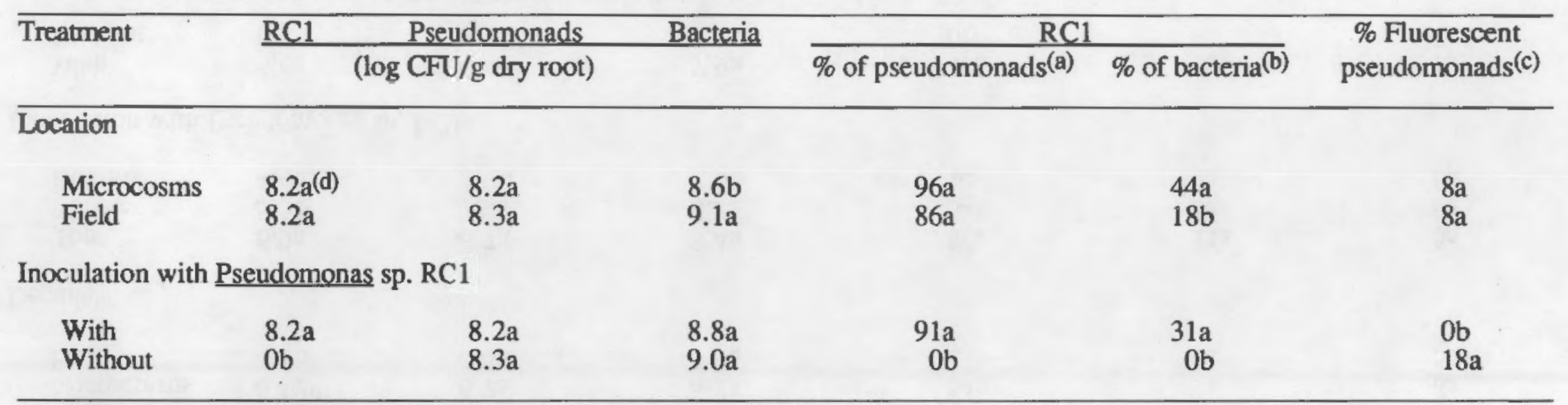

(a) $\mathrm{RC} 1$ counts divided by pseudomonad counts using non-tranformed data

(b) $\mathrm{RC} 1$ counts divided by bacterial counts using non-transformed data

(c) Percent of colonies on Sands plates that were fluorescent

(d) Main effect means in the same column that are followed by the same letter are not significantly different ( $p \leq 0.05, n=12$ for location and inoculation with Pseudomonas sp. RC1) 
TABLE 4.2. Microbial Populations on the Rhizoplane of Wheat at the Boot Stage of Growth. The means of the main effects of location, depth, and inoculation with Pseudomonas sp. RC1 are presented.

\begin{tabular}{|c|c|c|c|c|c|c|}
\hline \multirow[t]{2}{*}{ Treatment } & \multirow[t]{2}{*}{$\underline{\mathrm{RC} 1}$} & \multirow{2}{*}{$\frac{\text { Pseudomonads }}{\text { (log CFU/g dry root) }}$} & \multirow[t]{2}{*}{ Bacteria } & \multicolumn{2}{|l|}{$\mathrm{RC} 1$} & \multirow{2}{*}{$\begin{array}{l}\text { \% Fluorescent } \\
\text { pseudomonads }(\mathrm{c})\end{array}$} \\
\hline & & & & $\%$ of pseudomonads ${ }^{(a)}$ & $\%$ of bacteria(b) & \\
\hline \multicolumn{7}{|l|}{ Location } \\
\hline Microcosms & $6.4 a^{(d)}$ & $6.7 \mathrm{a}$ & $8.2 \mathrm{a}$ & $54 a$ & $9 a$ & $8 a$ \\
\hline Field & $4.8 b$ & $6.4 a$ & $7.9 a$ & $27 b$ & $2 \mathrm{a}$ & $5 a$ \\
\hline \multicolumn{7}{|l|}{ Depth(e) } \\
\hline Top & $6.9 \mathrm{a}$ & $6.7 \mathrm{a}$ & $8.4 \mathrm{a}$ & $86 a$ & $11 \mathrm{a}$ & $5 a$ \\
\hline Middle & $5.5 b$ & $7.0 \mathrm{a}$ & $8.2 \mathrm{a}$ & $34 b$ & $6 a$ & $9 a$ \\
\hline Bottom & $4.4 \mathrm{c}$ & $5.9 \mathrm{~b}$ & $7.6 \mathrm{~b}$ & lc & $0 \mathrm{a}$ & $6 a$ \\
\hline \multicolumn{7}{|c|}{ Inoculation with Pseudomonas sp. RC1 } \\
\hline With & $5.6 \mathrm{a}$ & $6.4 a$ & $7.9 \mathrm{a}$ & $40 \mathrm{a}$ & $6 a$ & $6 a$ \\
\hline Without & $\mathrm{Ob}$ & $6.7 \mathrm{a}$ & $8.2 \mathrm{a}$ & $\mathrm{Ob}$ & $\mathrm{Ob}$ & $7 a$ \\
\hline
\end{tabular}

(a) RC1 counts divided by pseudomonad counts using non-tranformed data

(b) $\mathrm{RC} 1$ counts divided by bacterial counts using non-transformed data

(c) Percent of colonies on Sands plates that were fluorescent

(d) Main effect means in the same column that are followed by the same letter are not significantly different ( $p \leq 0.05$, $n=36$ for location and inoculation with Pseudomonas sp. RC1 and 24 for depth)

(e) Depths were 0 to $15 \mathrm{~cm}, 15$ to $35 \mathrm{~cm}$, and 35 to $55 \mathrm{~cm}$ for top, middle, and bottom of the cores, respectively. 


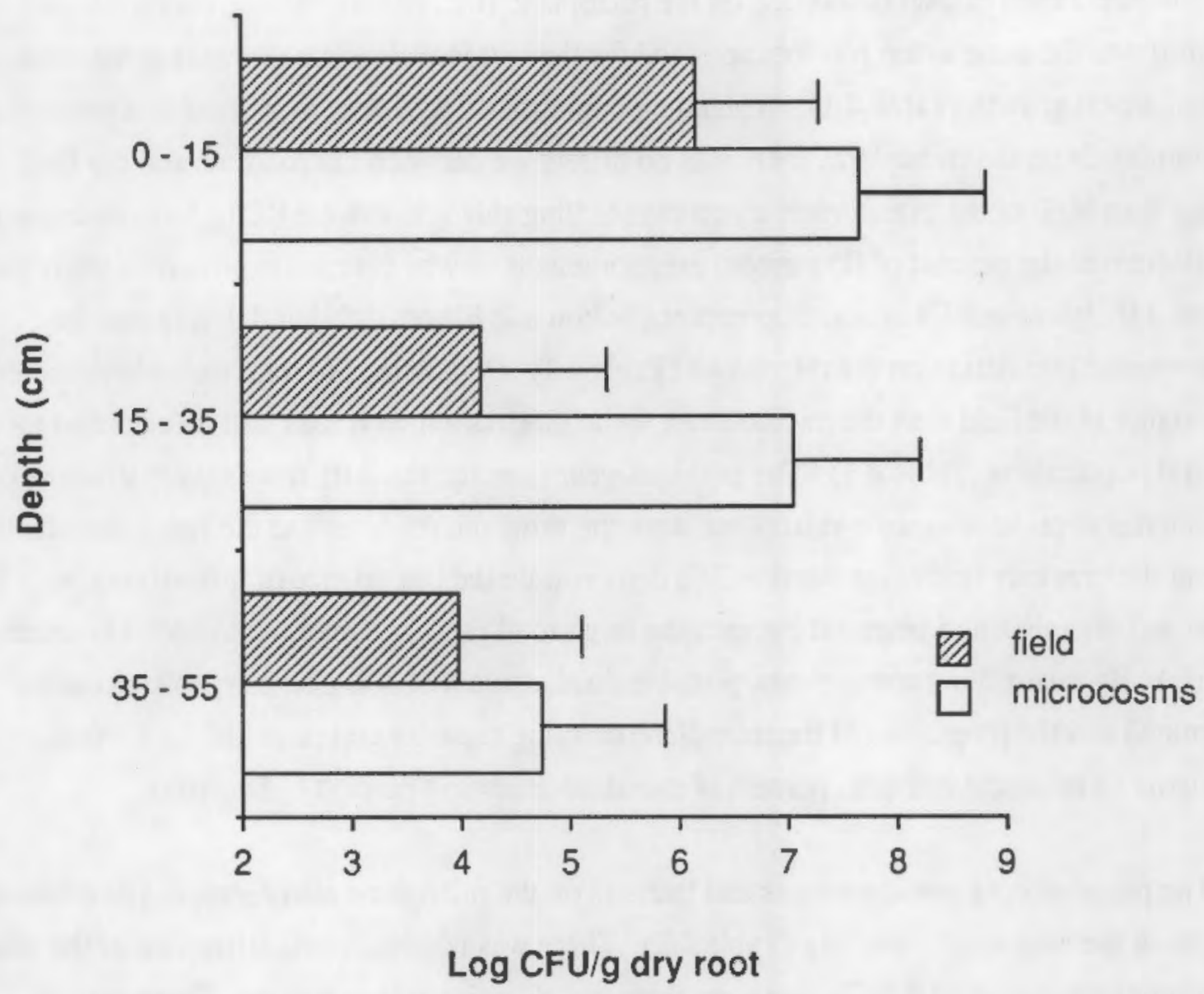

FIGURE 4.3. Populations of the Introduced Pseudomonas sp. RC1 on the Rhizoplane of Wheat as a Function of Depth in Microcosms and the Field at the Final Boot Stage Sampling. Error bars represent the least significant differences between treatment means $(p \leq 0.05, n=6)$.

Bacterial movement with root growth has been postulated to be caused not only by water flow down the roots (Chao et al. 1986), but also by bacterial attachment to the root and movement as the root grows (Howie et al. 1987). Rigorous control and measure of soil water content and movement is necessary to determine more precisely how water movement influences root colonization in microcosms and the field. 


\subsubsection{Ecosystem Structural Comparisons}

The population of pseudomonads on the rhizoplane (i.e., colonies that grew on Sands medium) was the same at the two locations and for the two inoculation treatments at the three-leaf stage of wheat growth (Table 4.1). When the population of $\mathrm{RC} 1$ was expressed as a percent of pseudomonads on the rhizoplane, there was no difference between microcosms and the field. Greater than $90 \%$ of the pseudomonads on the seedling rhizoplane were $\mathrm{RC}$. Inoculation with $\mathrm{RC} 1$ decreased the percent of fluorescent pseudomonads as was the case in an earlier study (see Section 3.0), because $\mathrm{RCl}$ is non-fluorescent (Bolton and Elliott 1989) and dominated the pseudomonad population on the rhizoplane (Table 4.1). Populations of total rhizoplane bacteria were higher in the field than the microcosms, while inoculation with $\mathrm{RC} 1$ had no effect on total bacterial populations (Table 4.1). The previous year (see Section 3.0), trends were similar except the bacterial populations on the rhizoplane were the same microcosms and the field. Results from this and the previous study (see Section 3.0) demonstrate the importance of quantifying both the introduced organism and potential competitors (e.g., total pseudomonads and/or total heterotrophic bacteria). By quantifying competitors, possible displacement of soil-borne organisms can be determined and the proportion of the rhizoplane carrying capacity composed of the introduced organism can be calculated (i.e., percent of pseudomonads and percent of bacteria).

The population of pseudomonads and bacteria on the rhizoplane also decreased as a function of depth at the boot stage sampling (Table 4.2). There was no significant difference as the result of location or inoculation with $\mathrm{RC} 1$, nor were there any significant interactions. There was no significant difference in the percent of fluorescent pseudomonads on the rhizoplane at the boot stage sampling resulting from location, depth, or inoculation with $\mathrm{RCl}$ (Table 4.2). The percent of the total bacterial population composed of $\mathrm{RCl}$ was only significantly different as the result of inoculation with $\mathrm{RC} 1$ with no significant interactions (Table 4.2). The percent of pseudomonads on the rhizoplane that were composed of $\mathrm{RCl}$ decreased as a function of depth because the population of $\mathrm{RCl}$ on the rhizoplane decreased at a faster rate than the pseudomonad population as depth increased (Table 4.2).

The differences found between the microcosms and the field for rhizoplane bacterial populations in this study and a previous one (see Section 3.0) suggest caution in using microcosms as field surrogates. Results suggest that microcosms may be limited by the ability to control key environmental variables such as moisture and temperature. This study and previous ones (see Sections 2.0 and 3.0 ) used 30-year average values for field simulation. The growth chambers 
used were unable to precisely simulate winter conditions because of low temperature limitations $\left(5^{\circ} \mathrm{C}\right)$. A useful next step in microcosm-field simulations would be to use an environmental chamber with greater temperature and humidity range to simulate 30 -year average values or actual field temperatures and humidities. Actual field temperature could be simulated by recording field conditions and then programming these conditions into the environmental chamber. It still remains to be seen how well must the environmental conditions in the growth chamber simulate the field to adequately simulate GEM fate and ecosystem effects in the field.

\subsubsection{Ecosystem Functional Comparisons}

The dry weight of wheat shoots was no different in microcosms and the field at the three-leaf stage and inoculation with $\mathrm{RCl}$ had no effect at either the three-leaf or boot stages (Table 4.3). However, the biomass of wheat shoots in the field was significantly higher than in the microcosms at the boot stage (Table 4.3). The previous year (see Section 3.0), microcosms incubated at ambient laboratory temperature were unable to simulate wheat shoot growth in the field, while microcosms in the growth chamber simulated wheat shoot growth in the field quite well. Thus in the first study (October 1988 - September 1989), the growth chamber simulated the field for wheat biomass production (see Section 3.0), while in this study (October 1989 - September 1990) it did

TABLE 4.3. Ecosystem Functional Measurements (Soil and Plant) at the Three-Leaf and Boot Stage of Wheat Growth. The means of the main effects of location and inoculation with Pseudomonas sp. $\mathrm{RCl}$ are presented.

\begin{tabular}{llll}
\hline Treatment & \multicolumn{2}{c}{ Soil dehydrogenase activity(a) } & Shoot biomass (g) \\
& Three-leaf stage & Boot stage & Three-leaf stage Boot stage
\end{tabular}

Location

$\begin{array}{llrlr}\text { Microcosms } & 9.0 \mathrm{~b}^{(\mathrm{b})} & 13.9 \mathrm{a} & 0.05 \mathrm{c}^{(\mathrm{b})} & 8.6 \mathrm{~b} \\ \text { Field } & 8.2 \mathrm{~b} & 7.9 \mathrm{~b} & 0.05 \mathrm{c} & 11.5 \mathrm{a}\end{array}$

Inoculation with $\underline{\text { Pseudomonas }} \mathrm{sp} . \mathrm{RC1}$
With
Without
$8.0 \mathrm{c}$
$9.7 \mathrm{~b}$
$0.06 \mathrm{~b}$
$10.0 \mathrm{a}$
$12.1 \mathrm{a}$
$0.05 \mathrm{~b}$
$10.1 \mathrm{a}$

(a) $\mu \mathrm{g}$ triphenylformazan produced $\mathrm{g}^{-1}$ dry soil $24 \mathrm{~h}^{-1}$

(b) Data from the three-leaf and boot stage samplings were statistically analyzed together so that the main effect means at both sampling times that are followed by the same letter are not significantly different $(\mathrm{p} \leq 0.05, \mathrm{n}=12$ for location and inoculation with Pseudomonas $\mathrm{sp}$. $\mathrm{RC} 1$ ) 
not (this section). Also, wheat biomass production in the growth chamber in this study (Table 4.3) was less than the previous year (see Section 3.0). The temperature in the growth chamber was very similar in this study and the previous year, while the field temperature varied substantially from year to year (Fig. 4.1 and Section 3.0). This suggests that some factor other than temperature, such as soil moisture, influenced wheat shoot biomass. The simulation of field soil moisture regimes in microcosms would require more rigorous monitoring and control of field and microcosm soil moistures. This could be accomplished by using soil moisture monitoring devices such as tensiometers or gypsum blocks.

The dehydrogenase activity of the surface soil was the same in the microcosm and the field at the three-leaf stage, but was significantly higher in the microcosms at the boot stage sampling (Table 4.3). Inoculation with RC1 had no effect on soil dehydrogenase activity, except at the boot stage where inoculation with $\mathrm{RCl}$ resulted in a decrease in soil dehydrogenase activity. In a previous study (see Section 3.0), soil dehydrogenase activity was significantly higher in the microcosms than the field at the three-leaf stage of wheat growth and there was no difference resulting from the inoculation with $\mathrm{RC}$. The dehydrogenase activity was not determined at the boot stage in this earlier study.

The mean nitrate and total inorganic $\mathrm{N}$ contents of the surface soil were significantly higher in the microcosms than the field (Table 4.4) when the three-leaf and boot stage analysis were combined. There was a significant interaction between time and location for the nitrate and total inorganic $\mathrm{N}$. The microcosms at three-leaf stage had a much larger nitrate pool $\left(36.4 \mu \mathrm{g} \mathrm{N} \mathrm{g}^{-1}\right.$ dry soil) than the lysimeters ( $13.6 \mu \mathrm{g} \mathrm{N} \mathrm{g}^{-1}$ dry soil), which resulted in significant differences in the main effect means for location. The ammonium content of the soil was similar at both locations. Soil in the microcosms was sampled earlier than the field, 35 and 119 days after planting, respectively, because of the different times required to reach the three-leaf stage. It may have been that nitrate in the field soil leached below the top $15 \mathrm{~cm}$, was assimilated by the plant, or was denitrified. Inoculation with $\mathrm{RC} 1$ had no effect on soil inorganic $\mathrm{N}$ pools in the surface layer of soil (Table 4.4).

The total amount of inorganic $\mathrm{N}$ in the soil-cores from the microcosms and the field lysimeters was determined at the boot stage sampling by multiplying the inorganic $\mathrm{N}$ content on a dry weight of soil basis ( $\mu \mathrm{g} \mathrm{N} \mathrm{g}^{-1}$ dry soil) by the total amount of soil in the various microcosm and lysimeter layers. The nitrate and the total inorganic $\mathrm{N}$ content of the soil were similar in microcosms and the field (Table 4.5). The ammonium content of the soil was significantly higher in the field than the microcosms (Table 4.5), presumably because a few of the replicates had detectable quantities of 
TABLE 4.4. Inorganic $\mathrm{N}\left(\mathrm{NH}_{4}-\mathrm{N}, \mathrm{NO}_{3}-\mathrm{N}\right.$, and their Sum) Content of the Surface Soil (0 to 15 $\mathrm{cm}$ Depth). The means of the main effects of location, sampling time, and inoculation with Pseudomonas sp. $\mathrm{RCl}$ are presented.

$\begin{array}{llll}\text { Treatment } & \mathrm{NO}_{3}-\mathrm{N} & \mathrm{NH}_{4}-\mathrm{N} & \mathrm{NH}_{4}-\mathrm{N}+\mathrm{NO}_{3}-\mathrm{N}\end{array}$

Location

$$
\text { ( } \mu \mathrm{g} \text { N/g dry soil) }
$$

$\begin{array}{lccc}\text { Microcosms } & 22.9 \mathrm{a}^{(\mathrm{a})} & 18.7 \mathrm{a} & 41.6 \mathrm{a} \\ \text { Field } & 9.3 \mathrm{~b} & 12.7 \mathrm{a} & 22.0 \mathrm{~b}\end{array}$

Sampling time

$\begin{array}{lrrr}\text { Three-leaf } & 25.0 \mathrm{a} & 27.9 \mathrm{a} & 52.9 \mathrm{a} \\ \text { Boot } & 4.5 \mathrm{~b} & 0.2 \mathrm{~b} & 4.7 \mathrm{~b}\end{array}$

Inoculation with Pseudomonas sp. RC1
With
$15.8 \mathrm{a}$
$16.9 \mathrm{a}$
$32.7 \mathrm{a}$
Without
$16.1 \mathrm{a}$
$14.4 \mathrm{a}$
$30.6 \mathrm{a}$

(a) Main effect means in the same column that are followed by the same letter are not significantly different ( $\mathrm{p} \leq 0.05, \mathrm{n}=24$ for location, sampling time, and inoculation with Pseudomonas sp. $\mathrm{RC} 1$ ).

ammonium (data not shown). There was a significant interaction of location by depth with the bottom soil layer of the lysimeters having a substantial increase in the ammonium content when compared to the other depths and the microcosms (data not shown). The nitrate, ammonium, and total inorganic $\mathrm{N}$ content of the soil increased as a function of depth (Table 4.5) suggesting a more efficient uptake by the plant from the surface soil presumably because of an increased density of roots in the surface soil and/or leaching of nitrate into the soil-cores. Inoculation with $\mathrm{RCl}$ had no effect on the pools of inorganic soil $\mathrm{N}$.

Year-to-year variability was found in comparing this study to previous ones (see Sections 2.0 and 3.0) for the colonization of the rhizoplane by $\mathrm{RCl}$ at the boot stage and in wheat biomass production at the boot stage; however, for the majority of parameters similarities and differences between microcosms and the field were the same. These results suggest that while microcosms may be useful for simulating the field to study the fate and effects of an introduced microorganism, better controls of both temperature and moisture regimes may be necessary to more closely simulate the field. 
TABLE 4.5. Inorganic $\mathrm{N}\left(\mathrm{NH}_{4}-\mathrm{N}, \mathrm{NO}_{3}-\mathrm{N}\right.$, and Their Sum) Content of Soils as a Function of Depth at the Boot Stage Sampling. The inorganic N content of the soil on a weight basis was multiplied by the total weight of soil to provide the total weight of $\mathbf{N}$. The means of the main effects of location, depth, and inoculation with Pseudomonas sp. $\mathrm{RC} 1$ are presented.

\begin{tabular}{llcc}
\hline Treatment & $\mathrm{NO}_{3}-\mathrm{N}$ & $\mathrm{NH}_{4}-\mathrm{N}$ & $\mathrm{NH}_{4}-\mathrm{N}+\mathrm{NO}_{3}-\mathrm{N}$ \\
\hline Location & & $(\mu \mathrm{g} \mathrm{N})$ & \\
$\quad$ & & \\
Microcosms & $16702 \mathrm{a}^{(\mathrm{a})}$ & $240 \mathrm{~b}$ & $16942 \mathrm{a}$ \\
$\quad$ Field & $16222 \mathrm{a}$ & $2356 \mathrm{a}$ & $18578 \mathrm{a}$
\end{tabular}

Depth(b)

\begin{tabular}{|c|c|c|}
\hline $\begin{array}{l}\text { Top } \\
\text { Middle } \\
\text { Bottom }\end{array}$ & $\begin{array}{l}12555 b \\
17456 a \\
19169 a\end{array}$ & $\begin{array}{r}444 \mathrm{~b} \\
200 \mathrm{~b} \\
3259 \mathrm{a}\end{array}$ \\
\hline
\end{tabular}

Inoculation with Pseudomonas sp. RC1

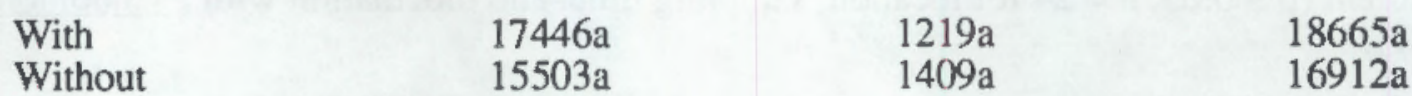

(a) Main effect means in the same column that are followed by the same letter are not significantly different $(\mathrm{p} \leq 0.05, \mathrm{n}=36$ for location and inoculation with Pseudomonas sp. $\mathrm{RCl}$ and $\mathrm{n}=$ 24 for depth)

(b) Depths were 0 to $15 \mathrm{~cm}, 15$ to $35 \mathrm{~cm}$, and 35 to $55 \mathrm{~cm}$ for top, middle, and bottom of the cores, respectively

\subsection{REFERENCES}

Bahme, J. B., and M. N. Schroth. 1987. "Spatial-Temporal Colonization Pattems of a Rhizobacterium on Underground Organs of Potato." Phytopathology 77:1093-1100.

Bentjen, S. A., J. K. Fredrickson, S. W. Li, and P. Van Voris. 1989. "Intact Soil-Core Microcosms for Evaluating the Fate and Ecological Impacts from the Release of Genetically Engineered Microorganisms." Appl. Environ. Microbiol. 55:198-202.

Bolton, Jr., H., and L. F. Elliott. 1989. "Toxin Production by a Rhizobacterial Pseudomonas sp. that Inhibits Wheat Root Growth." Plant Soil 114:269-278.

Bolton, Jr., H., L. F. Elliott, S. Gurusiddaiah, and J. K. Fredrickson. 1989. "Characterization of a Toxin Produced by a Rhizobacterial Pseudomonas sp. that Inhibits Wheat Growth." Plant Soil 114:279-287. 
Cairns, J., and J. R. Pratt . 1986. "Ecological Consequence Assessment: Effects of Bioengineered Organisms." In Biotechnology Risk Assessment. Issues and Methods for Environmental Introductions, eds. J. Fiksel, V. T. Covello, pp. 88-108. Pergamon Press, New York.

Chao, W. L., E. B. Nelson, G. E. Harman, and H. C. Hoch. 1986. "Colonization of the Rhizosphere by Biological Control Agents Applied to Seeds." Phytopathology 76:60-65.

Dean-Ross, D. 1986. "Release of Genetically Engineered Microorganisms: Hazard Assessment." ASM News 11:572-575

Fredrickson, J. K., S. A. Bentjen, H. Bolton, Jr., S. W. Li, and P. Van Voris. 1989. "Fate of Tn 5 Mutants of Root Growth-Inhibiting Pseudomonas sp. in Intact Soil-Core Microcosms." Can. J. Microbiol, 35:867-873.

Fredrickson, J. K., H. Bolton, Jr., S. A. Bentjen, K. M. McFadden, S. W. Li , and P. Van Voris. 1990a. "Nutrient Efflux from Intact Soil-Core Microcosms for Evaluating the Impacts of Genetically Engineered Microorganisms on Ecological Processes. Environ. Tox. Chem. 9:551558.

Fredrickson, J. K., P. Van Voris, S. A. Bentjen, and H. Bolton, Jr. 1990b. "Terrestrial Microcosms for Evaluating the Environmental Fate and Risks Associated with the Release of Chemicals or Genetically Engineered Microorganisms to the Environment." Hazard Assess. Chem.-Curr. Develop. 7:157-202.

Gile, J. D., J. C. Collins, and J. W. Gillett. 1982. "Fate and Impacts of Wood Preservatives in a Terrestrial Microcosm." J. Agric. Food Chem. 30:295-301.

Gillett, J. W., and J. M. Witt. 1979. "Terrestrial Microcosms." In Proceedings of the workshop at Otter Rock and Portland. Oregon, June and December, 1977. NSF/RA-790034, p. 34. National Science Foundation, Washington, D.C.

Howie, W. J., R. J. Cook, and D. M. Weller. 1987. "Effects of Soil Matric Potential and Cell Motility on Wheat Root Colonization by Fluorescent Pseudomonads Suppressive to Take-All." Phytopathology 77:286-292.

Keeney, D. R., and D. W. Nelson. 1982. "Nitrogen-Inorganic Forms." In Methods of Soil Analysis Part 2 of Chemical and Microbiological Properties, ed.A. L. Page, pp. 643-698. 2nd ed. Am Society of Agronomy, Madison, Wisconsin.

Madsen, E., and M. Alexander. 1982. "Transport of Rhizobium and Pseudomonas Through Soil." Soil Sci. Soc. Am. J 46:557-560.

Martin, J. K. 1975. "Comparison of Agar Medium for Counts of Viable Soil Bacteria." Soil Biol. Biochem. 7:401-402.

Omenn, G. S. 1986. "Controlled Testing and Monitoring Methods for Microorganisms." In Biotechnology Risk Assessment, Issues and Methods for Environmental Introductions, eds. J. Fiksel, V. T. Covello, pp 144-163. Pergamon Press, New York.

Pritchard, P. H., and A. W. Bourquin. 1984. "The Use of Microcosms for Evaluation of Interactions Between Pollutants and Microorganisms." Adv. Microb. Ecol. 7:133-217. 
Rickard, W. H., and B. E. Vaughan. 1988. "Plant Community Characteristics and Responses." In Shrub-Steppe: Balance and Change in a Semi-Arid Terrestrial Ecosystem, eds.W. H. Rickard, L. E. Rogers, B. E. Vaughan, S. F. Liebetrau, pp. 109-179. Elsevier, New York.

Sands, D. C., and A. D. Rovira. 1970. "Isolation of Fluorescent Pseudomonads With a Selective Medium." Appl, Microbiol, 20:513-514

Steel, R. G. D., J. H. Torrie. 1980. Principles and Procedures of Statistics: a Biometrical Approach. 2nd ed. McGraw-Hill Book Company, New York.

Stone, W. A., J. M. Thorp, O. P. Gifford, D. J. Hoitink. 1983. Climatological Summary for the Hanford Area. PNL-4622, UC-11, National Technical Information Service, Springfield, Virginia.

Strauss, H. S., D. Hattis, G. Page, K. Harrison, S. Vogel, C. Caldert. 1986. "GeneticallyEngineered Microorganisms: II. Survival, Multiplication, and Genetic Transfer." RAC. Tech. Bull. 9:16-28.

Tabatabai, M. A. 1982. "Soil Enzymes". In Methods of Soil Analysis, Part 2. Chemical and microbiological properties, 2nd ed., eds. A. L. Page, R. H. Miller, D. R. Keeney, pp. 903-947. American Society of Agronomy, Madison, Wisconsin.

Tolle, D. A., M. F. Arthur, J. Chesson, and P. Van Voris (1985). "Comparison of Pots Versus Microcosms for Predicting Agroecosystem Effects Due to Waste Management." Environ. Toxicol. Chem. 4:501-509.

Tolle, D. A., M. F. Arthur, and P. Van Voris. 1983. "Microcosm/field Comparison of Trace Element Uptake in Crops Grown in Fly-Ash Amended Soil. Sci. Tot. Environ. 4:501-509.

Trevors, J. T. 1988. "Use of Microcosms to Study Genetic Interactions Between Microorganisms." Microbiol. Sci. 5:132-136.

Van Voris, P. 1988. "Standard Guide for Conducting a Terrestrial Soil-Core Microcosm Test." Standard E 1197. In Annual Book of ASTM Standards, Vol. 11.04, pp. 743-755. American Society for Testing and Materials, Philadelphia.

Van Voris P., D. A. Tolle, M. F. Arthur. 1983. Experimental Terrestrial Soil-Core Microcosm Test Protocol. A Method For Measuring Potential Ecological Effects. Fate, and Transport of Chemicals in Terrestrial Ecosystems. EPA/600/3-85/(047, PNL-5450, Corvallis Environmental Research Laboratory, Corvallis, Oregon.

Van Voris P., D. A. Tolle, M. F. Arthur, J. Chesson. 1985. "Terrestrial Microcosms:

Application, Validation, and Cost-Benefit Analysis. In Multispecies toxicity testing, ed. J. Cairns, pp 117-142. Pergamon Press, New York. 


\subsection{FIELD CALIBRATION OF SOIL-CORE MICROCOSMS INOCULATED WITH STREPTOMYCES LIVIDANS TK24}

\subsection{SUMMARY}

Intact soil-core microcosms, a potential tool for assessing the fate and effects of releasing genetically engineering microorganisms (GEMs) to the environment, must first be calibrated with the field to ensure that they adequately simulate key parameters. Soil-core microcosms located in a growth chamber with diurnal temperature fluctuations were compared with a field site in Southeastern Washington State for the fate of the introduced Gram-positive bacterium, Streptomyces lividans TK24 and its effects on ecosystem structural and functional properties. Soil populations of TK24 declined less than $2 \log$ units over the 10-month study (November 1989 to September 1990). There were no differences between the microcosms and the field for the soil population of TK24 until after 45 weeks when the population was 1 log unit higher in the microcosms. At the initial sampling in the fall, soil dehydrogenase activity was larger in the microcosms than the field and inoculation with TK24 depressed activity. Dehydrogenase activities were higher in microcosms than in the field during the winter and summer, but there were no differences at the spring sampling. Soil B-glucosidase activity was higher in microcosms than the field during the winter and summer, but were the same during the fall and spring. Aerobic heterotroph and actinomycete populations were higher in microcosms than in field soils during winter and summer, while the field had larger populations in spring. The rate of ${ }^{14} \mathrm{C}$-cellulose mineralization was similar until early May when there was a flush of ${ }^{14} \mathrm{CO}_{2}$ in the field. The ${ }^{14} \mathrm{C}$ labelled soil microbial biomass was significantly larger in the microcosm than the field, while inoculation with TK24 had no effect. In summary, results obtained for most parameters using microcosms in a growth chamber were similar to those obtained in the field or differences could be attributed to the greater extremes in temperature that occurred in the field compared to the microcosms.

\subsection{INTRODUCTION}

Soil-core microcosms have been used to study the potential effects to the ecosystem from genetically engineered microorganisms and chemicals released into the environment (Fredrickson et al. 1990b). In previous laboratory studies of microcosms containing soil-cores from agricultural ecosystems, the survival and fate of Azospirillum lipoferum $\mathrm{Tn} 5$ mutants in soil, plant tissues and 
insects were studied (Bentjen et al. 1989). The effects of inoculation with $\underline{A}$. ఏipoferum on nutrient cycling was also studied by chemically analyzing leachates from microcosms containing soil-cores (Fredrickson et al. 1990a). In another laboratory study, Pseudomonas sp. RC1, an aggressive wheat root-colonizing pseudomonad was transported through the soil-core by percolating water as demonstrated by its presence in microcosm leachates. Earthworms harvested from the microcosms also had detectable levels of $\mathrm{RCl}$ in their intestines (Fredrickson et al. 1989). All of these studies used microcosms incubated in the laboratory.

To be useful for predicting the fate and effects of genetically engineered microorganisms when released into the ecosystem, however, laboratory microcosms must be calibrated with the field (Dean-Ross 1986; Fredrickson et al. 1989, 1990b; Gillett and Witt 1979; Pritchard and Bourquin 1984). For calibrating microcosms with field observations, Pseudomonas sp. $\mathrm{RC} 1$ was introduced into the surface soil and winter wheat was planted. Ecosystem structure and function (see Section 3.0) and microbial fate (see Section 2.0) were compared in field lysimeters, field plots, microcosms incubated in a growth chamber, and microcosms incubated at $22^{\circ} \mathrm{C}$ in the laboratory. Populations of $\mathrm{RC} 1$ in soil declined faster in microcosms incubated in the laboratory than those in the field and growth chamber. However, when the stage of wheat growth was used to compare $\mathrm{RC} 1$ population in soil, all treatments were similar.

These microcosm-field comparisons (see Sections 2.0 and 3.0) used a Gram-negative Pseudomonas sp. While there have been many reports of survival and gene exchange in Gramnegative bacteria (Trevors et al. 1987), there have been few using Gram-positive bacteria (Graham and Istock 1979; Wang et al.1989). In many cases little is known of the possible microbial ecological effects of a Gram-positive bacterium introduced into the ecosystem. Many species of Gram-positive bacteria can form spores that may persist for a long period of time because they are not as vulnerable to growth limiting conditions such as moisture, temperature, and nutrients as Gram-negative bacteria. Foreign genes carried by such genetically manipulated Gram-positive bacteria would be expected to persist longer when released into the environment in comparison to gram-negative. In this study, a Streptomyces sp. was used as the model genetically engineered microorganism. Streptomyces spp. are a group of spore-forming bacteria which are native to soil and are important in the breakdown of recalcitrant $C$ compounds (Williams et al. 1984). Although Streptomyces have been studied extensively in the laboratory, there have been few studies of their long-term survival and effects on the soil ecosystem. In a laboratory study (Wang et al. 1989), four Streptomyces spp. introduced at $\log 6$ to $\log 7 \mathrm{cfu} / \mathrm{g}$ into nonsterile soil remained at population levels of $\log 2$ to $\log 5 \mathrm{cfu} / \mathrm{g}$ after 10 months, depending on the species or strain tested.

Therefore, there is the possibility that Streptomyces may persist for long periods of time when 
released into the field and, when conditions are favorable, transfer foreign DNA to native soil bacteria (Rafii and Crawford 1988).

Recently, many genetically engineered strains of Streptomyces spp. have been produced. A genetically manipulated strain, $\mathbf{S}$. lividans TK23-3561, was found to increase mineralization of C in soil amended with lignocellulose in a 30-day laboratory study (Wang et al. 1989). Because Streptomyces are commercially important, many of these genetically engineered strains may be used in large bioreactors or deliberately released outside the laboratory for use in composting. For example, Streptomyces lividans TK24 was transformed with plasmids carrying a cellulase (Ghangas and Wilson 1987) and a xylanase (Ghangas et al. 1989) gene from Thermomonospora fusca, with a concomitant high level of gene expression and secretion into the culture medium.

Laboratory studies must mimic the field in order for fate data to be used for predictive models.

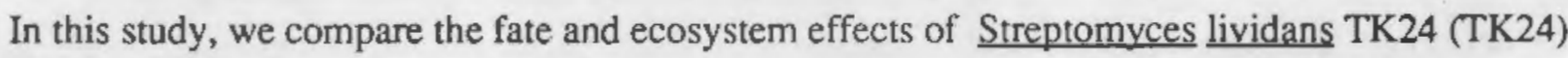
introduced into intact soil-core microcosms in a growth chamber and field lysimeters for 10 months.

\subsection{MATERIALS AND METHODS}

\subsubsection{Bacterial Strain and Media}

Streptomyces lividans TK24 (TK24) was obtained from Don Crawford (University of Idaho, Moscow, Idaho) and was maintained on the medium of Küster and Williams (1964). TK24 was chosen because it has been used extensively as a recipient for recombinant DNA (Crawford 1988) and has favorably survival characteristics in soil (Wang et al. 1989).

\subsubsection{Field Site, Microcosms, and Inoculation}

The field site was located on the Arid Lands Ecology Reserve contained within the U.S. Department of Energy's Hanford Site in southeastern Washington State. The study site receives $19.5 \mathrm{~cm}$ of annual precipitation and has a mean annual temperature of $10^{\circ} \mathrm{C}$ (Rickard and Vaughan 1988). The soil at the field site is classified as coarse-silty, mixed, mesic, Xerollic Camborthid. This soil type is used for irrigated agriculture and for dryland winter wheat production in other 
areas of southeastern Washington.

Intact soil cores for use as microcosms $(17.5 \mathrm{~cm}$ diameter, $60 \mathrm{~cm}$ length) were obtained from the field site using a steel coring device containing Driscopipe ${ }^{\circledR}$ (polyethylene pipe, Phillips Petroleum Co., Dallas, Texas), as described by Van Voris (1988). The intact soil cores, held inside the polyethylene pipe after removal from the driving tube, were returned to the laboratory. The surface soil (top $15 \mathrm{~cm}$ ) was removed from all cores and combined, mixed, and sieved to pass a $2-\mathrm{mm}$ screen. The sieved surface soil was amended with $1.0 \%$ cellulose (Sigmacell ${ }^{\circledR}$, Sigma Chemical Company, St. Louis, Missouri) and divided into two equal portions. One soil treatment was inoculated with TK24, and the other soil treatment was not inoculated. Inoculum was prepared by growing TK24 on R2YE agar (Hopwood et al. 1985) and harvested by flooding R2YE plates with sterile deionized water and dislodging the spores with a sterile bent glass rod. The inoculated soil received log 6.4 colony forming units (cfu)/g dry soil ( $105^{\circ} \mathrm{C}$ for $24 \mathrm{~h}$ ) of TK24 spores. The soil was thoroughly mixed in a V-mixer. Sufficient water was added to the soil to bring the soil to a water potential of $-0.03 \mathrm{MPa}$ or a soil moisture content of $16 \%$ as determined by pressure plate (Klute, 1986).

The mineralization of ${ }^{14} \mathrm{C}$-labelled cellulose was studied in minitubes in the field and in the growth chamber. Minitubes consisted of PVC pipe ( $4.3 \mathrm{~cm}$ diameter, $24 \mathrm{~cm}$ length) containing $250 \mathrm{~g}$ of sieved surface soil spiked to a specific activity of $3.66 \times 10^{5} \mathrm{dpm} / \mathrm{g}$ soil with finely ground uniform- ${ }^{14} \mathrm{C}$-labelled cellulose (from Nicotiana tobacum, specific activity $51.0 \mathrm{mCi} / \mathrm{g}$, Dupont, Wilmington, Delaware) The bottom of the PVC pipe was covered with polyester monofilament cloth (160 mesh) and the soil added. Two 17- x 60-cm polyethylene pipes, containing a total of six minitubes were used for each treatment. The minitubes were placed in the soil-cores and soil was filled in around the tube to the same level as in the minitubes. $\mathrm{A} \mathrm{CO}_{2}$ trap, consisting of a vial containing $2.5 \mathrm{ml}$ of $2.0 \mathrm{M} \mathrm{NaOH}$, was placed inside the minitube and the upper end of the minitube was plugged with a Teflon-wrapped rubber stopper. The $\mathrm{CO}_{2}$ traps were changed weekly or biweekly as the mineralization decreased with a subsample analyzed for ${ }^{14} \mathrm{C}$ content by liquid scintillation counting.

The soil cores were placed in either a growth chamber or back into holes at the field site. Growth chamber microcosms were incubated under a cycling temperature regime that approximated the average daily minimum temperature (dark period) and the average daily high temperature during the photoperiod at the Hanford Site (Stone et al. 1983). A photoperiod of $10 \mathrm{~h}$ was used during the fall and winter months and a photoperiod of $12 \mathrm{~h}$ was used for spring and summer. A micro-meteorological weather station, which measured air temperature and 
precipitation, was located near the field site. Air temperature profiles for the field and growth chamber are shown in Fig. 5.1.

The field lysimeters consisted of intact soil cores within polyethylene pipe, which were placed back into the soil at the field site. The bottoms of the microcosms and field lysimeters were covered with polyester monofilament cloth ( $160 \mathrm{mesh})$ to prevent soil movement outside the core.

All treatments were replicated six times. Soil inoculation and placement at the four locations occurred on November 2, 1989. The study ended on September 11, 1990. Microcosms and field lysimeters were routinely watered with tap water to maintain soil moisture at approximately -0.03 $\mathrm{MPa}$.

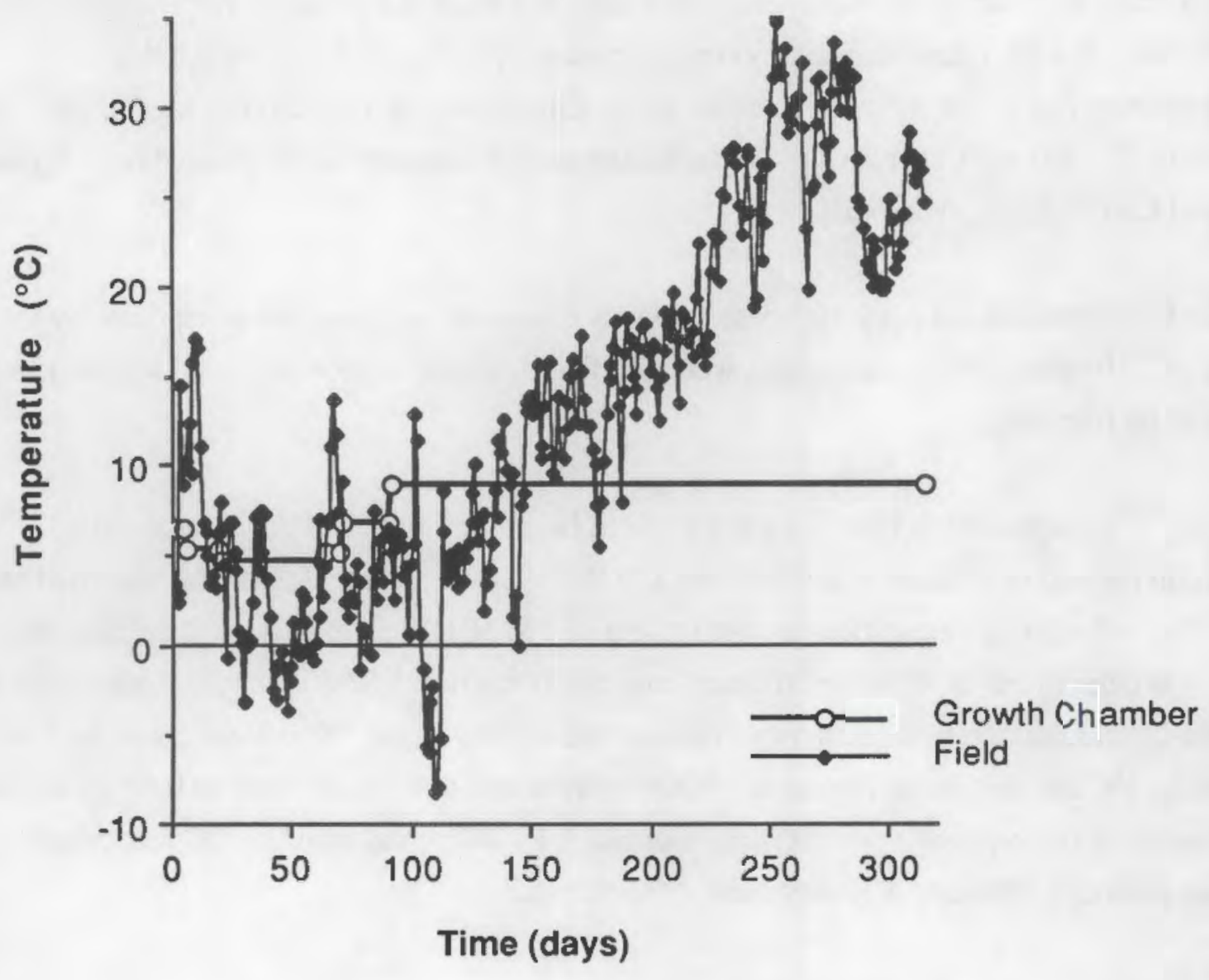

Nov. Jan. March May July Sept.

FIGURE 5.1. Average Daily Air Temperatures in the Growth Chamber and the Field During the Study Period. 


\subsubsection{Sampling}

There were four seasonal samplings of the surface soil which occurred in late November, early March, early June, and early September. The surface soil was sampled at these four times for populations of total aerobic heterotrophs and actinomycetes, the soil enzyme activities of dehydrogenase and $\beta$-glucosidase, and ${ }^{14} \mathrm{C}$-labelled microbial biomass. Additionally, surface soil was sampled as necessary to monitor TK24 soil populations.

Microbial populations were enumerated by dilution spread plate methods using the following media: A $0.1 \mathrm{X}$ strength solution of Trypticase Soy Broth (Difco, Detroit, Michigan) solidified with 15 agar $\mathrm{g} / \mathrm{L}$ (Difco) for total aerobic heterotrophs; Actinomycete Isolation Agar (Difco) for actinomycetes; and Starch-Casein mineral salts media of Küster and Williams (1964) amended with carbenicillin (25 mg/L), streptomycin (50 mg/L), nystatin (50 mg/L), Benomyl (Methyl 1[Butylcarbamoyl]-2-benzimidazolecabamate; Chas. Lilly, Portland, Oregon) (50 mg/L), and cycloheximide $(500 \mathrm{mg} / \mathrm{L})$ for TK24. All antibiotics except Benomyl were obtained from Sigma Chemical Co (St. Louis, Missouri).

The B-glucosidase and dehydrogenase activities of the soil were assayed in triplicate by the method of Tabatabai (1986), but extracts were clarified by centrifugation at $13,000 \mathrm{xg}$ for $15 \mathrm{~min}$ instead of by filtration.

The ${ }^{14} \mathrm{C}$ incorporated in biomass was measured by a modification of the chloroform furmigation method of Jenkinson and Powlson (1976). Approximately $10 \mathrm{~g}$ of soil was used and the ${ }^{14} \mathrm{CO}_{2}$ evolved after fumigation trapped in $5 \mathrm{ml}$ of $1 \mathrm{M} \mathrm{NaOH}$. The activity of the trapped ${ }^{14} \mathrm{CO}_{2}$ was determined by liquid scintillation counting (Beckman LS 9800, Irvine, California); 0.2 $\mathrm{ml}$ of the $\mathrm{NaOH}$ solution from each trap. The specific activity of the ${ }^{14} \mathrm{C}$-cellulose was used to convert the ${ }^{14} \mathrm{C}$ counts (dpms) into ng of ${ }^{14} \mathrm{CO}_{2}$ evolved and this was divided by 0.41 (Anderson and Domsch 1978) to provide the microbial biomass ${ }^{14} \mathrm{C}$. Microbial biomass ${ }^{14} \mathrm{C}$ was calculated with and without subtracting a 10-day control (no fumigation).

\subsubsection{Experimental Design}

The experimental design was a $2 \times 2$ completely randomized factorial design with two inoculation treatments (with TK24 and without) and two locations (microcosms incubated in a growth chamber and field lysimeters). Log transformed data were used for the statistical analysis 
of microbial plate counts. Results from six replicates were statistically analyzed using a fixedeffects model (StatView ${ }^{\text {TM }}$ II Program, Abacus Concepts, Inc., Berkeley, California). Fischer's least significant difference test was used to test differences among means ( $p \leq 0.05$ ), but only when F-tests (ANOVA) for main effects or interactions were statistically significant (Steel and Torrie 1980).

\subsection{RESULTS}

Growth chamber air temperatures were not as extreme as those in the field during the winter and summer months, but average spring and fall temperatures were comparable (Fig. 5.1). The variation found in the field temperature was not simulated in the growth chamber. The diumal temperatures were not increased in the growth chamber during the spring months (Fig. 5.1) to determine the effect that divergent temperatures would have on the response of TK24 soil populations, which until that time were similar in the microcosms and the growth chamber (Fig. 5.2). Microcosms in the growth chamber were watered weekly or biweekly to maintain a soil water content approximately equal to that of the field (approximately $16 \%$ ).

The soil populations of TK24 declined less than $2 \log$ units over the course of the 10-month experiment (Fig. 5.2). Although there were significant differences between populations of TK24 in the microcosm and field soils at week 18 , these differences were generally less than $0.25 \mathrm{log}$ units until May. However, at the final soil sampling after 45 weeks (late August), the soil population of TK24 in the field was tenfold less than the population in microcosm soils.

Community structural and functional measurements consisted of plate counts of total aerobic heterotrophs and actinomycetes and activities of the soil enzymes dehydrogenase and B-glucosidase at the four seasonal samplings (Fig. 5.3). There were no interactions between experimental factors at any of the samplings. Statistical differences among treatment means for soil dehydrogenase and B-glucosidase activities were in agreement with each other. There were significant differences among each seasonal sampling as well as among treatments. At the fall sampling, soil inoculated with TK24 had lower soil dehydrogenase activities as did field soil compared to microcosms.

Dehydrogenase activities of soils were higher in microcosms than in the field at the winter and summer sampling points. There were no differences in the activity of soil dehydrogenase among any of the treatments at the spring sampling. The B-glucosidase activity in soils followed similar trends identical to dehydrogenase activity except that at the fall sampling there were no differences 


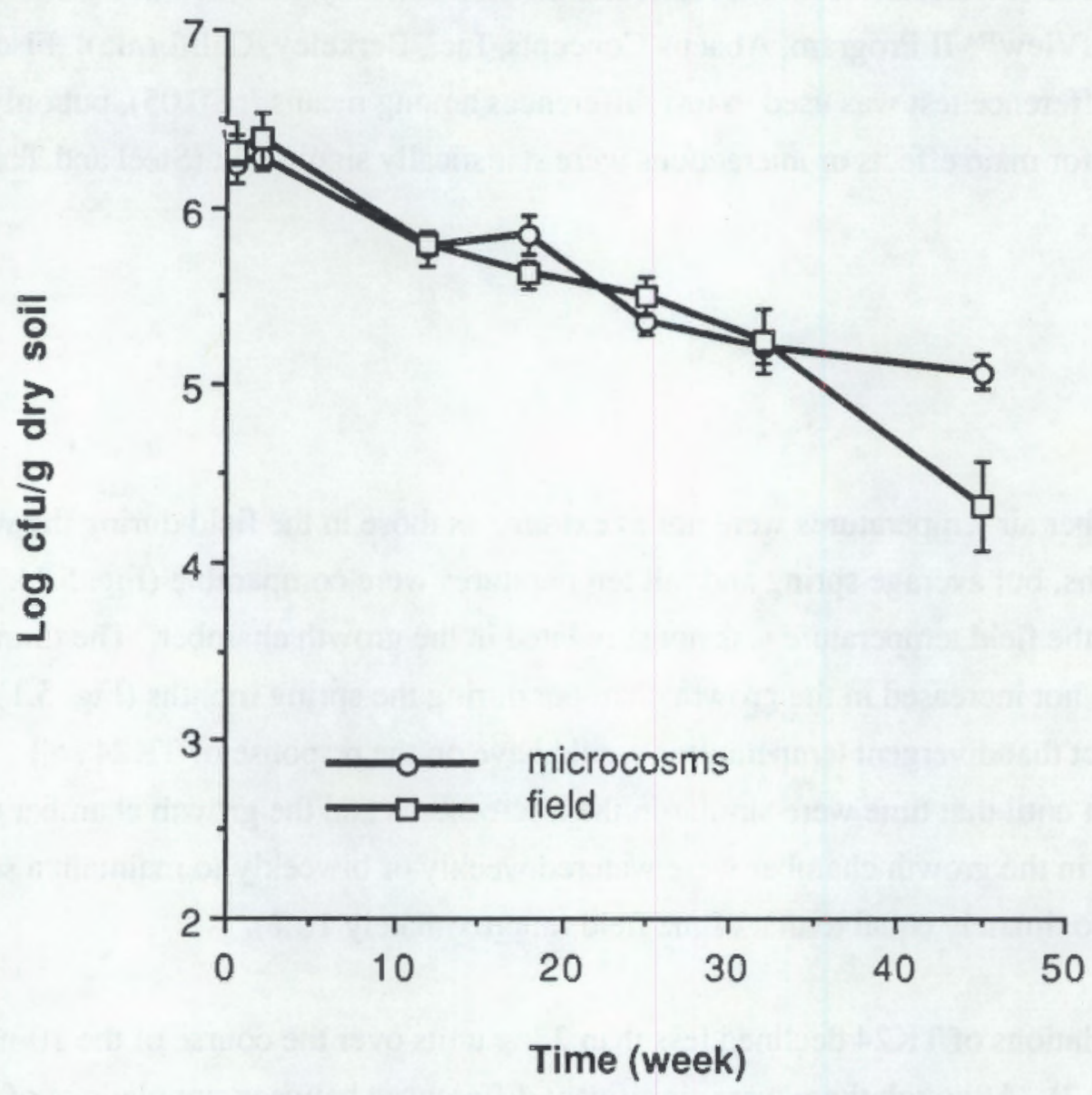

Nov. Jan. March May July Sept.

FIGURE 5.2. Streptomyces lividans TK24 Population in Microcosms and Field Soils as a Function of Time.

because of soil inoculation.

Statistical differences in populations of aerobic heterotrophs and actinomycetes among treatments were also in general agreement. At the fall sampling, there were significantly higher populations of both aerobic heterotrophs and actinomycetes in the inoculated soils, although the differences were small ( $<0.12 \mathrm{log}$ units). At the winter sampling microbial populations were 1 to $1.5 \mathrm{log}$ units higher in microcosm than in field soils, but by the spring sampling, the field populations had increased and were significantly higher than in the microcosm soils. Aerobic heterotroph populations at the summer sampling were higher in microcosm soils than in the field 

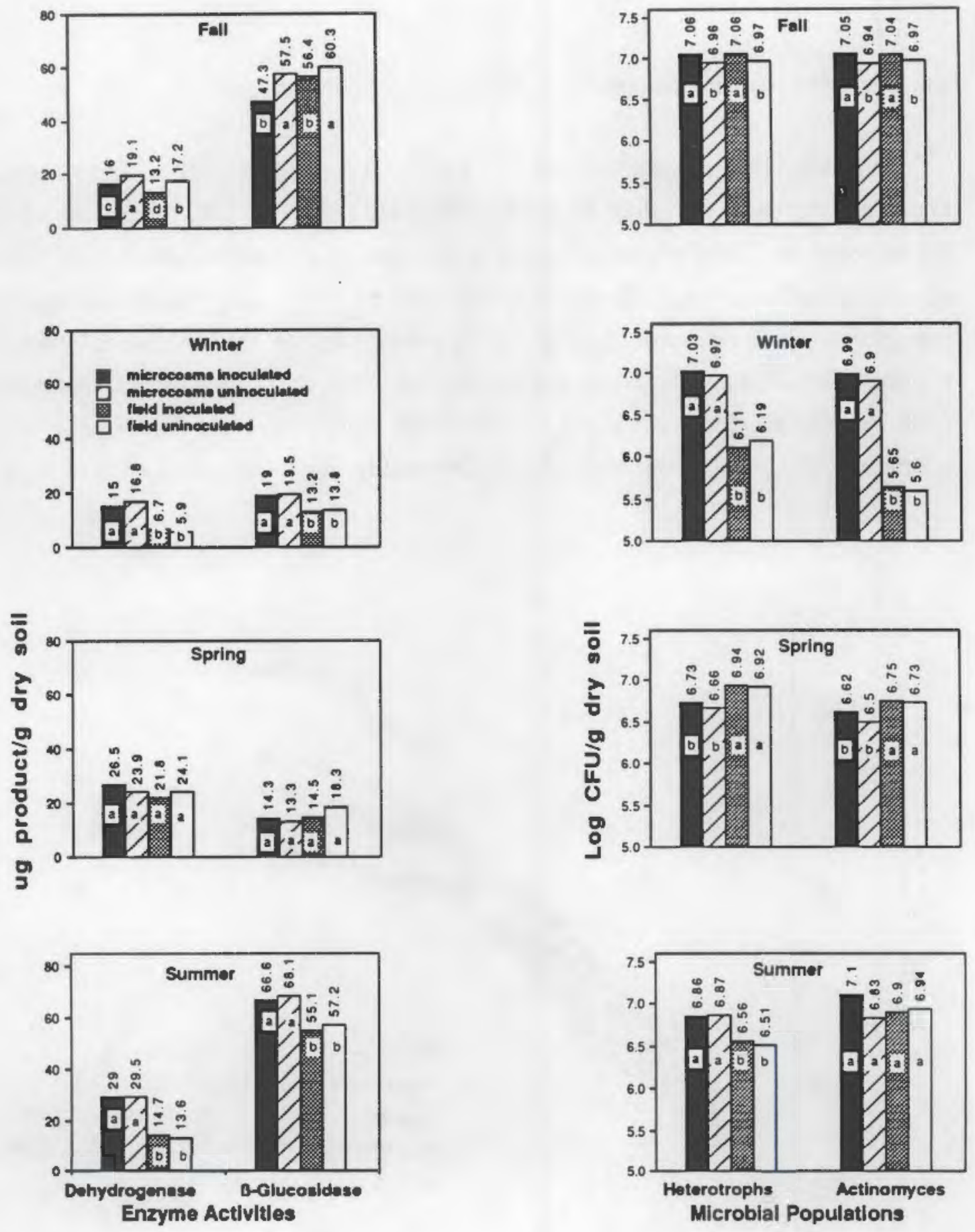

FIGURE 5.3. Microbial Community Structure and Function in Soils Sampled in the Fall, Winter, Spring, and Summer from the Microcosms and the Field. Bars marked with the same letters were not significantly different $(p \leq 0.05, n=6)$. Products were triphenyl formazan and $\rho$-nitrophenol for dehydrogenase and $\beta$-glucosidase, respectively. 
soils, but there were no differences in actinomycetes populations.

The cumulative mineralization of ${ }^{14} \mathrm{C}$ cellulose was similar for all soil treatments until early May when there was a flush of ${ }^{14} \mathrm{CO}_{2}$ from the field soils (Fig. 5.4). There was no such flush in the microcosms. There was no difference in cellulose mineralization between the inoculated and non-inoculated treatments. There was a large flush of ${ }^{14} \mathrm{CO}_{2}$ during the first week of the experiment, which was most likely caused by perturbations of the soil system by wetting the previously dried soil, soil mixing, and the addition of the cellulose substrate, therefore this initial flush was not included in the Fig. 5.4. The ${ }^{14} \mathrm{CO}_{2}$ evolved over the first week averaged 11.646 $\mathrm{kdpm} /$ tube. During the 10 -month course of this study, approximately $0.17 \%$ of the amended ${ }^{14} \mathrm{C}$

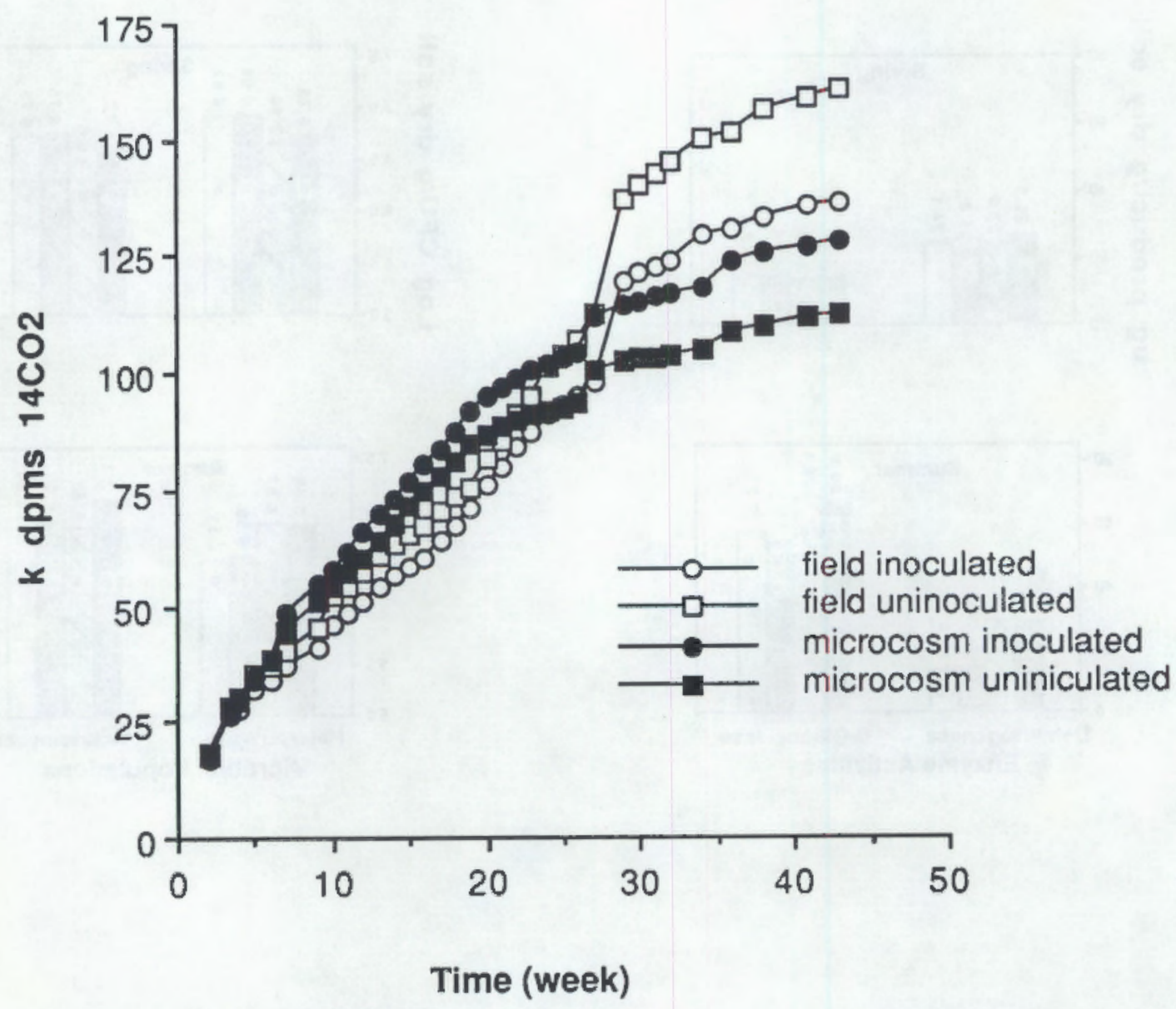

FIGURE 5.4. Cumulative ${ }^{14} \mathrm{CO}_{2}$ Evolved from Sealed Minitubes Containing Soil Amended with ${ }^{14} \mathrm{C}$-Labelled Cellulose as a Function of Time. Results are presented in 10,000 disintegrations per minute (kdpms). 
cellulose was mineralized.

The amount of ${ }^{14} \mathrm{C}$ incorporated into soil microbial biomass, as expected from the mineralization data, was low and at the level of $\mathrm{ng}$ biomass- ${ }^{14} \mathrm{C} / \mathrm{g}$ soil (Table 5.1). Similar results were obtained when soil microbial biomass was calculated with and without subtracting the control soil respiration. The ${ }^{14} \mathrm{C}$-labelled soil microbial biomass means were significantly larger in the microcosm than the field, while inoculation with TK24 had no effect (Table 5.1). The ${ }^{14} \mathrm{C}$ biomass values were approximately the same at the first three samplings but had increased by the final sampling in the summer (Table 5.1). There was a significant interaction between location and time with the summer sampling having a larger increase in ${ }^{14} \mathrm{C}$-biomass in the growth chamber than the field (data not shown).

TABLE 5.1. ${ }^{14}$ C-Labelled Soil Microbial Biomass of the Surface Soil (0 to $15 \mathrm{~cm}$ Depth). Microbial biomass was calculated from both the fumigated sample alone and from the fumigated minus the control sample. The means of the main effects of location, sampling time, and inoculation with $\underline{\text { Streptomyces }} \underline{\text { lividans }}$ TK24 are presented.

Treatment

Biomass C

(Fumigated only)
Biomass $\mathrm{C}$

(Fumigated minus control)

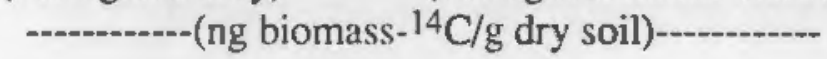

Location
Microcosms
$17 a^{(a)}$
$13 a$
Field
$8 \mathrm{~b}$
$3 b$

Sampling time

Fall

Winter

Spring

Summer
$6 b$

$3 b$

$2 b$

$42 \mathrm{a}$
$4 b$

$2 b$

$1 \mathrm{~b}$

$32 \mathrm{a}$

Inoculation with $\underline{\text { Streptomyces lividans TK24 }}$
With
$13 \mathrm{a}$
Without
$13 \mathrm{a}$
$6 a$
$11 \mathrm{a}$

(a) Main effect means in the same column that are followed by the same letter are not significantly

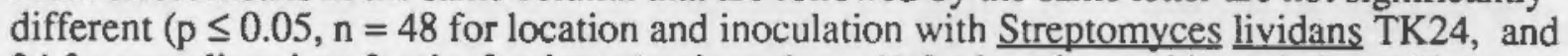
24 for sampling time for the fumigated only and $n=41$ for location and inoculation with Streptomyces lividans TK24, and 20 for sampling time for the fumigated - control) 


\subsection{DISCUSSION}

The differences found in ecosystem structural and functional parameters between the microcosms incubated in the growth chamber and the field lysimeters can be accounted for by temperature differences. Field lysimeters were subjected to lower temperatures in the winter and higher temperatures in the summer than were microcosms (Fig. 5.1). These greater temperature extremes probably resulted in the lower soil enzyme activities and microbial populations. Decreased temperatures, and possibly fewer wet and dry cycles in the growth chamber, were responsible for the higher TK 24 populations in microcosms compared to the field at the final sampling. The population of TK24 in microcosm and field soils were very close up until week 32 (Fig. 5.2) when temperatures in the field and growth chamber diverged considerably (Fig. 5.1). The higher temperatures in the field likely decreased the viability of TK24 in the field.

The population of TK24 declined at a very slow rate in soil, with only a $2 \log$ unit decrease over the 10 months. This is in contrast to other microcosm-field comparison studies, which used a Gram-negative root-colonizing pseudomonad. In a previous study (October 1988 to September 1989) (see Section 2.0), the soil population of the root-colonizing pseudomonad RC1 was followed in microcosms and the field. There was a $3.5 \mathrm{log}$ unit decline in population of $\mathrm{RC} 1$ in microcosms incubated in a growth chamber after 3 months, while it took 5.5 months in the field to reach the same value, and only 1 month in microcosms incubated at ambient laboratory temperature. In a subsequent study (October 1989 to September 1990) (see Section 4.0), for the soil population of $\mathrm{RCl}$ to decrease approximately $3.5 \log$ units in microcosms incubated in the growth chamber it took 4 months, while the same decline took 6 months in the field. Thus, the population of Gram-positive spore-forming bacteria used in the present study declined more slowly in both the field and in growth chamber microcosms than did the Gram-negative bacteria used by our laboratory in related studies. This demonstrates the importance of conducting long-term survival studies based on knowledge of the introduced strain. It is not surprising that TK24 had a slower population decline than $\mathrm{RC1}$, because TK24 is a spore-former and was added to the soil as spores. The rate of decline of TK24 population in this study was in agreement with a previous study where a spore inoculum was used (Wang et al. 1989).

During the fall, winter and early spring, when the soils in the field lysimeters remained moist and received no additional water, the soils in the microcosms were watered biweekly because the constant air circulation dried the soil surface. There was little difference in populations of TK24 between the field and microcosm soils. During the summer the field soils were watered weekly. 
The population of TK24 in field soils declined during the summer. This decline in the field soil may be a function of both higher soil temperature and the extremity of the wet and dry cycles rather than the number of cycles.

Soil dehydrogenase activity was the most sensitive of the functional parameters measured in this study. Significant differences in both inoculation and location were observed at the fall sampling, whereas other parameters detected differences only from inoculation. Higher activity of soil dehydrogenase in microcosms at the winter sampling was probably caused by the higher temperature in growth chamber inoculated microcosms as compared to the field. Soil dehydrogenase activity in inoculated treatments was significantly lower than the uninoculated treatments at the fall sampling and cannot be explained by temperature differences. Because dehydrogenase activity is used as an indicator of general soil microbial activity, it may be that the decrease was caused by the suppression of soil microbial activity by germinating TK24 spores.

Fall populations of total aerobic heterotrophs and actinomycetes were significantly higher in inoculated microcosm and field soils, although the differences were small. TK24 was able to grow on the media used to enumerate aerobic heterotrophs and actinomycetes. Therefore, the increase in the populations of heterotroph and actinomycetes populations in soil was probably caused by the growth of TK24 on these media and not from a direct effect.

The B-glucosidase activity of soil was highest in the fall and summer (Fig. 5.3). A high level of activity would be expected at the initial (fall) sampling as the cellulose added would induce these enzymes and there may have been an initial germination of some of the TK24 spores. $\underline{S}$. lividans has some B-glucosidase activity (Kluepfel et al. 1986). The high level of activity at the summer sampling may have been caused by the higher temperature.

The lower populations of aerobic heterotroph and actinomycete populations in the field during the winter and the lower aerobic heterotroph populations in the summer were probably due to the more extreme temperatures in the field. Temperatures were most similar at spring sampling. Microbial populations in the field in the spring, for example, were 0.1 to 0.2 log units higher than in the microcosms.

The rate of mineralizarion of cellulose added at $1 \%$ (wt/wt) was most likely limited by $\mathrm{N}$ and/or other essential elements, although the type of cellulose added might have played a role. Because of its hydrophobic nature, cellulose availability may have been limited, even though it was extensively mixed into the soil. The flush of ${ }^{14} \mathrm{C}$-cellulose mineralization in the the field in May 
suggests a nutrient tumover occurred in the field. The fact that no apparent tumover took place in the growth chamber microcosms is not unexpected. Less extreme temperatures in the growth chamber during the winter, including the absence of freezing temperarures, as well as numerous wet and dry cycles from repeated waterings are probably the main factors contributing to the lack of a spring flush in the microcosms. The field soils needed no water until May and experienced many below-freezing temperatures.

It is clear that temperature was a major environmental variable controlling microbial growth, survival, and enzyme activities in microcosm soil versus the field. Environmental chambers in which temperature extremes can be programmed are not widely available. The growth chamber used in this study had a lower temperature limit of $5^{\circ} \mathrm{C}$. The results from this study suggest that if field temperature and moisture conditions could be simulated exactly in an environmental chamber, then chamber-incubated microcosms would more closely track the field for the given year. This could be accomplished by off setting the chamber experiment and inputting the field meteorological data. However, this approach may not be as useful as a general predictive tool as using the 30 year average because it does not take into account year-to-year variation in field conditions. The fate and ecological effects of Pseudomonas sp. RCl were studied for two consecutive years in microcosms incubated in a growth chamber and in the field (see Sections $2.0-4.0$ ). In general, we found (see Section 4.0) that year-to-year variability can affect certain field calibration end points such as wheat root colonization by $\mathrm{RCl}$ at the boot stage of growth and final wheat shoot biomass, while other variables such as the decline in soil population of $\mathrm{RCl}$ and microbial scrucrural properties on the rhizoplane were similar from year-to-year. Results from (see Sections 2.0 - 4.0) suggested that while microcosms could simulate the field with respect to the fate and effects of a Gram-negative rhizobacterium, better environmental controls of temperature and moisture would be necessary for the use of microcosms for risk assessment.

In summary, growth chamber-incubated microcosms simulated the field quite well for microbial fate and effects. Exceptions include a flush of ${ }^{14} \mathrm{CO}_{2}$ from the field soils in early May and the higher populations of TK24 in microcosm soils at the summer sampling, both of which could be attributed to differences in temperature and water regimes. The differences in microbial populations and enzyme activities at the winter and summer sampling points were attributed to the inability of the growth chamber to mimic temperature extremes in the field during these periods. 


\subsection{REFERENCES}

Anderson, J. P. E., and K. H. Domsch. 1978. "Mineralization of Bacteria and Fungi in Chloroform-Fumigated Soils. Soil Biol. Biochem. 10:207-213.

Bentjen, S. A., J. K. Fredrickson, P. Van Voris, and S. W. Li . 1989. "Intact Soil-Core Microcosms for Evaluating the Fate and Ecological Impact of the Release of Genetically Engineered Microorganisms." Appl.Environ, Microbiol. 55:198-202.

Crawford, D. L. 1988. "Development of Recombinant Streptomyces for Biotechnological and Environmental Uses." Biotech. Adv. 6:183-206.

Dean-Ross, D. 1986. "Release of Genetically-Engineered Microorganisms: Hazard Assessment." ASM News 11:572-575.

Fredrickson, J. K., S. A. Bentjen, H. Bolton, Jr., S. W. Li, and P. Van Voris. 1989. "Fate of Tn5 Mutants of Root Growth-Inhibiting Pseudomonas sp. in Intact-Soil Core Microcosms." Can. J. Microbiol. 35:867-873.

Fredrickson, J. K., H. Bolton, Jr., S. A. Bentjen, S. W. Li, and P. Van Voris. 1990a. "Nutrient Efflux from Intact Soil-Core Microcosms for Evaluating the Impacts of Genetically Engineered Microorganisms on Ecological Processes." Environ. Tox. Chem 9:551-558.

Fredrickson, J. K., H. Bolton, Jr., S. A. Bentjen, and P. Van Voris. 1990b. "Terrestrial Microcosms for Evaluating the Environmental Fate and Risks Associated with the Release of Chemicals or Genetically Engineered Microorganisms to the Environment." In Hazard Assessment of Chemicals-Current Developments, Vol. 7, ed. J. Saxena, pp.157-202. Hemisphere Publishing Co., New York.

Ghangas, G. S., and D. B. Wilson. 1987. "Expression of a Thermomonospora fusca Cellulase Gene in Streptomyces lividans and Bacillus subtilus." Appl. Environ. Microbiol. 53:1470-1475.

Ghangas, G. S., Y. J. Hu, and D. B. Wilson. 1989. "The Cloning of a Thermomonospora fusca Xylanase Gene and Its Expression in Escherichia colj and Streptomyces lividans." L Bacteriol. $171: 2963-2969$.

Gillette, J. W., and J. M. Witt. 1979. "Terrestrial Microcosms." In Proceedings of the Workshop at Otter Rock and Portland. Oregon. June and December, 1977, NSF/RA-790034, p. 34. National Science Foundation, Washington D.C.

Graham, J. B., and C. A. Istock. 1979. "Gene Exchange and Natural Selection Cause Bacillus subrilus to Evolve in Soil Culture." Science 204:637-639.

Hopwood, D. A., M. G. Bibb, K. F. Chater, T. Kieser, C. J. Bruton, H. M. Kieser, D. J. Lydiate, C. P. Smith, J. M. Ward, and H. Shrempf. 1985. Genetic Manipulation of Streptomyces, A Laboratory Manual. The John Innes Foundation, Norwich.

Jenkinson, D. S., and D. S. Powlson. 1976. "The Effects of Biocidal Treatments on Metabolism in Soil: V. A Method for Measuring Soil Biomatss. Soil Boil. Biochem. 8:209-214.

Kluepfel, D., F. Shareck, F. Mondou, and R. Morosoli. 1986. "Characterization of Cellulase and Xylanase of Activities of Streptomyces lividans." Appl. Microbiol, Biotechnol. 24:230-234. 
Klute, A. 1986. "Water Retention: Laboratory Methods" In Methods of Soil Analysis. Chemical and Microbiological Properties, No. 9, Part 2, 2nd ed., eds. A. L. Page, R. H. Miller, D. R. Keeney, pp. 635-662. American Society of Agronomy, Inc., Madison, Wisconsin.

Küster, E., and S. T. Williams. 1964. "Selection of Media for Isolation of Streptomycetes." Nature 202:928-929.

Pritchard, P. H., and A. W. Bourquin. 1984. "The Use of Microcosms for Evaluation of Interactions Between Pollutants and Microorganisms." Adv, Microb. Ecol 7:133-217.

Raffi, F., and D. L. Crawford. 1988. "Transfer of Conjugative Plasmids and Mobilization of a Nonconjugative Plasmid Between Streptomyces Strains on Agar and in Soil." Appl. Environ. Microbiol. 54:1334-1340.

Rickard, W. H., and B. E. Vaughan. 1988. "Plant Community Characteristics and Responses." In Shrub-Steppe: Balance and Change in a Semi-Arid Terrestrial Ecosystem eds. W. H. Rickard, L. E. Rogers, B. E. Vaughan, S. F. Liebetrau, pp. 109-179. Elsevier, New York.

Steel, R. G. D., and J. H. Torrie. 1980. Principals and Procedures of Statistics: a Biometrical Approach. 2nd ed. McGraw-Hill Book Company, New York.

Stone, W. A., J. M. Thorp, O. P. Gifford, and D. J. Hoitink. 1983. Climatological Summary for the Hanford Area. PNL-4622, UC-11, National Technical Information Service, Springfield, Virginia.

Tabatabai, M. A. 1986. "Soil Enzymes" In Methods of Soil Analysis. Chemical and Microbiological Properties, No. 9, Part 2, 2nd ed., eds. A. L. Page, R. H. Miller, D. R. Keeney, pp. 903-948. American Society of Agronomy, Inc., Madison, Wisconsin.

Trevors, J. T. 1988. "Use of Microcosms to Study Genetic Interactions Between Microorganisms. Microbiol. Sci 5:132-136.

Trevors, J. T., T. Barkay, A. W. Bourquin. 1987. "Gene Transfer Among Bacteria in Soil and Aquatic Environments: a Review." Can. J. Microbiol. 33:191-198.

Van Voris, P. 1988. "Standard Guide for Conducting a Tertestrial Soil-Core Microcosm Test." Standard E 1197. In Annual Book of ASTM Standards, Vol. 11.04, pp. 743-755. American Society for Testing and Materials, Philadelphia.

Wang, Z., D. L. Crawford, A. L. Pometto, III, F. Rafii. 1989. "Survival and Effects of WildType, Mutant, and Recombinant Streptomyces in a Soil Ecosystem." Can.J. Microbiol, 35:535. 543.

Williams, S. T., S. Lanning, E. M. H. Wellington. 1984. "Ecology of Actinomycetes." In The Biology of the Actinomycetes, eds. M. Goodfellow, M. Mordarski, S. T. Williams, pp. 481-495. Academic Press, lnc., London. 


\section{DISTRIBUTION}

No. of

Copies

\section{QFESITE}

12 DOE/Office of Science and

Technical Information

3 J. L. Armstrong

U. S. Environmental Protection Agency

Corvallis Environmental Research Laboratory 200 SW 35th Street

Corvallis, OR 97333

C. W. Hendricks

U. S. Environmental Protection Agency

Corvallis Environmental Research Laboratory 200 SW 35th Street

Corvallis, OR 97333

R. J. Seidler

U. S. Environmental Protection Agency

Corvallis Environmental Research Laboratory 200 SW 35th Street

Corvallis, OR 97333

J. L. Smith

U. S. D. A. - Agricultural Research Service 215 Johnson Hall

Washington State University

Pullman, WA 99164
No. of

Copies

ONSITE

DOE Richland Operations Office

P. W. Kruger

Westinghouse Hanford Company

R. D. Budd

28 Pacific Northwest Laboratory

S. A. Bentjen

H. Bolton, Jr. (5)

J. W. Falco

J. K. Fredrickson (3)

J. M. Hales

P. C. Hays

S. L. Hays

S. W. Li

B. F. Metting

W. T. Pennell

L. E. Rogers

R. L. Skaggs

J. M. Thomas

P. Van Voris

R. E. Wildung

D. J. Workman

Publishing Coordination

Technical Report Files (5) 
' 